Franz Fischer

\title{
DAS WIRTSCHAFTSBÜRGERTUM DES RHEIN-MAIN-GEBIETS IM 19. JAHRHUNDERT. \\ EIN BEITRAG ZUR HISTORISCHEN MOBILITÄTSFORSCHUNG
}

\section{Einführung}

Die vorliegende sozialgeschichtliche Regionalanalyse zum Wirtschaftsbürgertum des Rhein-Main-Gebiets in der Zeit von 1815-1914 beschäftigt sich mit dem Aspekt der Entstehung und Herkunft der im 19. Jahrhundert typologisch vorherrschenden industriellen Eigentümerunternehmer'. Die Feststellung der Rekrutierung und des Mobilitätsverhaltens dieser Schlüsselgruppe des Industrialisierungsprozesses erfolgt anhand der Fragen nach der beruflich-sozialen Herkunft, der regionalen Herkunft und der konfessionellen Zusammensetzung einer größeren Anzahl industrieller Firmengründer. Diese drei Fragestellungen werden untersucht für die Gesamtheit des Rhein-Main-Gebiets, für seine wichtigsten Wirtschaftszweige und seine wichtigsten Städte.

Zur Erkenntnisgewinnung bedient sich diese Langzeitanalyse zur sozialen Mobilität der Unternehmer der für sozialstrukturelle Erhebungen vorrangig angemessenen quantifizierenden Methode der Sozialgeschichtsschreibung. Sie wird, besonders bei nichtquantifizierbaren Fragestellungen, ergänzt durch die biographisch-qualifizierende Betrachtungsweise und die Heranziehung weiterer Beispiele vor allem dann, wenn bei Aufschlüsselungen der tabellarisch ausgewerteten 175 (bei der Konfessionszugehörigkeit 250) ${ }^{2}$ Fabrikantenunternehmer nach verschiedenen Gesichtspunkten die Basis- und Prozentzahlen zu wenig

\footnotetext{
${ }^{1}$ Fritz Redlich, Der Unternehmer. Wirtschafts- und sozialgeschichtliche Studien. Mit einem Nachwort von Edgar Salin, Göttingen 1964, S. 155, 208f., S. 363f.

${ }^{2}$ Siehe Anlage 1: Liste der 175 (bei der Konfessionsstatistik 250) umtersuchten Firmengründer des Rhein-Main-Gebiets 1815-1914. Zur Methode: Hartmut Kaelble, Historische Mobilitätsforschung. Westeuropa und die USA im 19. und 20. Jahrhundert (Erträge der Forschung 85) Darmstadt 1978, S. 5f.; Konrad H. Jarausch, Möglichkeiten und Probleme der Quantifizierung in der Geschichtswissenschaft, in: Konrad H. Jarausch (Hg.), Quantifizierung in der Geschichtswissenschaft. Probleme und Möglichkeiten, Düsseldorf 1976, S. 24f.; Lawrence Stone, Prosopographie - englische Erfahrungen, in: Jarausch (Hg.), Quantifizierung, S. 6497; Konrad H. Jarausch, Gerhard Arminger, Manfred Thaller, Quantitative Methoden in der Geschichtswissenschaft. Eine Einfibhrung in die Forschung, Datenverarbeitung und Statistik, Darmstadt 1985.
} 
aussagefähig werden für repräsentative Ergebnisse. Insofern sind die Zahlen nur als Indikatoren zu sehen, die durch weitere Beispiele und Detailstudien abzusichern oder zu korrigieren wären.

Allgemeines Kriterium der Auswahl des untersuchten Personenkreises war, die Gründer der im 19. Jahrhundert neuentstehenden und die Industriestruktur des Rhein-Main-Gebiets am Ende des Untersuchungszeitraums kennzeichnenden Industriezweige zu erfassen. Der Begriff Firmengründer wurde weit gefaßt, indem auch Unternehmer, die an sich ältere Betriebe weitergeführt oder übernommen haben, diesen aber eine neue Richtung oder überhaupt erst ein industrielles Erzeugungsprogramm gegeben haben, aufgrund dieser echt gründerischen Leistung den Gründern zugerechnet wurden.

Das Rhein-Main-Gebiet stellt keine festumrissene Einheit dar. Als Produkt des hier mit einem Teilaspekt untersuchten, einem ständigen Wandel unterworfenen Industrialisierungs- und Urbanisierungsprozesses bedarf es daher der Abgrenzung. Diese Untersuchung nimmt pragmatisch und unter Berücksichtigung historischer Grenzen ihre Beispiele aus einem Gebiet, das um den wirtschaftlichen Mittelpunkt Frankfurt am Main liegend durch die Punkte Hanau - Friedberg/Hessen - Rheinknie bei Rüdesheim/Bingen - Worms - Bensheim Darmstadt - Hanau begrenzt wird. Sie läßt damit das nach dem heutigen Stand der wirtschaftlichen Integration einzubeziehende unterfränkische Gebiet westlich des Spessarts (z.B. Aschaffenburg) außerhalb der Betrachtung, bezieht aber das während des Untersuchungszeitraums hessische, zum Kernbereich des Rhein-Main-Gebiets schon randständige Worms noch in die Untersuchung ein ${ }^{3}$. Sie faßt damit retrospektiv einen Personenkreis in einer polyzentrischen Wirtschaftsund Verstädterungsregion mit höchst unterschiedlichen Traditionen und vielgestaltigem funktionalen Gefüge zusammen, die bis heute keine politische oder administrative Einheit bildet. Zudem haben die bis 1866 fünf (Kurhessen, Großherzogtum Hessen, Nassau, HessenHomburg, Frankfurt am Main), dann die zwei (Großherzogtum Hessen, Preußen) am Rhein-Main-Gebiet teilhabenden Territorien durch ihre Traditionen und die Wirtschaftspolitik den Gang der Industrialisierung durchaus beeinflußt. Es haben auch mancherlei vorindustrielle gewerbepolitische Maßnahmen und Traditionen weitergewirkt.

\footnotetext{
${ }^{3}$ Anneliese Krenzlin, Werden und Gefüge des rhein-mainischen Verstädterungsgebietes. Ein Versuch landeskundlicher Darstellung, in: Frankfurter Geographische Hefte 37 (Festschrift zur 125-Jahrfeier der Frankfurter Geographischen Gesellschaft) (1961), S. 313 und S. $379 f$.
} 
Gleichzeitig haben aber auch die überkommenen funktionalen Verflechtungen sowie die weitgehend gleichartigen natürlichen Voraussetzungen der Industrialisierung des Rhein-Main-Gebiets bestimmte Bahnen gewiesen: Sie lagen und liegen in Verkehrsgunst, Rohstoffarmut und Rohstofferne sowie zunehmend auch in der Eigendynamik des vorhandenen Sozial- und Wirtschaftspotentials.

2. Die beruflich-soziale Herkunft der Firmengründer

\subsection{Die beruflich-soziale Herkunft der Firmengründer nach Berufs- gruppen}

Wie in anderen deutschen Industrielandschaften bildet auch im RheinMain-Gebiet das Gewerbe in Handwerk, Industrie und Handel in gewissem Sinne in Selbstergänzung das Hauptreservoir unternehmerischer Herkunft: $61,9 \%$ oder 101 Firmengründer des Rhein-MainGebiets entstammten diesen Berufszweigen ${ }^{4}$. Dabei war beim Übergang zur Industrie von Söhnen dieser wirtschaftsverbundenen Herkunftsgruppe die Kontinuität der Betriebe erheblich geringer als die Kontinuität der unternehmerischen Aktivität, die sich in einzelnen Familien offenkundig sehr viel häufiger mehr oder weniger bruchlos von der vorindustriellen in die industrielle Periode fortsetzte.

Dies gilt auch für die Handwerksmeister und selbständigen Handwerker, die mit 32 Personen (19,6\%) während des gesamten Untersuchungszeitraums die stärkste Einzelabkunftsberufsgruppe der Firmengründer stellen.

Ihr Anteil ist relativ am höchsten in der Zeit der Frühindustrialisierung bis 1850. Damals gelang es wiederholt Handwerkersöhnen besonders in metall-, holz- und lederverarbeitenden Handwerken ohne Bruch mit der väterlichen Berufs- und teilweise Betriebstradition

\footnotetext{
${ }^{4}$ Siehe Tabelle Anlage 2: Die beruflich-soziale Herkunft der Firmengründer. Zum Vergleich sei statt einer Vielzahl von Einzeluntersuchungen auf zusammenfassende Darstellungen und Gesamterhebungen zur Unternehmerherkunt verwiesen: Wilhelm Stahl, Der Elitekreislauf in der Unternehmerschaft, Frankfurt am Main, Zürich 1973, S. 104ff. und S. 119ff; Hartmut Kaelble, Soziale Mobilität und Chancengleichheit im 19. und 20. Jahrhundert (Kritische Studien zur Geschichtswissenschaft 55), Göttingen 1983, S. 104 und S. 228-245; Kaelble, Mobilitätsforschung, S. 119-121; über das Problem der Kontinuität von der vorindustriellen zur industriellen Periode: Jürgen Kocka, Unternehmer in der deutschen Industrialisierung (Kleine Vandenhoeck-Reihe 1412), Göttingen 1975, S. 30-34.
} 
ihren Handwerksbetrieb zum Ausgangspunkt eines Fabrikbetriebs zu machen. Beispiele dafür bieten unter anderen die Entwicklungen der Kutschenwagen- und späteren Waggonfabrik Gastell in Mainz ${ }^{3}$ oder die Maschinenbaubetriebe Johann Simon Fries in Frankfurt ${ }^{6}$ und Johannes Heim in Offenbach am Main?

$\mathrm{Ab}$ der Jahrhundertmitte erzwang die sich komplizierende Technik bei Handwerkersöhnen immer häufiger den Bruch mit der väterlichen Berufs- und Betriebstradition. Sehr viele von ihnen bleiben aber gekennzeichnet durch die ihnen durch Herkunft und Berufsqualifikation eigenen Interessen im Leistungsbereich und ihre Hinwendung zu mechanischen und zu solchen Industriezweigen, in denen ihnen aufgrund manueller und technischer Fertigkeiten ein unternehmerischer Aufstieg möglich war.

Wie sehr das einmal entstandene Unternehmertum sich in der Folge aus sich selbst ergänzte, zeigt sich daraus, daß die genuin der industriellen Welt zugehörigen und wegen ihrer geringen Traditionstiefe in sich keineswegs homogene Gruppe der Fabrikanten, Industriellen, Bauunternehmer und Direktoren mit 27 Personen $(16,6 \%)$ bereits das zweitgrößte Kontingent unter den Unternehmervätern stellt. Es umfaßt Angehörige alter vorindustrieller Unternehmerfamilien wie der Eifeler Reidemeisterfamilie Schoeller ${ }^{8}$ oder der Papiermacherfamilie Flinsch ${ }^{9}$.

${ }^{3}$ Stadtarchiv Mainz, Heiratsregister 14. August 1810; Albert Kimberger, Aus der Geschichte der ältesten deutschen Waggonfabrik, in: Kultur und Wirtschaft im rheinischen Raum. Festschrift für Prof. Christian Eckert, Mainz 1949, S. 267ff; Dieter Gessner, Metallgewerbe, Maschinen- und Waggonbau am Mittelrhein und Untermain (1800-1860/65), in: Archiv für hessische Geschichte und Altertumskunde. Neue Folge 38 (1980), S. 287-338, insbes. S. 291ff.

${ }^{6}$ Konrad F. Bauer, Brücken zum Aufbau. 200 Jahre Firma J.S. Fries in Frankfurt am Main, Frankfurt am Main 1948, S. 15ff.

${ }^{7}$ Andreas Voigt, Die Maschinenindustrie der Kreise Frankfurt am Main, Darmstadt und Offenbach, in: Zeitschrift des Vereins deutscher Ingenieure. Festnummer zur 45sten Hauptversammlung in Frankfurt am Main und Darmstadt (1904), S. 16; Offenbachs erste Maschinbauer, in: Offenbach Nachrichten 5.9.1937; Adolf Völker, Aus Offenbachs Maschinbau, in: Offenbacher Monatsrundschau H. 5 (Mai 1941), S. 21; Robert Müller, Die industrielle Entwicklung Offenbachs. Eine historische Standortbetrachtung, Offenbach/Main 1932, S. 75; Auskunft Margarete Heim, Hofheim/Taunus; vgl, auch: Gessner, Metallgewerbe, S. 287-301.

${ }^{8}$ Leopold Schoeller, Stammblätter der Familie Schoeller. Stammblatt IV: Eifeler Zweig, Detmold 1965; Deutsches Geschlechterbuch. Genealogisches Handbuch bürgerlicher Familien 123 (1958), S. $312 \mathrm{f}$.

"Friedrich Wilhelm Süs, Das Handlungshaus Ferdinand Flinsch. Gedenkbuch zu dessen 50jähriger Jubelfeier 1869, Frankfurt am Main 1869, S. 11ff., 35ff,, 83ff.; Hans Georg Kutzner, Ferdinand Traugott Flinsch, in: Neue Deutsche Biographie 5 
Dieser Herkunftsgruppe gehören aber auch bereits moderne Großindustrielle wie der Chemieindustrielle Heinrich Albert (1835-1908) ${ }^{10}$ oder Angestellten-Unternehmer wie Gustav Heinrich Brüning (18051865), Direktor der Vaterländischen Feuerversicherungs-Gesellschaft $^{11}$ sowie Fabrikanten an, bei denen die Nähe zu ihren handwerklichen Ursprüngen unverkennbar ist, wie der Zimmermeister und spätere Zigarrenkisten- und Zigarrenwickelformenfabrikant Johann David Siebert (1835-1906) ${ }^{12}$ in Hanau.

Infolge der späten Industrialisierung des Rhein-Main-Gebiets und der Unterentwicklung eines zahlenmäßig breiten vorindustriellen großgewerblichen Fabrikantenunternehmertums im Rhein-MainGebiet treten die Firmengründer dieser Herkunftsgruppe verstärkt erst nach 1850 auf. Sie stellen aber im Doppeljahrzehnt 1851-1870, das die eigentliche industrielle Gründungsphase, besonders in der chemischen Industrie für das Rhein-Main-Gebiet darstellt, sogar die größte Herkunftsgruppe. Dabei sind bezeichnenderweise sieben von zwölf firmengründenden Söhnen von Unternehmern dieser Jahre von außerhalb in das Rhein-Main-Gebiet zugewandert.

Eine Eigenart der industriell tätig werdenden Söhne von Großkaufleuten (einschließlich Bankiers, Hoteliers und Verlegern), die als drittgrößte Herkunftsgruppe mit 24 Unternehmervätern (14,7\%) auftreten, war, daß sie ausgeprägter als andere Gruppen dank ihrer Finanzmittel als kapitalkräftige Partner bei Firmengründungen mitwirkten oder durch Darlehen oder Kauf in den Besitz oder Mitbesitz schon bestehender Firmen gelangten. Zum Teil stand bei diesen Großkaufleute-

(1961), S. 248f; Geschichte der Handelskammer zu Frankfurt am Main (17071908). Beiträge zur Frankfurter Handelsgeschichte. Hg. von der Handelskammer zu Frankfurt a. M., Frankfurt am Main 1908, S. 1290 .

${ }^{10}$ Frithjof Kroemer, Heinrich Albert, in: Nassauische Lebensbilder I (1940), S. 220-231; Fritz Geisthardt, Heinrich Albert, in: NDB I (1953), S. 138; Heinrich Albert, Mein Leben, o.O. 1951; Fünfundzwanzig Jahre Dr. Kurt Albert GmbH. Zur Geschichte der Firma Dr. Kurt Albert GmbH Chemische Fabriken, WiesbadenBiebrich, o.O. [1935].

${ }^{11}$ Gothaisches Genealogisches Taschenbuch der Adeligen Häuser, Reihe B: Briefadel, Gotha 1917, 3. 124f.; Emst Fischer, Meister, Lucius und Brüning. Die Gründer der Farbwerke Hoechst AG, in: Tradition 3 (1958), S. 65ff; Ernst Fischer, Die Gründer der Farbwerke Hoechst AG. Eugen Lucius, Wilhelm Meister, Adolf Brüning, in: Nassauische Lebensbilder 6 (1961), S. 248ff.; Dolf von Brüning, Johann Adolf (von) Brüning, in: NDB 2 (1955), S. 665.

${ }^{12} \mathrm{H}$. Houben ( $\mathrm{Hg}$.), Festschrift zum fünfzigjährigen Bestehen der Platinschmelze G. Siebert GmbH, Hanau 1881-1931, Hanau 1931, S. III; DGB 129 (1962), S. $397 f$. 
söhnen die Aufnahme des Fabrikationsbetriebs in einem ursächlichen oder weiteren Zusammenhang mit ihren bisherigen Handelsfirmen. So gingen die Inhaber der Frankfurter Farbwarengroßhandlung Leopold Cassella, die Brüder Friedrich Ludwig Gans (1833-1920) und Leo Ludwig Gans (1843-1935) nach dem Aufkommen der Teerfarbenindustrie selbst zur synthetischen Farbstoffherstellung über ${ }^{13}$. Ähnliche Motive veranlaßten auch die Gründung der chemischen Fabrik Kalle \& Co. in Wiesbaden-Biebrich ${ }^{14}$.

Die langandauernde Zurückhaltung der Frankfurter Großkaufleute und Bankiers, die immerhin 13 der 24 Großkaufleute-Gründerväter stellen, gegen das industrielle Anlagengeschäft zeigt sich auch darin, daß ihre Nachkommen erst nach dem Ende der freistädtischen Zeit verstärkt sich persönlich an Industrieunternehmungen beteiligten. Im Zeitraum 1871-1890 dominieren jedoch dann Frankfurter Großkaufleute unter den Gründervätern derart, daß sie von zehn acht stellen. Darunter befinden sich so bekannte Altfrankfurter Namen wie Andreae, Passavant, Ziegler und Johann Christian Fellner (1851-1920), der Sohn des letzten freistädtischen Bürgermeisters ${ }^{15}$.

16 Unternehmerväter $(9,8 \%)$ waren als Kaufleute tätig. Mit wenigen Ausnahmen, für die beschränkte wirtschaftliche Verhältnisse bezeugt sind (z.B. die Gebrüder Wertheim, Gründer einer Nähmaschinenfabrik und eines Asbestwerks ${ }^{16}$ ), gehörten die Kaufleute-Väter in

${ }^{13}$ Werk Mainkur der Firma Leopold Cassella \& Co., Gesellschaft mit beschränkter Haftung 1870-1920, Frankfurt am Main 1920, S. 11; Geschichte Handelskammer Frankfurt, S. 1285f; Franz Lerner, Leo Ludwig Gans, in: NDB 6 (1964), S. 64; Ahnen- und Verwandtschaftskreis Gans (Maschinschrift), in: Institut zur Erforschung historischer Führungsschichten, 6140 Bensheim a.d. Bergstraße 1, EmstLudwig-Straße 21; Gerd Schneider, Leo Gans, in: Jüdische Stiftungen in Frankfiut am Main. Stiftungen, Schenkungen, Organisationen und Vereine mit Kurzbiographien jüdischer Bürger dargest. von Gerhard Schiebler, hg. von Amo Lustiger, Frankfurt a.M. 1988, S. 333-338.

${ }^{14}$ Kalle \& Co. Aktiengesellschaft Biebrich am Rhein 1863-1913, Mannheim 1913, S. 4; Heinrich Voelcker, 75 Jahre Kalle. Ein Beitrag zur nassauischen Industriegeschichte 1863-1938. Kalle \& Co. AG Wiesbaden-Biebrich, Frankfurt a.M. 1938, S. 34ff; Grete Ronge, Wilhelm Kalle, in: NDB 11 (1977), S. 65-68.

15 Bookenheim. Seine Entwicklung, gegenwärtigen Einrichtungen und sonstigen Verhältnisse, hg. vom Verein für Handel und Industrie, Bockenheim 1892, S. 87ff.; Geschichte Handelskammer Frankfurt, S. 1066, 1262; 75 Jahre Fellner \& Ziegler 1882-1957, Frankfurt a.M.-West, 0.O., o.J. [1957]; Stadtarchiv Frankfurt, Einwohnermeldekartei: Johann Christian Fellner.

${ }^{16} \mathrm{Zu}$ Joseph Wertheim: Joseph Wertheim $\uparrow$, in: Frankfurter Kleine Presse 68, 21.3.1899; Stadtarchiv Frankfurt, Einwohnermeldekartei: Joseph Wertheim; Staatsarchiv Wiesbaden, Judenregister Nr. 741-743; Geschichte Handelskammer 
ihrem Lebensbereich durchaus zur gutsituierten wirtschaftlichen Führungsschicht und standen manchen Großkaufleuten nicht fern (z.B. Bäckermeister und Mehlhändler, Inhaber einer renommierten Antiquitätenhandlung). Insgesamt deutet aber die Herkunftshäufigkeit der Firmengründer aus dem handwerklich-industriellen und handeltreibenden Wirtschaftsbürgertum mit (einschließlich der leitenden Angestellten) 101 Unternehmervätern $(61,9 \%)$ auf einen herkunftsbedingten, sich auf Berufsqualifikation und Unternehmermotivation, teilweise auch auf finanziellen und familialen Hintergrund sich gründenden Chancen- und/oder Mentalitätsvorsprung gegenüber anderen $\mathrm{Ab}$ kunftsberufen hin.

Liegt im internationalen Vergleich eine Besonderheit der sozialen Herkunft deutscher Unternehmer im hohen Anteil der Beamtenabkunft $^{17}$, so zeichnet sich innerhalb Deutschlands das Rhein-MainGebiet wiederum durch die Stärke des Anteils der Abkunft der Firmengründer von dem beamteten und freiberuflichen Bildungsbürgertum aus. Den höheren und mittleren Beamten, den evangelischen Pfarrern und freien akademischen Berufen einschließlich der Apotheker gehörten - ohne die unteren Beamten - ziemlich genau ein Viertel $(25,1 \%)$ oder 41 Unternehmerväter an. Unter ihnen bilden die höheren Beamten mit $18(11,0 \%)$ Personen, gefolgt von den mittleren Beamten mit neun $(5,5 \%)$ Gründervätern die stärkste Herkunftsgruppe. Darunter befinden sich Angehörige von Familien, die speziell den mittelrheinischen Territorialherrn oft durch Generationen die Staatsdiener-Führungsschicht in Verwaltung, Militär, Geistlichkeit und Geistigkeit gestellt haben (z.B.: Beck ${ }^{18}$, die Chirurgenfamilie Büchner ${ }^{19}$,

Frankfurt, S. 1243, 1247, 1255, 1258; Voigt, Maschinenindustrie, S. 15f. Zu Louis Wertheim: Stadtarchiv Frankfurt, S. 2/4334: Louis Wertheim †; Stadtarchiv Frankfurt, Einwohnermeldekartei: Louis Wertheim; Staatsarchiv Wiesbaden, Judenregister Nr. 741-743; Geschichte Handelskammer Frankfurt, S. $1297 f$.

${ }^{17}$ Stahl, Elitekreislauf, S. 110; Kaelble, Mobilität, S. 234.

${ }^{18}$ Harry Gerber, Ludwig Beck, in: Nassauische Lebensbilder 4 (1950), S. 247-252; Hugo Racine, Ludwig Beck, in: NDB 1 (1953), S. 698f.

${ }^{19}$ DGB 144 (1967), S. 1ff, insbes, 41-49; Anton Büchner, Die Familie Büchner. Georg Büchners Vorfahren, Eltern und Geschwister (Hessische Beiträge zur deutschen Literatur), Darmstadt 1963, S. 30ff; Armin Hildebrandt, Die Industrialisierung in Pfungstadt - von der Gründung der Krapp-Manufaktur bis zum modernen Industriebetrieb (1767-1945), in: Pfungstadt. Vom fränkischen Mühlendorf zur modernen Stadt. Hg. von J. Friedrich Battenberg, Pfungstadt 1985, S. 219-260, hier insbes. S. 233-239; Valentin Liebig, Wilhelm Büchner. Sozialer Unternehmer und liberaler Politiker (Ausstellungskatalog), Pfungstadt 1988. 
teilweise Dietze ${ }^{20}$, Euler ${ }^{21}$, Koch $^{22}$, Römheld ${ }^{23}$, Scriba $^{24}$, Schenck $^{25}$, Schleussner ${ }^{26}$, Sell ${ }^{27}$, oder auf einer niedrigeren Ebene die Försterfamilie Albert ${ }^{28}$.

Neben den Pfarrern (sechs Personen, 3,7\%), welche den höheren Beamten durch Herkunft, amtsorientiertes Dienstverständnis und Konnubium nahestehen, bilden die freien akademischen Berufe eine eigenständige Facette. Fünf der acht $(4,9 \%)$ Unternehmerväter dieser Herkunftsrichtung waren Apotheker. Damit ist auch bereits die pharmazeutische und chemische industrielle Betätigung ihrer Söhne vorgegeben. Darunter befinden sich noch heute bekannte Namen wie E. Merck in Darmstadt ${ }^{29}$, W.C. Heraeus in $\mathrm{Hanau}^{30}$ und die kleiner ge-

${ }^{20}$ Hermann Dietze, Aus meinem Leben, Frankfurt a.M. 1913, S. 92; W. Bornemann, Hermann Dietze, in: Frankfurter Kirchenkalender 31, 1919 (1918), S. 1721; Verein für chemische Industrie, in: Historisch-biographische Blätter. Industrie, Handel und Gewerbe. Das Großherzogtum Hessen, Berlin: Eckstein o.J. [um 1910].

${ }^{21}$ Friedrich Wilhelm Euler, Wilhelm Euler (1847-1934) und seine Vorfahren. Maschinschriftl. Manuskript, in: Institut.

${ }^{22}$ Friedrich Ludwig Koch, in: Hessische Biographien 1 (1913), S. 166-168.

${ }^{23}$ August Römheld, Familienbuch der Familie Römheld, Darmstadt 1900, S. 33ff.; DGB 98 (1937), S. 338ff; J Jürgen Schwab, Eine eiserne Tradition 1859-1959, hg. anläßlich des hundertjährigen Bestehens der Firma Julius Römheld Eisengießerei, Maschinen- und Stahlbau, Mainz, Darmstadt 1959, S. 5ff.

${ }^{24}$ Otfried Praetorius, Ferdinand Scriba, Familienbuch Scriba-Schreiber aus Medebach im Sauerland, Neustadt a.d.Aisch, 1955, S. 27ff., Christian Scriba, Genealogisch-biographische Übersicht der Familie Scriba, Friedberg 2. Aufl. 1884, S. 42ff., 79, 113f; Herbert Büschenfeld, Höchst. Die Stadt der Farbwerke (RheinMainische Forschungen 45), Frankfurt a.M. 1958, S. 65.

${ }^{25}$ DGB 96 (1937), S. 281ff,, insbes. S. 286. Im Zeichen der Waage. Biographie über Carl Schenck, hg. von der Carl Schenck Maschinenfabrik GmbH Darmstadt, anläß1. d. 75. Jahrestages der Werksgründung, Darmstadt 1956, S. 10ff.

${ }^{26}$ Irene Schleußner, Schleußner, Geschichte eines in Thüringen, Franken und Hessen beheimateten Geschlechts und seiner Ahnen, in: Deutsches Familienarchiv 14 (1959), S. 53ff; 75 Jahre Schleussner 1860-1935, Frankfurt/M. 1935, S. 3ff.; 100 Jabre Dr. Schleussner Fotochemie ADOX, Stuttgart 1960, S. 6ff;; Dr. C. Schleussner AG, in: Historisch-biographische Blätter. Industrie, Handel und Gewerbe. Der Regierungsbezirk Wiesbaden, Berlin: Eckstein 1912.

${ }^{27}$ DGB 52 (1927), S. 482-486; Hagenböcker, Zur Geschichte des Werkes Offenbach der IG-Farbenindustrie, maschr. Manuskript Stadtarchiv Offenbach, Offenbach 1936; Denkschrift der C.F. Boehringer \& Söhne GmbH., Mannheim-Waldhof anläßlich ihres 75jährigen Bestehens 1859-1934, S. 39ff.

${ }^{28}$ Siehe oben Anm. 10 und DGB 92 (1936), S. 62f. Anm. 70.

${ }^{29}$ Carl Wernher, Heinrich Emanuel Merck, in: Hessische Biographien 2 (1927), S. 369-371; DGB 18 (1910), S. 249ff;; Wilhelm Michel, E. Merck - Darmstadt 1937, Darmstadt 1937, S. 16ff; Die Chemische Fabrik E. Merck - Darmstadt. Ein Rückblick auf die Geschichte der Firma in Wort und Bild, Darmstadt 1952, S. 54f. 
bliebenen Pharmafirmen Dr. E. Fresenius in Frankfurt, dann in Bad Homburg bzw. Oberursel ${ }^{31}$ und Karl Engelhard in Frankfurt ${ }^{32}$.

Für die Struktur der Industrie im Rhein-Main-Gebiet mußte es aber formend wirken, wenn sich Nachkommen von Berufsgruppen verhältnismäßig stark an Industriegründungen beteiligten, die entweder traditionell oder aus sozialem Aufstiegsstreben, wie z.B. bei den Lehrersöhnen, wenn schon nicht eine akademische, so doch eine qualifizierte, auch theoretisch abgesicherte Ausbildung erhielten oder sie sich im Fall von Ausbildungsdefiziten um eine theoretische Weiterbildung bemühten.

Dabei ist aus der Abwendung der Söhne dieses beamteten und freiberuflichen Bildungsbürgertums von der bisherigen humanistischen Geistesbildung und traditionellen Berufslaufbahn nicht von vornherein auf eine bei dieser Herkunftsgruppe plötzlich erwachte Technik- oder Wirtschaftshochschätzung zu schließen. Häufig haben nämlich gerade bei ihnen die nicht vorrangig erwerbsorientierten Konventionen Bedenken der Väter gegen die technische, weniger gegen die bereits aus der Pharmazeutenausbildung her vertraute naturwissenschaftiche Berufswahl ihrer Söhne ausgelöst (z.B. bei Heinrich Voigt (1857$1937)^{33}$ und Carl Linde (1842-1934) ${ }^{34}$. Jedenfalls führte bei ihnen häufig kein direkter oder von vornherein beabsichtigter Weg zum Fabrikantenberuf. Vielmehr erzwang wiederholt auch eine schon an den Schulleistungen erkennbare technisch-naturwissenschaftliche Begabung (z.B. Wilhelm Ludwig Büchner (1816-1892)) oder die

${ }^{30}$ Wilhelm Heraeus, Geschichte der Familie Heraeus. Zur Feier des 250jährigen Besitzes der Einhorn-Apotheke zu Hanau, Offenbach a.M. 1910, 59ff.; Festschrift zum 75jährigen Bestehen der Platinschmelze W.C. Heraeus GmbH 1851-1926, Hanau 1926, S. 6ff; Karl Siebert, Hanauer Biographien aus drei Jahrhunderten. Wilhelm Carl Heraeus, in: Hanauer Geschichtsblätter, Neue Folge 3/4 (1919), S. 81-83; Wilhelm Geibel u.a. (Hg.), Festschrift zum 70. Geburtstag von Dr.phil. Dr.Ing. e.h. Wilhelm Heraeus, Hanau 1930, S. Iff; Günther Mehl, Wilhelm Carl Heraeus, in: NDB 8 (1969), S. 571.

${ }^{31}$ DGB 98 (1937), S. 98f.; Dr. E. Fresenius KG, Bad Homburg v.d.H., o.O., o.J. [1962].

${ }_{32}$ Institut. Geschichte Handelskammer Frankfurt, S. 1288; 90 Jahre Fabrik pharmazeutischer Präparate Karl Engelhard, Frankfurt a.M., maschr. Manuskript in Firmenbesitz 1962.

${ }^{33}$ Heinrich Voigt, Nachdenkliches und Heiteres aus den ersten Jahrzehnten der Elektrotechnik, Leipzig 1925, S. 153.

${ }^{34}$ Carl Linde, Aus meinem Leben und von meiner Arbeit, München 1916, 3. Aufl. 1983, S. 10; Kurt Mayer, Karl Michaelis, Carl Ritter von Linde, in: NDB 14 (1985), S. 577-581. 
Notwendigkeit zur finanziellen Entlastung des Lebensunterhalts des elterlichen Beamtenhaushalts beizutragen, entgegen anderen Berufszielen eine frühe technische oder kaufmännische Berufswahl (z.B. Ludwig Beck (1841 - 1918) ${ }^{33}$ ).

Mehrheitlich wandten sich aber Angehörige dieser beamteten und Bildungsbürger-Herkunftsgruppe verstärkt erst nach 1850 Industriegründungen zu, als ihnen der Ausbau des naturwissenschaftlichen und technischen höheren Schulwesens einen ihrer Herkunft bzw. ihrem Anspruch entsprechenden bildungsmäßigen Zugang zur Industrie ermöglichte.

Die völlig ephemere Erscheinung des Großgrundbesitzes an Untermain und Mittelrhein sowie die industrieabstinenten Wertorientierungen dieser Schichten erklären wohl das völlige Fehlen der auch im übrigen Deutschland nur regional unter besonderen Entwicklungsbedingungen (z.B. Oberschlesien ${ }^{36}$ ) bedeutsamen agrarisch-feudalen Spitze der Großgrundbesitzer als Herkunftsreservoir der Industriegründer. Infolge des zeitlichen Ansatzes der Untersuchung fehlen unter ihnen auch die wesentlich erst der industriellen Welt zugehörigen Ingenieure, Chemiker und Techniker.

Im Hinblick auf das große Arbeitskräftereservoir der klein- und zwergbäuerlichen Bevölkerung mit oft ländlichem Hausnebengewerbe im Untersuchungsgebiet und seinen mittelgebirgigen Nachbarregionen, ihrer schlechten, gebietsweise trostlosen wirtschaftlichen Lage, der Verstädterung und dem Zwang des Berufswechsels zur Arbeiterschaft im 19. Jahrhundert blieb die Abkunftshäufigkeit der Firmengründer von Bauern mit sechs $(3,7 \%)$ und von Werkmeistern und Arbeitern mit neun $(5,6 \%)$ Personen ähnlich wie die von unteren Beamten mit drei $(1,8 \%)$ Herkunftsfällen beschränkt. Das verstärkte Auftreten dieser Abkunftsberufe nach 1870 deutet aber doch auf verbesserte Aufstiegsmöglichkeiten und ein Offener-Werden der Gesellschaft für sozial von unten Aufsteigende in der Zeit seit der Hochindustrialisierung und nach der Reichsgründung hin.

\footnotetext{
${ }^{35}$ Siehe oben Anm. 18 und Büchner, Familie Büchner, S. 30f.

${ }^{36}$ Konrad Fuchs, Wirtschaftliche Führungskräfte in Schlesien vom ausgehenden 18. Jahrhundert bis zum Beginn des Ersten Weltkriegs, in: Führungskräfte der Wirtschaft im 19. Jahrhundert 1790-1914, Teil II, Büdinger Vorträge 1969-1970. Hg. von Herbert Helbig (Deutsche Führungsschichten der Neuzeit 7), Limburg/Lahn 1977, S. 59-108, insbes. S. 65ff. und S. 78.
} 
Entgegen manchen neueren Untersuchungen und Ansichten über die deutsche Unternehmerrekrutierung im 19. Jahrhundert ${ }^{37}$, scheint damit das vorliegende rhein-mainische, nur die Firmengründer und nicht die Gesamtunternehmerschaft einschließlich der Unternehmenserben einbeziehende Material wieder in Grenzen die ältere, zum Teil zeitgenössische und insgesamt sicher zu optimistische Ansicht zu bestätigen, nach der die „leitenden Männer des Wirtschaftslebens ... aus immer breiteren und somit immer tieferen Schichten der Bevölkerung" aufstiegen $^{38}$.

Zwar gehörten gut die Hälfte, nämlich 85 Unternehmerväter $(52,2 \%)$ der Oberschicht (Fabrikanten, Großkaufleute, höhere Beamte, Pfarrer, freiberuflich tätige Akademiker und Leitende Angestellte) an. Der Mittelschicht (mittlere Beamte einschließlich Lehrer, Kaufleute, Handwerksmeister und selbständige Handwerker, Bauern und Angestellte) entstammen aber immerhin $64(39,2 \%)$ der Firmengründer. Die Unterschicht der unteren Beamten, Arbeiter und der von diesen wiederum erheblich geschiedenen Werkmeister ist mit 12 Personen $(7,4 \%)$ als Herkunftsbereich vertreten.

In der chronologischen Abfolge überwiegt in der frühindustriellen Ära bis 1850 entschieden die Herkunft aus der Mittelschicht. Der bedeutende Anstieg und das deutliche Übergewicht der Herkunft der Firmengründer aus der Oberschicht erfolgt dann im Untersuchungsdoppeljahrzehnt 1851-1870. Und offensichtlich hat man in der nunmehr verstärkten Beteiligung der kapital- und bildungsbesitzenden Kreise an Industriegründungen das entscheidende Moment des in diesen Jahrzehnten erfolgten Durchbruchs zur industriellen Gründungsund Wachstumsphase zu sehen. In der industriell, beruflich und gesellschaftlich vielgestaltiger werdenden Welt des entwickelten Kapitalismus des Kaiserreichs, insbesonders erkennbar im letzten Untersuchungsdoppeljahrzehnt ab 1891, finden sich unter den Vätern der Firmengründer dann verstärkt Angehörige unterer Schichten bei gleichzeitiger Angleichung der Herkunftswerte der Mittelschicht zu

\footnotetext{
${ }^{37}$ Hartmut Kaelble, Sozialer Aufstieg in Deutschland 1850-1914, in: Vierteljahresschrift für Sozial- und Wirtschaftsgeschichte 60 (1973), S. 41-71, hier bes. S. 5253; Kaelble, Mobilität, S. 102-110, insbes. S. 104; zum Teil anhand desselben Basismaterials (Neue Deutsche Biographie) wie H. Kaelble für die Gesamtunternehmerschaft kommt W. Stahl bei feinerer Differenzierung der Schichtzugehörigkeit für Gründer-Unternehmer zu einem günstigeren Bild der Aufstiegsmöglichkeit. Stahl, Elitekreislauf, S. 126.

${ }^{38}$ Werner Sombart, Der moderne Kapitalismus, 3. Bd. 1. Halbbd., Das Wirtschaftsleben im Zeitalter des Hochkapitalismus, Neudruck Berlin 1955, S. 19f.
} 
denen der Oberschicht ${ }^{39}$. Die Herkunft aus der Oberschicht hat aber insofern besonderes Gewicht, da das vorliegende Material das Grundmuster der elitären Rekrutierung bestätigt, nach der mit steigender Unternehmensgröße die Unternehmer in wachsendem Maße den oberen Schichten, in sinkendem dagegen den sozial unteren Berufen entstammen. Insofern kommt dem Thema der Verbindung und Differenzierung von Aufstiegsmobilität und Wirtschaftszweig größte Bedeutung zu.

\subsection{Die beruflich-soziale Herkunft und der Wirtschaftszweig}

Die unterschiedlichen Anforderungen der einzelnen Wirtschaftszweige an die bildungsmäßigen, technischen und kaufmännisch-finanziellen Ansprüche der Unternehmer führen im Hinblick auf die beruflichsoziale Stellung der Väter und die Wahl der Wirtschaftszweige durch die Firmengründer zur Unterscheidung von sozial offenen Branchen, also Aufstiegsbranchen und Branchen, die gegen Aufsteiger weitgehend resistent waren.

Von den 48 Unternehmervätern des Maschinen-, Stahl- und Fahrzeugbaus gehören 28 den mittleren und unteren Berufen an $^{40}$. 19 Unternehmerväter waren Angehörige der Oberschicht. Die für die Hinwendung zu mechanischen Industriezweigen besonders ansprechbaren Handwerkersöhne bilden mit 17 Vertretern das weitaus größte Kontingent einer Einzelabkunftsberufsgruppe. Handwerksmeister als Väter besaßen unter anderen z.B. die Gründer der Maschinenfabrik Goebel in Darmstadt, Johann Peter Gandenberger (1804-1869) 11 und Johann Georg Goebel (1830-1900) ${ }^{42}$, Adam Opel (1837-1895) in

${ }^{39}$ Siehe Tabelle Anlage 2. Den Sonderfall eines erstaunlichen untermehmerischen Aufstiegs von bäuerlicher Herkunft und keiner irgendwie erkennbaren höheren Spezialausbildung zu einem Großunternehmer stellt Louis Peter (1841-1921), Gründer der Mitteldeutschen Gummiwarenfabrik Louis Peter AG in Frankfurt am Main dar. Auf ihn ließe sich das Wort von Fritz Redlich „Unternehmer trotz Abkunft" anwenden: Wolfgang Medding, Louis Peter, in: Lebensbilder aus Kurhessen und Waldeck 1830-1930 (1950), S. 248ff; Helm Wienkötter, Geschichte der Luftbereifung und der Peters Union, Frankfurt a.M. 1930, insbes. S. 13ff.

${ }^{40}$ Für diese und die folgenden Zahlen siehe bitte Tabelle Anlage 3: Die beruflichsoziale Herkunt und der Wirtschaftszweig.

${ }^{41}$ Staatsarchiv Darmstadt, Sterbeprotokoll Pfungstadt 15.Nov.1813.

${ }^{42}$ Evangel. Pfarramt Ober-Ramstadt, Heirat 9.8.1829; Ali Lichtenstein, Die Maschinenfabrik Goebel und die Stadt Darmstadt, Darmstadt o. J. [um 1926], S. 10ff; Hundert Jahre Goebel AG 1851-1951, Darmstadt 1951; Gandenberger'sche 
Rüsselsheim ${ }^{43}$ oder die Gründer der Maschinenfabrik und Eisengießerei Gebr. Schmaltz in Offenbach, die Brüder Johann Philipp Schmaltz (1819-1881) und August Felix Schmaltz (1821-1874) ${ }^{44}$. Auf die handwerkliche Herkunft von Joseph Gastell (1785-1852) in Mainz, Johann Simon Fries (1777-1835) in Frankfurt und Johannes Heim (1786-1844) wurde bereits oben hingewiesen ${ }^{43}$. Sie gilt auch für den Maschinenbauer Jacob Wilhelm Philippi (1829-1877) in Wiesbaden ${ }^{46}$, den Glasdachfabrikanten Claus Meyn (1871-1953) in Frankfurt ${ }^{47}$ oder den Kesselschmied und Stahlbauer Michael Lavis (1842-1906) in Offenbach ${ }^{48}$.

Beispiele für eine nicht-handwerkliche einfache oder mittlere beruflich-soziale Stellung von Vätern, deren Söhne Maschinen-, Stahl- oder Fahrzeugbaubetriebe gründeten, bieten unter anderen Anton Joseph Collet (1830-1885), 1862 Mitgründer der Werkzeugmaschinenfabrik Collet \& Engelhard in Offenbach, dessen Vater Gold- und Silberarbeiter und Inhaber eines kleinen Ladengeschäfts in Kassel war ${ }^{49}$, und der Eisenbahnpacker und Güterwieger Johann Conrad Donges (18131866), dessen Sohn Georg Theodor Donges (1843-1924) 1872 die Darmstädter Eisenbahnbau-Anstalt gründete ${ }^{50}$. Der Vater von Johann Forst (1814-1879), neben dem Schlossermeistersohn Johannes Klein

Maschinenfabrik Georg Goebel, in: Histor.-biograph. Blätter, Großherzogtum Hessen.

${ }^{43}$ Hans Friedrich von Ehrenkrook, Karl Förster u.a., Ahnenreihen aus allen deutschen Gauen 1 (1928), S. 242ff; Hans Schäcker: Die Familie Opel, in: Der Uhrturm. Zeitschrift der nassauischen familiengeschichtlichen Vereinigung 16 (1936), S. $301 \mathrm{ff}$.

${ }^{14}$ Georg Lehnert, Johann Philipp Schmaltz und August Felix Schmaltz, in: Hessische Bigoraphie 1 (1918), S. 428-430; A. Voigt, Maschinenindustrie, S. 13f; Gebr. Schmaitz, Maschinenfabrik und Eisengießerei, in: Histor.-biograph. Blätter, Großherzogtum Hessen.

${ }^{43}$ Siehe oben Anm. 5-7.

${ }^{46}$ Auskunft Maschinenfabrik Wiesbaden GmbH., Wiesbaden; Verein Deutscher Ingenieure. Festschrift zur 50. Hauptversammlung in Mainz und Wiesbaden vom 14. bis 17. Juni 1909, hg. vom Bezirksverein Rheingau, Mainz 1909, S. 190f; Maschinenfabrik Wiesbaden GmbH, in: Histor--biograph. Blätter, Reg.Bez. Wiesbaden.

${ }^{47}$ Claus Meyn, Zum 80. Geburtstag des Firmengründers, Frankfurt/M. 1951, S. 5.

${ }^{48}$ Auskunft Standesamt Offenbach am Main,; 50 Jahre Stahlbau Lavis. Eine Jubiläumsschrift, Offenbach/M. 1947, S. 1.

${ }^{49} \mathrm{O}$. Mahr, 75 Jahre Collet \& Engelhard, Werkzeugmaschinenfabrik AG, Offenbach/M. 1862-1937, Berlin 1937, S. 6f.

${ }^{50}$ Stadtarchiv Darmstadt, Einwohnermeldekartei Georg Donges; mündl. Auskunft W. Paulmann, Darmstadt. 
(1819-1896) 1847 Mitgründer der Druckmaschinenfabrik Johannisberg im Rheingau, war ein bei Waterloo gefallener Soldat, die Mutter war Hausiererin ${ }^{51}$. Der Beruf von Johannes Hartmann (1823-1887), dessen Söhne 1885 die Maschinenfabrik F. A. Hartmann in Offenbach gründeten, wird aufeinanderfolgend als Arbeiter, Mechaniker, Monteur und Werkführer angegeben ${ }^{32}$.

Das Übergewicht der Abkunft aus sozial mittleren und unteren Berufen kennzeichnet jedenfalls den Maschinen-, Stahl- und Fahrzeugbau als eine Aufstiegsbranche. Wesentlich für die soziale Durchlässigkeit ist aber, daß sich gegen Ende des Untersuchungszeitraums keineswegs eine Verengung der Herkunftshäufigkeit aus mittleren und unteren Berufen zeigt. Vorteilhaft für die Herkunftsbreite und die bis 1914 andauernden Erfolgsmöglichkeiten für Maschinenbaugründer erwies sich im Rhein-Main-Gebiet die mit der fortschreitenden Mechanisierung einhergehende Spezialisierung und Produktionsvielfalt, das Fehlen des aufstiegserschwerenden kapital- und technikintensiven Baus schwerer Maschinen und damit ein Überwiegen spezialisierter kleinerer und mittelgroßer Betriebe neben einigen Großbetrieben, insbesondere im Arbeitsmaschinen- und Fahrzeugbau (Nähmaschinen, Schreibmaschinen, Fahrräder, Autos, z.B. Adam Opel in Rüsselsheim $^{33}$, Adler Fahrrad- und Autowerke vorm. Heinrich Kleyer in Frankfurt ${ }^{54}$ ).

Die Söhne der unter den Maschinenbaugründern in nicht unbeträchtlicher Zahl vertretenen Oberschicht wandten sich bezeichnenderweise mit einer einzigen Ausnahme erst nach 1850 - am stärksten im Zeitraum 1871-1890 - der Gründung von Maschinenbaubetrieben zu (z.B. Otto Engelhard (1838-1926) in der Werkzeugmaschinenfa-

${ }^{51}$ Theodor Goebel, Die Maschinenfabrik Johannisberg: Klein, Forst \& Sohn Nachfolger zu Geisenheim/Rhein, Johannisberg 1897, S. 6f.

${ }^{52}$ Einwohnermeldeamt Offenbach/M., Friedrich August Hartmann; Staatsarchiv Darmstadt, ev. Geburtsprotokoll Darmstadt 30. August 1855; Staatsarchiv Darmstadt, ev. Copulationsprotokoll Darmstadt (Steinbuch) 22. Okt. 1854; Hans Birling, H.W. Flemming, F. Klemm, 75 Jahre Maschinenfabrik Hartmann AG, Offenbach/M. 1885-1960, Darmstadt 1960, S. 9ff.

${ }_{33}$ L. Opel, Adam Opel und sein Haus, 50 Jahre der Entwicklung 1862-1912, Darmstadt 1912, S. 6ff.; Heinrich Hauser, Opel, ein deutsches Tor zur Welt, Frankfurt 1937.

${ }^{54}$ Alexander Lang, Die Adler-Fahrradwerke vorm. Heinrich Kleyer, Frankfurt/M. 1880-1905, Berlin 1905, S. 11ff.; Heinrich Schmitt, Die Adlerwerke 1880-1926, in: Industrie-Bibliothek 9 (1926), S. 3ff; Paul W. Exhardt, So entsteht ein Auto (50 Jahre Adler 1880-1930), Frankfurt/M. 1930, S. 7ff.; Hans Christoph Graf von Seherr-Thoß, Heinrich Kleyer, in: NDB 12 (1980), S. 63f. 
brik Collet \& Engelhard in Offenbach ${ }^{55}$, Carl Schenck (1835-1910) in der gleichnamigen Maschinen- und Waagenbaufabrik in Darmstadt ${ }^{36}$, Johann Christian Fellner (1851-1920) in der Frankfurt-Bockenheimer Firma Fellner \& Ziegler ${ }^{57}$ oder Karl Wittekind (1855-1912) in der Frankfurter Maschinenbau AG., vorm. Pokorny \& Wittekind ${ }^{88}$ ). Konnte man doch erst seit den 1840 er Jahren, vor allem aber mit dem industriellen Aufschwung der 1850er Jahre überhaupt von der Existenz eines deutschen Maschinenbaus als selbständigem Industriezweig sprechen. Es war dies auch die Zeit, in der der Ausbau der Polytechnischen Schulen und des technischen Schulwesens eine standesgemäße theoretisch-technische Ausbildung zu ermöglichen begonnen hatten und sich gegenüber der Frühindustrialisierung zudem die Renditemöglichkeiten im Maschinenbau verbesserten. ${ }^{s 9}$

Mit der chemischen Industrie ist das Gegenteil der sozial offenen Maschinenbauindustrie angesprochen. Von 38 Unternehmervätern der Chemiegründer gehörten allein 29 der Oberschicht, acht der Mittelschicht und einer der Unterschicht an. Dieses Übergewicht der Herkunft aus der Oberschicht bei Firmengründern von Chemieunternehmen wird dadurch verschärft, daß Söhne von Mittel- und Unterschichtsangehörigen ihre Firmen mehrheitlich vor der Etablierung der chemischen Großindustrie, der Grundstoff-, Teerfarben- oder Düngemittelherstellung kurz nach der Jahrhundertmitte gegründet haben. Zudem befaßten sie sich vorrangig mit der Herstellung von chemischen Spezialerzeugnissen und Fertigprodukten in Klein- und Mittelbetrieben, deren Fertigungsprobleme zum Zeitpunkt der Unternehmensgründung durchaus noch durch die Empirie erlernbar und lösbar waren (z.B. die Seifensiedereien und Seifenfabriken August Jacobi in

\footnotetext{
${ }^{55}$ Siehe oben Anm. 49.

${ }^{36}$ Siehe oben Anm. 25.

${ }^{57}$ Siehe oben Anm. 15.
}

58 Institut: Stammbaum der Familie Wittekind; Geschichte Handelskammer Frankfurt, S. 1248, 1255f.; Bockenheim, Entwicklung, S. 83f.

${ }^{59}$ Alfred Schröter, Die Entwicklung der deutschen Maschinenbauindustrie in der ersten Hälfte des 19. Jahrhunderts, in: Alfred Schröter, Walter Becker, Die deutsche Maschinenbauindustrie in der industriellen Revolution (Veröffentlichungen des Instituts für Wirtschaftsgeschichte an der Hochschule für Ökonomie BerlinKarlshorst), Berlin 1962, S. 70, 101f, 111; Walter Becker, Die Entwicklung der deutschen Maschinenbauindustrie von 1850 bis 1870, in: Schröter, Becker, Maschinenbauindustrie, S. 140ff., 195f. und S. 228ff; Otto Froriep, Zur Geschichte der Maschinenbau-Industrie und der Maschinenzölle im deutschen Zollverein (Tübinger staatswissenschaftliche Abhandlungen, NF 16), Stuttgart 1918, S. 40, 54, 59; Gessner, Metallgewerbe, S. 287-338. 
Darmstadt ${ }^{60}$, Martin Kappus in Offenbach ${ }^{61}$, die Spiritus- und Öllackfabrik Friedrich Roßbach in Friedberg ${ }^{62}$, der Wachswaren-, Schuhcreme- und Reinigungsmittelhersteller Werner \& Mertz (Erdalwerke) in Mainz ${ }^{63}$ u. dgl.)

Der Durchbruch zur nahezu vollständig auf wissenschaftlicher Forschung betriebenen modernen chemischen Industrie verlangte den Firmengründern in erster Linie ein chemisches Studium ab, erfordete einen höheren Kapitalbedarf, begünstigte die Verbindung eines Chemikers mit einem Kaufmann/Kapitalisten und ließ die Herkunft aus der Oberschicht für Chemiegründer die Regel werden. Der Aufstieg zum Beispiel von Friedrich Merz (geb. 1884) aus bäuerlicher Herkunft zum Chemie-, Pharma- und Kosmetikhersteller knapp vor 1914 erfolgte bezeichnenderweise über ein chemisches und pharmazeutisches Studium ${ }^{64}$.

Dabei lag der Zugang zur Gründung der lange als chemische Kleinindustrie bezeichneten pharmazeutischen Betriebe, deren Initiatoren wiederum meist Apotheker oder Söhne der im Chemieunternehmertum relativ stark vertretenen geistigen Oberschicht waren, auch schon im Vormärz fast durchwegs in einer guten theoretischen Ausbildung bzw. im Studium.

Die Feststellung des Überwiegens der Herkunft der Chemiegründer aus der Oberschicht ist noch durch den Hinweis zu vertiefen, daß ein Teil von ihnen derjenigen Schicht entstammte, die man durchaus als die bürgerliche Spitzenschicht in Deutschland bezeichnen könnte. Der

${ }^{60}$ Stadtarchiv Darmstadt, Einwohnermeldekartei: Johannes Jacobi und Johann August Jacobi, Evgl. Kirchenbuch Darmstadt, Heirat 26.Sept. 1844; Arthur Uecker, Die Industrialisierung Darmstadts im 19. Jahrhundert, Darmstadt 1928, S. 150; generell über die Bedeutung des traditionellen vorindustriellen „Chemiehandwerks" und neuerer chemischer Industrie an Mittelrhein und Untermain siehe: Dieter Gessner, Chemiehandwerk und chemische Großindustrie an Mittelrhein und Untermain. Zur Vorgeschichte der chemischen Industrie im Rhein-MainRaum (1790-1865), in: Nassauische Annalen 91 (1980), S. 144-179.

${ }^{61}$ Reinhold Ruhr, Offenbacher Lebensbilder 18: Johann Martin Kappus, in Offenbacher Volkszeitung 24.2.1923.

${ }_{62}^{2}$ Georg Lehnert, Friedrich Roßbach, in: Hessische Biographien 2 (1927), S. 404f.; Spiritus- und Oellackfabrik F. Roßbach, in: Histor.-biograph. Blätter, Großherzogtum Hessen.

${ }^{63}$ Standesamt Mainz, Familienregister 8942 und 15947: Laurenz Adam Werner und Friedrich Christoph Werner.; P. Stautz, Wanderungen durch die hessische Industrie, in: Mainzer Tageszeitung 29.Nov.1923.

${ }^{64}$ Auskunt Chemische Fabrik Merz \& Co., Frankfurt/M.; Friedrich Merz 80 Jahre, in: Frankfurter Allgemeine Zeitung 16. und 17.10.1964. 
Vater des Hauptinitiators bei der Gründung der Farbwerke Hoechst Nikolaus Eugen Lucius (1834-1903), der Großkaufmann und Textilunternehmer Sebastian Lucius (1781-1857), war selbst bereits Kommerzienrat, Präsident der Handelskammer Erfurt und Besitzer der Rittergüter Stödten und Klein-Ballhausen. Von seinen vier überlebenden Söhnen waren drei Mitglieder des Reichstags, unter ihnen Robert Lucius (1835-1914), seit 1888 Freiherr Lucius von Ballhausen, von 1879-1890 konservativer preußischer Minister für Landwirtschaft und seit 1895 Mitglied des Herrenhauses ${ }^{65}$. Abkunft, wirtschaftliche Unabhängigkeit, Branchenbedeutung und zum Teil auch die Betriebsgröße, die Verfügbarkeit für öffentliche Betätigung ermöglichte, sowie Nähe zu den traditionell staatstragenden Gesellschaftsschichten haben bei den Chemieindustriellen anscheinend auch stärker als in anderen erfaßten Branchen, und zum Teil schon in der Gründergeneration zur Übernahme von Abgeordnetenmandaten, besonders zu Reichstagsmandaten, zu Nobilitierungen und zum Teil zum Übergang ihrer Nachkommen in hohe Beamtenstellungen geführt ${ }^{66}$.

Ein Beispiel für die Beteiligung der „geistigen Führungsschicht" an Gründungen der chemischen Industrie und deren öffentliche Betätigung stellt der Gründer der Ultramarinfabrik in Pfungstadt bei Darmstadt und Reichstagsabgeordnete der Fortschrittspartei Wilhelm Ludwig Büchner (1816-1892) dar. Er entstammte einer in seiner Generation genial-hochbegabten alten Odenwälder Bader-, Ärzte- und Chirurgenfamilie und war Bruder des Dichters Georg Büchner (18131837), des seinerzeit vielgelesenen materialistischen „Kraft- und Stoff-Büchners" Ludwig Büchner (1824-1892) und der Vorläuferin der Frauenbewegung Luise Büchner (1821-1877) ${ }^{67}$.

${ }^{65}$ DGB 4 (1896), S. 229 ff.; Ehrenkrook, Ahnenreihen 3 (1936), S. 59ff; Fischer, Gründer, S. 251; Wolfgang Metternich, Eugen Lucius, in: NDB 15 (1987), S. 277278; Fischer, Meister, S. 65ff; Wilhelm Treue, Unternehmer und Finanziers, Chemiker und Ingenieure in der chemischen Industrie im 19. Jahrhundert, in: Helbig (Hg.), Führungskräfte, S. 235-254, hier bes. S. 241ff.

${ }^{66}$ Mitglieder des Reichstags unter den erfaßten Chemiegründern waren z.B. der Mitgründer der Farbwerke Hoechst Johann Adolf (von) Brüning (1837-1884), der Offenbacher Toiletteseifen- und Parfümeriefabrikant Gustav Boehm (1827-1900), der Teilhaber der Chemischen Fabrik Kalle \& Co. Jakob Friedrich Kalle (18371915) und der Oestricher Oxalsäurefabrikant Rudolph Koepp (1830-1897). Siehe Max Schwarz, MdR, Biographisches Handbuch der Reichstage, Hannover 1965. Nobiltiert wurden von Chemieindustriellen Angehörige der Familien von Brüning, von Meister (beide Farbwerke Hoechst), von Gans und von Weinberg (beide Cassella). Zu den MdR gehört auch Wilhelm Büchner, siehe Anm. 13 und 19.

${ }^{67}$ Siehe oben Anm. 19. 
Insgesamt läßt sich aber feststellen, die chemische Industrie war wenig aufstiegsfreundlich; am sozial offensten war sie noch in einigen chemischen Spezialsparten, am geringsten in der späteren chemischen Großindustrie.

Bei den 20 erfaßten Gründern der Leder- und Lederwarenindustrie, für die das Rhein-Main-Gebiet während des Untersuchungszeitraums ein Hauptzentrum ihres Standorts in Deutschland war, ist wegen der unterschiedlichen Anforderungen dieser beiden Industriesparten an den Unternehmer zu differenzieren zwischen der ledererzeugenden und der lederverarbeitenden Industrie.

Die Gründer der Lederfabriken entstammen dabei weniger dem Gerbereihandwerk, wie man dies unter dem naheliegenden Gesichtspunkt "aus Gerberei wird Lederfabrik" vermuten würde, sondern vielmehr überwiegend der Gruppe der Großkaufleute, Kaufleute, zum Teil auch den Fabrikanten. Sie besaßen zudem überwiegend eine kaufmännische Ausbildung, auch wetn es Beispiele erfolgreicher, von Gerbern gegründeter Lederfabriken gibt, wie z,B. die bereits auf das Jahr 1798 zurückgehende Lederfabrik von Mayer, Michel und Deninger in Mainz ${ }^{68}$. Die bis zur Verwendung synthetischer Gerbstoffe im letzten Drittel des 19. Jahrhunderts auffallend rückständige Ledertechnologie mit langem Gruben-, dann Faßgerbungsprozeß und entsprechend langer Kapitalbindung, wie auch die kaufmännischen Kalkulationen beim Einkauf der Rohstoffe und beim Verkauf der Fertigprodukte, haben offenkundig die Abkunft von kapitalkräftigen Oberschichtsnachkommen oder Kaufleuten unter den Lederfabrikanten begünstigt ${ }^{69}$. Da es sich bei den untersuchten Gründungen letztlich um eine Auslese durchgekommener und arrivierter Firmen handelt - dar-

${ }^{68}$ Lederwerke vormals Mayer, Michel \& Deninger, Mainz 1798-1898, Mainz 1898, S. 1-44.

${ }^{69}$ Hans Hanisch, Deutschlands Lederproduktion und Lederhandel, in: Zs. für die gesamte Staatswissenschaft, Erg.H. XVI (1905), S. 25, 50, 52; Adolf Link, Die Lederindustrie (erzeugende und verarbeitende), in: Alfred Weber, Über den Standort der Industrien II. Teil: Die deutsche Industrie seit 1860, 3, Tübingen 1913, S. 37, 41; C.L. Becker, Die wirtschaftliche Entwicklung der deutschen Lederindustrie, Straßburg 1918, S. 32ff., 42f., 52; Helmtraut Hendinger, Vom Gerberhandwerk zur Lederindustrie. Eine Untersuchung des Bedeutungs- und Strukturwandels der Gerberei in vier Jahrhunderten an Beispielen aus Franken und Schwaben (in: Jahrbuch für fränkische Landesforschung 30 (1970), S. 25ff., S. 62f., S. 68) betont, $\mathrm{da} B$ sich nur ein kleiner Teil der Lederfabriken aus Handwerksbetrieben entwickelt hat; Dieter Gessner, Industrialisierung des Lederhandwerks am Mittelrhein und Untermain, in: Archiv für Frankfurts Geschichte und Kunst 57 (1980), S. 55-85, insbes. S. $62 \mathrm{f}$. 
unter die zeitweise größte Lederfabrik der Weit, die Lederwerke Cornelius Heyl in Worms ${ }^{70}$ - treten wohl auch die kapitalkräftigeren, rentabler arbeitenden und daher rascher expandierenden Gründungen von Kaufleuten stärker hervor als dies in der Gesamtzahl der zeitgenössischen Gerbereibetriebe begründet läge.

Die Aufstiegsbranche schlechthin unter den untersuchten Wirtschaftszweigen bildet die Lederwarenindustrie, wenn auch die sieben erfaßten Offenbacher Lederwarenerzeuger, die dem Handwerk, den unteren Beamten und der Arbeiterschaft entstammen, dies nur beispielhaft verdeutlichen können.

Entstanden als ein von der Buchbinderei verselbständigter Gewerbezweig ausgangs des 18 . Jahrhunderts, ist die Lederwarenindustrie Mitte des 19. Jahrhunderts mit der Erfindung des Lederwarenportemonnaies mit Metallrahmen und der Ergänzung des bis dahin bestimmenden geschlossenen Manufakturbetriebs durch Heimarbeit und Verlagssystem sowie der Nachfragesteigerung nach Damenhandtaschen, Photoalben und handlichen Reiseutensilien (Koffer, Reiseetuis, Reisetaschen) infolge der Verbesserung der Verkehrsverhältnisse für soziale Aufsteiger noch offener geworden. Die mehr arbeitsintensive als kapitalintensive Herstellung von Qualitätswaren, die Möglichkeit zur Mitarbeit von Familienangehörigen und die Kreditierung durch Grossisten begünstigten - unter Umständen über das Stadium eines Zwischenmeisters im Heimarbeitsprozeß - den Weg in die Selbständigkeit $^{71}$. Der Wert der Zahl der sozialen Aufsteiger in der Lederwarenfabrikation wird dadurch gemildert, daß viele dieser Lederwarenproduzenten oft über Kleinst- und Mittelbetriebe nicht hinausgelangten und ihre Firmen infolge der Modeabhängigkeit und Konjunkturanfälligkeit dieser Konsumgüterbranche mit seltenen Ausnahmen wie z.B. die Firma Ludwig Krumm AG, mitbedingt durch die Schaffung

${ }^{70}$ Daniel Bonin, Cornelius Heyl, in: Hessische Biographien 1 (1918), S. 177-179; Friedrich M. Illert, Umriß einer Geschichte des Hauses Cornelius Heyl, zum 60. Geburtstag des Seniorchefs Dr. jur. Cornelius Freiherr Heyl zu Herrnsheim. Maschr. Worms 1934; Günther Kriegbaum, Comelius Heyl, in: NDB 9 (1972), S. 81f.

${ }^{71}$ Ludwig Hager, Die Lederwaren-Industrie in Offenbach/Main und Umgebung (Volkswirtschaftliche Abhandlungen der badischen Hochschule VII/3), Karlsruhe 1905, S. 2, 43ff.; Müller, Entwicklung, S. 34ff., 104; Franz Jörissen, Die deutsche Leder- und Lederwaren-Industrie, Berlin 1909, S. 252; Carl Klöß, Heimarbeit und Verlag in der Offenbacher Lederwarenindustrie, wirtschafts- und sozialwiss. Diss. Frankfurt/M., Gelnhausen 1933, S. 5ff., 29ff., S. 35; Gessner, Industrialisierung Lederhandwerk, S. 63ff. 
der Warenmarke Gold-Pfeil anstelle der bisherigen Anonymität in der Offenbacher Lederwarenindustrie, oft sehr kurzlebig waren.

Wenn auch in der Frühzeit der Portefeuillefabrikation die Buchbinderabkunft und Buchbinderausbildung, z.B. bei Johann Jakob Mönch (1786-1874) ${ }^{72}$ und später in der Reiseartikelbranche, der sogenannten Sattlerwarenbranche, die Sattlerherkunft oder -ausbildung nicht unüblich waren, so ist doch die Arbeiterherkunft für Lederwarenfabrikanten ein gängiges Herkunftsspektrum. Wilhelm Friedrich Bauer (1881-1961), 1906 Gründer einer Reiseartikelfabrik in OffenbachBieber, war z.B. der Sohn und Enkel von Fabrikarbeitern ${ }^{73}$. Der Vater von Ludwig Krumm (1827-1886), 1856 Gründer der heutigen GoldPfeil-Lederwaren, ist unbekannt, sein Großvater war Fuhrknecht, dann Bürger und Mehlhändler in Offenbach ${ }^{74}$.

Für die Erkenntnis der sozialen Mobilität sind diese Offenbacher Lederwarenfabrikanten von größter Bedeutung. Von der Größe und der Dauer ihrer Betriebe, der Wirtschaftskraft des einzelnen und wohl auch von ihrem Sozialanspruch sind sie mit wenigen Ausnahmen mit den Unternehmern anderer Branchen nur schwer vergleichbar.

Ähnlich der Trennung der Leder- von der Lederwarenfabrikation, sind bei der Eisen- und Metallwarenindustrie wegen der unterschiedlichen Anforderungen dieser beiden Industriesparten an den Unternehmer die Eisen- und Metallgießereien von den Betrieben der Eisen-, Blech- und Metallverarbeitung zu separieren.

Der Gießereiindustrie, der im 19. Jahrhundert im Industrieguß, dem Bauguß und dem Kunstguß eine ganz andere wirtschaftliche Bedeutung als heute zukommt, ist zwar die herkömmliche empirische Ausbildung und die entsprechende Herkunft nicht fremd. Bald als Halbzeug-, bald als Fertigwarenindustrie, bald als Teilbetrieb eines größeren Unternehmens, bald als Kundengießerei für den Markt oder als

${ }^{72}$ Reinhold Ruhr, Johann Jakob Mönch, in: Hessische Biographien 1 (1918), S. 375-376; Reinhold Ruhr, Offenbacher Lebensbilder 24: Jakob Mönch, in: Offenbacher Volkszeitung 5.6.1923.

${ }^{73}$ Einwohnermeideamt Offenbach/M.: Wilhelm Friedrich Bauer; Kathol. Pfarramt Offenbach-Bieber; Wilhelm Friedrich Bauer $\mathrm{GmbH}$, Lederwaren- und Reiseartikelfabrik Offenbach-Bieber, in: Die Westdeutsche Wirtschaft und ihre fuihrenden Männer, Land Hessen, Teil 2, Frankfurt a.M. 1956, S. 47-49.

${ }^{74}$ Evgl. Kirchenbuchgemeinde Offenbach, Dt. ref. Heirat 28. Okt. 1777, luth. Beerdigungen 21. Mai 1839, evgl. Heirat 15. Jan. 1852; Die Geschichte der Firma Ludwig Krumm AG, in: Offenbacher Monatsrundschau, H. 7, (Juli 1940), S. 16f; Gold-Pfeil-Jubiläumsschrift anläßlich des 100jährigen Bestehens der Ludwig Krumm AG Offenbach/M., Offenbach/M. 1956; Hugo Eberhardt, Heinrich Krumm, in: NDB 13 (1982), S. 121f. 
beides zusammen organisiert, war die Stellung der Gießereien in der Industrie und ihre Betriebsgrößenstruktur durchaus mannigfaltig. Die Zukunft gehörte aber schon seit der Mitte des 19. Jahrhunderts dem theoretisch gut vorgebildeten Gießereiunternehmer und wegen der umfangreicher werdenden Verwendung von Gießerei-, Form- und Transportmaschinen den Personen mit Kapitaleinsat ${ }^{75}$. Dies erklärt wohl überwiegend die Herkunft von Gießereiunternehmern aus der Oberschicht. So war z.B. der Vater des Eisenkunstgießereiunternehmers Alfred Richard Seebaß (1805-1884) in Offenbach Professor ${ }^{76}$, Ludwig Philipp Scriba (1847-1933) von der gleichnamigen Höchster Gießerei ${ }^{77}$ und Ludwig Beck (1841-1918) ${ }^{78}$ entstammten höheren Beamtenfamilien, während die in Frankfurt tätigen Julius Wurmbach (1831-1901) ${ }^{79}$ und Gebrüder Hesse Bergwerksverwalter bzw. Kupferhammerbesitzer zu Vätern hatten ${ }^{80}$.

Bei den Gründern von eigentlichen Eisen-, Blech- und Metallwarenbetrieben fehlt zwar auch die Abkunft von Fabrikanten und Großkaufleuten nicht. Herkunftsbedingt erklärbar gründeten zum Beispiel einige Söhne von Offenbacher Lederwarenfabrikanten als Zulieferer von Portefeuillefabriken fungierende Gürtlerwarenbetriebe beziehungsweise führten sie mit dieser oder einer geänderten Metallwarenproduktionsrichtung als eigene Unternehmen weiter (z.B. Johann Ja-

${ }^{75}$ Otto Brandt $(\mathrm{Hg}$.), Zur Geschichte der deutschen Eisengießerei. Festschrift zur fünfzigsten Hauptversammlung des Vereins Deutscher EisengießereienGießereiverband 1869-1920, Düsseldorf 1920, S. 24f;; Walther Maurmann, Aus der Wirtschaftsgeschichte der Gießerei-Industrie in Deutschland. 100 Jahre Vereinsarbeit, Düsseldorf 1969, S. 7ff., 13ff; U. Lohse, Die geschichtliche Entwicklung der Eisengießereien seit Beginn des 19. Jahrhunderts, in: Beiträge zur Geschichte der Technik und Industrie 2 (1910), S. 90ff, 132f., 147.

${ }^{76}$ DGB 143 (1967), S. 400 f., 408; Voigt, Maschinenindustrie, S. 6, 11, 17; Völker, Offenbachs Maschinenbau, S. 21.

${ }^{77}$ Siehe oben Anm. 24.

${ }^{78}$ Siehe oben Anm. 18.

${ }^{79}$ Nachkommen des Johann Wurmbach in Müsen, in: Mitteilungen der Genealogischen Gesellschaft zu Frankfurt/M. 3 (1920), S. 21-35; Bockenheim, Entwicklung, S. 80ff;; Geschichte Handelskammer Frankfurt, S. 1073, $1247 \mathrm{f}$.

${ }^{80}$ DGB 97 (1937), S. 191ff; ; Heddernheimer Kupferwerke und Süddeutsche Kabelwerke AG Frankfurt/M. und Mannheim. Festschrift zur Feier des 25jährigen Bestehens der AG und des 65jährigen Bestehens des Unternehmens 1853-18931918, Frankfurt/M. 1918, S. 3ff.; Geschichte Handelskammer Frankfurt, S. 1264. 
kob Mönch (1842-1926) ${ }^{81}$, Robert Weintraud (1860-1927), 1884 Gründer der nachmaligen Firma Rowenta Metallwarenfabrik ${ }^{82}$.

Ohne Zweifel ausgeprägter als es die paar angeführten Beispiele vermuten lassen, waren aber die Gründer von Betrieben der Eisen-, Blech- und Metallwarenindustrie einfacher oder mittelständischer Herkunft, überwiegend auch als Männer der Praxis mit entsprechender empirischer Ausbildung. Bis heute gehen ja zahlreiche Betriebe der Metallwarenproduktion, des Metallbaus, der Eisen- und Stahlkonstruktionen, des Apparatebaus u. dgl. auf Kunst- und Bauschlossereien, Spenglereien, Kupferschmieden und verselbständigte Facharbeiter zurück. Dabei sind die Übergänge von einem reinen Handwerksbetrieb über eine industriebetriebsähnliche große Werkstätte zu einem meist mittelständischen Industriebetrieb oft fließend und schwer festzustellen, sie haben sich auch wiederholt über zwei oder mehrere Generationen hingezogen.

Einige Beispiele sollen diese Aufstiegsmöglichkeiten in der Eisen-, Blech- und Metallwarenbranche über den gesamten Untersuchungszeitraum verdeutlichen. Johann Georg Huppe (1814-1871), 1847 Gründer der Taschenbügel- und Metallwarenfabrik Huppe \& Bender in Offenbach war der Sohn eines Taglöhners, der später „Seiler oder Peitschenmacher gewesen sein könnte". Der andere Namensgeber dieser Firma, Adam Philipp Bender (1827-1901), war der Sohn eines Bäckermeisters $^{83}$. Der Vater von Peter Schlesinger (1859-1934), 1885 Gründer der gleichnamigen Metallwarenfabrik in Offenbach, war Schlosser, dann Werkführer ${ }^{84}$. Emst Philipp Hinkels (1829-1894) Vater war Ackermann und Wirt, während der Gründer selbst vor Aufnahme der Gürtlerwarenfabrikation 1875 in Offenbach als Schlos-

${ }^{81} \mathrm{~K}$. Brockmann, Aus Alt-Offenbacher Tagen. Gürtlerwaren- und Taschenbügelfabrik Jakob Mönch, in: Offenbacher Generalanzeiger, Juli 1922; Reinhold Ruhr, Jakob Mönch. Ein Lebensbild, in: Stadtarchiv Offenbach Mappe 702/9.

${ }_{82}$ DGB 144 (1967), S. 502ff; ; Auskunf Dr. Wilhelm Weintraud, StuttgartBotnang; Auskunft Rowenta Metallwarenfabrik, Offenbach/ $M$.

${ }^{83}$ Evgl. Kirchengemeinde Offenbach, Heiraten 13. Nov. 1842; Rudolf Herrmann, 50 Jahre Huppe \&, Bender 1847-1897, Offenbach/M. 1897, S. 6 und 9; Taschenbügel- und Metallwaren 1847-1922. Eine geschichtliche Betrachtung anläßl. des 75jährigen Bestehens der Firma Huppe \& Bender in Offenbach/M., Offenbach 1922, S. 15ff; Die Entwicklung unserer Gürtlerwarenindustrie, in: Offenbacher Nachrichten 13. Jan. 1940.

${ }^{84}$ Staatsarchiv Darmstadt, Sterbeprotokoll Dietzenbach 4. März 1874; Die Entwicklung unserer Gürtlerwarenindustrie, in: Offenbacher Nachrichten 24. Jan. 1940. 
sergeselle, Stahlarbeiter und Gürtler gearbeitet hatte ${ }^{85}$. Die Metallwarenfabrik Louis Busch in Mainz wiederum geht auf eine Gürtlerei zurück, der Gründer des Fabrikbetriebs war ebenfalls Bronzearbeiter und Gürtler gewesen ${ }^{86}$. Die Gründer der Schraubenfabrik Gebr. Heyne in Offenbach stammten von einem Schneidermeister $a b^{87}$, während Balthasar Karl Hanss (1807-1880), 1847 Gründer einer Metallwarenfabrik in Mainz, Sohn eines Schreiners war ${ }^{88}$. Der Vater von Ludwig Voltz (geb. 1869), der eigentlich erst den Apparatebau Fritz Voltz Sohn in Frankfurt emporgebracht hat, war Kupferschmiedemeister ${ }^{89}$. Ähnlich führt das Preß- und Stanzwerk Jakob Faulstroh in GroßGerau seine Anfänge auf einen Kunst- und Bauschlossereibetrieb zurück ${ }^{90}$.

Jedenfalls verdeutlichen diese Beispiele, daß das Eisen- und Metallwarengewerbe in einem weit höheren $\mathrm{Maße}$ als es die in den Tabellen erfaßten Personen erkennen lassen, sozial eine ausgesprochene Aufstiegsbranche darstellt. Überhaupt könnte die stärkere Berücksichtigung beispielsweise der aufstiegsfreundlichen Lederwarenindustrie, von Teilen des Maschinenbaus und der Eisen-, Blech- und Metallwarenindustrie mit ihren zahlreichen Klein- und Mittelbetrieben bei unternehmerischen Herkunftsanalysen zu einem erheblich anderen und offeneren Bild des unternehmerischen Aufstiegsverhaltens führen, als manche bisherigen Untersuchungen zeigen, die vorrangig auf der Auswertung des Materials der in biographischen und genealogischen Nachschlagewerken überrepräsentierten Großunternehmer basieren.

In der elektrotechnischen Industrie setzte die stürmische technische und wirtschaftliche Expansion auf der Grundlage der Starkstrom-

${ }^{85}$ Staatsarchiv Darmstadt, Sterbeprotokoll Bisses 2. April 1833; Die Entwicklung unserer Gürtlerwarenindustrie, in: Offenbacher Nachrichten 16. Jan. 1940; K. Brockmann, Zur Geschichte der Offenbacher Portefeuille-Industrie, in: AltOffenbach 3 (1927), S. 83ff.

${ }^{86}$ Standesamt Mainz, Familienregister Nr. 9846, 18654; VDI-Festschrift, 50. Hauptversammlung, S. 203.

${ }^{87}$ Evgl. Kirchengemeinde Offenbach, Taufen 4. Juli 1841; Richard Heyne, Geschichte der Firma Gebr. Heyne GmbH 1869-1949, Maschr. in Firmenbesitz; K. Brockmann, Festvortrag anläB1. des 50jährigen Bestehens der Firma Gebr. Heyne (5.4.1919), Manuskript in Firmenbesitz.

88 Standesamt Mainz, Familienregister Nr. 5974; Metallwaren-Fabrik Wilhelm Hanss Mainz 1847-1922, Mainz 1922, S. 7ff.

${ }^{89}$ Hundert Jahre Fritz Voltz Sohn, Von der Kupferschmiede zum Apparatebau, Frankfurt/M. 1958, S. 1ff.

${ }^{90}$ Jakob Faulstroh, Preß- und Stanzwerk Groß-Gerau 1893-1953, Darmstadt 1953, S. 5. 
technik und ihrer Anwendung vor allem im Beleuchtungs- und Verkehrswesen sowie in der Energiewirtschaft erst zu einer Zeit ein, als ältere und entwickeltere Industriesparten (z.B. Montan-, Maschinenbau-, Textilindustrie und Eisenverarbeitung) in den Depressionsjahrzehnten nach der Krise von 1873 bereits in eine erste Konsolidierungsphase traten. Der Aufschwung besonders der elektrotechnischen und der an sich älteren feinmechanischen Industrie in den letzten Jahrzehnten des 19. Jahrhunderts ${ }^{11}$ hatte auch zur Folge, daß sich hier Entwicklungen auf wenige Jahrzehnte verkürzt zusammendrängten, für deren Ausformung in anderen Wirtschaftszweigen lange Zeiträume benötigt worden waren. Diese „Gleichzeitigkeit" der Entwicklung in der elektrotechnischen und feinmechanischen Industrie erklärt wohl die ungewöhnliche Abkunftsbreite der Firmengründer dieser Branche.

Von 13 Untemehmervätern der Elektrotechnik und Feinmechanik waren je fünf Angehörige der Ober- und der Mittelschicht und drei der Unterschicht, die zudem in höchst disparaten Berufen tätig waren. Ein Grund für diese weite Abkunftsbreite scheint auch in der Vielgestaltigkeit der Produktion und der Anforderungen an den Untemehmer zu liegen, die Feinmechaniker ${ }^{92}$ wie theoretisch geschulte Unternehmer gleichermaßen reüssieren ließen. Es erfolgten hier auch wiederholt Partnerschaftsgründungen von Kaufleuten und Technikern, wie dies manche Doppelnamen von Firmen belegen (z.B. Hartmann \& Braun, Voigt \& Haeffner). Darüber hinaus hat im letzten Viertel des 19. Jahrhunderts das Interesse der Frankfurter Bankiers, der Handelskammer und generell der Banken an der Entwicklung der Elektrotechnik dieser Branche von der Kapital- und Kreditierungsseite die

${ }^{91}$ Emil Kreller, Die Entwicklung der dentschen elektrotechnischen Industrie und ihre Aussichten auf dem Weltmarkt, phil. Diss. Greifswald, Leipzig 1903, S. 9; Waldemar Koch, Die Konzentrationsbewegung in der deutschen Elektroindustrie, München, Berlin 1907, S. 7ff., 14ff; Sombart, Kapitalismus, 3. Bd., 2. Halbbd., S. 752, 840f; A. Wirminghaus, Elektrizitätsindustrie, in: Handwörterbuch der Staatswissenschaften 3. Bd. 3. Aufl. 1909, S. 927ff.; Franz August Schmitt, Elektrizitätsindustrie und Elektrizitätswirtschaft, in: Handwörterbuch der Staatswissenschaften 3. Bd. 4. Aufl. 1926, S. 690-714; Karl Albrecht, Grundlagen und Leistungen der deutschen optischen und feinmechanischen Industrie (Schriftenreihe des Vereins zur Beförderung des Gewerbefleißes von 1821. H. 3), Berlin 1941, S. 3ff.

92 Ausgebildete Feinmechaniker waren z.B. Wilhelm Eugen Hartmann (18531915 ) in der Firma Hartmann \& Braun in Frankfurt, Carl Lehner (1871-1969) in der Firma Telefonbau \& Normalzeit (Telenorma) in Frankfurt und Albert Hauser (geb. 1884) in der Firma Albert Hauser, Fabrik für Meß- und Kontrollinstrumente in Frankfurt, dann in Oberursel. 
besten Entwicklungsmöglichkeiten und auch kapitalschwachen Gründern Aufstiegschancen geboten ${ }^{93}$.

Eine gewisse Bindung der Abkunft an die spätere Größe der Firma ergibt sich daraus, daß die Gründer der später größten Unternehmen oder der gleich als Großunternehmen geplanten Firmen der Ober- oder der Mittelschicht entstammten. Bei der Firma Hartmann \& Braun für Meß- und Regeltechnik in Frankfurt waren z.B. die Väter der Gründer Seminaroberlehrer bzw. Landgerichtsaktuar ${ }^{94}$. Heinrich Voigt (18571937) von der elektrotechnischen Fabrik Voigt \& Haeffner in Frankfurt entstammte einem Pfarrhaus, während sein Kompagnon Adolf Haeffner (1862-1947) Sohn eines Hoteliers war ${ }^{95}$. Wilhelm Lahmeyer (1859-1907) von der Elektrizitäts-Aktiengesellschaft vorm. Lahmeyer \& Co. in Frankfurt, einer der acht großen deutschen Elektrokonzeme um die Jahrhundertwende, hatte einen Bergrevisor zum Vater, einer seiner Großväter war Generalsuperintendent ${ }^{96}$.

Bei den kleineren Industriezweigen wird die Basiszahl der untersuchten 175 Firmengründer zu klein, um allgemeine Aussagen ohne Heranziehung weiterer Firmengründer machen zu können. Dies gilt auch für die regionale Sondererscheinung der Sektfabrikation und Weinbranderzeugung. Die erfaßten sechs Sektfabrikanten und Weinbranderzeuger entstammen zwar mehrheitlich mittelständischen, insbesondere handwerklichen Berufen, aber bei Heranziehung weiterer Unternehmer ist ein Berufszweig unter den Firmengründern untervertreten, der durch seine Vertrautheit mit der Beschaffung und den $\mathrm{Ab}$ satzwegen sowie wegen der Kapitalintensität des Produkts, des langfristigen Produktionsprozesses und der Lagerhaltung verhältnismäßig häufig den Zugang zur Sekterzeugung gefunden hat: die Weinhänd-

\footnotetext{
${ }^{93}$ Geschichte Handelskammer Frankfurt, S. 1265ff.

${ }^{94}$ Adolf Wißner, Wilhelm Eugen Hartmann, in: NDB 7 (1966), S. 740f; 50 Jahre elektrische Meßgeräte 1879-1929, Hartmann \& Braun AG, Frankfurt/M. 1929, S. lff.; Jonathan Zenneck, Ferdinand Braun, in: NDB 2 (1955), S. 554f; Franz Gräser, Der Fuldaer Nobelpreisträger Ferdinand Braun und seine Ahnen, in: Hessische Familienkunde, S. $203 \mathrm{ff}$.

${ }^{99}$ Emst König, 50 Jahre Voigt \& Haeffner, Frankfurt/M. 1941, S. 9 und S. 15; siehe oben Anm. 33; Paul O. Schneider, Adolf Haeffner $\uparrow$, in: Elektrotechnische Zeitschrift 69 (1948), S. 247; Stadtarchiv Frankfurt, Einwohnermeldekartei Adolf Haeffiner.

${ }^{96}$ Auskunft evgl. Kirchengemeinde Hohnstedt und Clausthal; Geschichte Handelskammer Frankfurt, S. 1271ff; Helmut Mielert, Wilhelm Lahmeyer, in: NDB 13 (1982), S. 415f;; Elektrizitäts-AG vorm. W. Lahmeyer \& Co., Frankfurt/M., in: Histor.-biogr. Blätter, Reg.Bez. Wiesbaden.
} 
ler ${ }^{97}$. Dies gilt z.B. für die Köln-Frankfurter Weinhandlung Mumm und ihre Angliederung eines Champagnerhauses in Reims ${ }^{98}$, die Gründung einer Champagnerfabrik 1832 in Mainz durch die Handlungen Lauteren, Mappes und Dael ${ }^{99}$ oder die Feist-Belmont'sche Sektkellerei in Frankfurt ${ }^{100}$, die ähnlich wie die bereits außerhalb des Untersuchungsgebiets liegende Sektkellerei Deinhard \& Co. in Koblenz auf eine Weinhandlung zurückgeht ${ }^{101}$.

Bemerkenswert ist, daß neben der Abkunft der Gründer von Sektkellereien von Weinhandlungen auch bei der Abkunft von anderen Berufszweigen nicht selten schon eine irgendwie geartete Vertrautheit des Gründers mit der späteren Tätigkeit durch den Beruf des Vaters gegeben war. Carl Burgeff (1813-1871) war z.B. der Sohn eines Weingutsbesitzers, der auch Weinbergsinspektor und Kellermeister auf Schloß Johannisberg im Rheingau war ${ }^{102}$. Von einem Schreiner und Kellermeister stammte auch Hugo Asbach (1806-1935) von der gleichnamigen Rüdesheimer Weinbrennerei $\mathrm{ab}^{103}$. Die Sekterzeuger

${ }^{97}$ Heinrich Mackenstein, Die deutsche Sektindustrie, maschr. wirtschafts- und sozialwiss. Diss. Univ. Köln 1924, S. 15; Günther Weiß, Die deutsche Sektindustrie. Thr Werden und das Einwirken des Staates auf ihre Geschichte (Tübinger wirtschaftswissenschaftliche Abhandlungen 13), Stuttgart 1931, S. 19ff; Leo Dütsch, Die Schaumweinindustrie Deutschlands, maschr. staatswiss. Diss. Exlangen 1923, S. 33, 35.

${ }_{98}$ Freiherr Mumm von Schwarzenstein, in: Frankfurter Blätter für Familiengeschichte 1 (1908), S. 13ff. und 2 (1909), S. 120f.: Stammbaum der Familie Mumm von Schwarzenstein; Alexander Dietz, Frankfurter Handelsgeschichte 5. Bd., Frankfurt 1925, S. 546.

${ }_{99}$ Bilder und Skizzen aus Mainz. Rheinwein-Champagner-Fabrikation, in: Der rheinische Telegraph 6, 24. Nov. 1839; Hermann Friedrich Macco, von Mappes †, in: Mitteilungen des Roland 3 (1918), S. 43fff; Die Sektkellerei Schönberger Cabinet AG in Mainz ging ebenfalls auf eine Weingroßhandlung zurïck, siehe: Paul Amsberg, Die jüdischen Gemeinden in Hessen. Anfang, Untergang, Neubeginn, 2. Bd., Frankfurt/M. 1971, S. 27; Dieter Gessner, Umfang und Bedeutung der Produktion von Genußmitteln am Mittelrhein und Untermain 1790-1865. Eine quantifizierende Regionalanalyse der frühen Industrialisierung, in: Archiv für Frankfurts Geschichte und Kunst 59 (1958), S. 366.

${ }^{100}$ Die Westdeutsche Wirtschaft und ihre führenden Männer. Land Hessen Frankfurt/M. 1956, S. 95ff; Alexander Dietz, Stammbuch der Frankfurter Juden, Frankfurt 1907, 79f.

${ }^{101}$ Wilhelm Treue, Deinhard. Erbe und Auftrag. Hg. zum 175jährigen Jubiläum der Firma Deinhard \& Co., Koblenz, München 1969.

${ }_{102}$ Helmut Arntz, Festschrift zum 125jährigen Bestehen der ältesten rheinischen Sektkellerei Burgeff \& Co. 1837-1962, Hochheim/M., Wiesbaden 1962, S. 10.

${ }_{103}$ Harry Rump, Hugo Asbach, in: NDB 1 (1953), S. 409; Siegfried Kretschmar, Ahnentafel Asbach, maschr. in Institut. 
Matheus Müller (1773-1847) in Eltville ${ }^{104}$ und Johann Jakob Söhnlein (1827-1912) in Wiesbaden-Schierstein ${ }^{105}$ waren hingegen Söhne von Küfermeistern.

Die Väter der sechs erfaßten Firmengründer der in sich heterogenen Industriegruppe der Steine und Erden, die Zement- und Zementwarenfabriken, ein Asbestwerk und eine Glashütte gegründet haben, waren vorwiegend Angehörige der Oberschicht (Fabrikanten und Großkaufleute, Kaufmann). Diese Herkunft ist für die erfaßte Personengruppe auch verständlich: Eine rein handwerksmäßige Herstellung z.B. von Zement hat es nie gegeben und die Gewinnung und das Brennen des Rohmaterials haben von Anfang an für Öfen, Mühlen, Brennstoff usw. einen hohen Kapitaleinsatz, die technisch-wissenschaftliche Durchdringung des Herstellungsprozesses und wegen der latenten Überproduktion und Konjunkturabhängigkeit eine scharfe kaufmännische Kalkulation und gute Absatzsicherung erfordert ${ }^{106}$,

Insofern waren die Angehörigen der Familie Dyckerhoff durch ihre generationenlange Tätigkeit als Baumeister, Architekten, Ingenieure und im einschlägigen Großhandel geradezu schicksalshaft prädestiniert, in der Zement-, Zementwaren- und Baubranche tätig zu werden ${ }^{107}$. Nicht übersehen werden sollte aber auch, daß die von der allgemeinen Baukonjunktur, der Verstädterung und der Bevölkerungsvermehrung im 19. Jahrhundert emporgetragenen Inhaber von Ziegeleien vermutlich auch die Inhaber von Steinbruchbetrieben in den bergigen Randzonen des Rhein-Main-Gebiets wie das gesamte Bau-

${ }^{104}$ Auskunft kathol. Pfarramt Kiedrich und Frau Müller-Gastell, Eltville.

${ }^{105}$ Stadtarchiv Frankfurt, Trauungsbuch 30. Sept. 1819; Rheingold Söhnlein \& Co., in: Histor.-biogr. Blätter, Reg.Bez. Wiesbaden.

${ }^{106}$ Günther Kühn, Die Zementindustrie. Thre wirtschaftliche und organisatorische Struktur, Jena 1927, S. 28, 30. Emst Madelung, Die Entwicklung der deutschen Portland-Zementindustrie von ihren Anfängen bis zur Gegenwart mit besonderer Berücksichtigung der Kartelle, München, Leipzig 1913, S. 14ff.; Peter Hans Riepert, Die deutsche Zementindustrie, Charlottenburg 1927; Hans Hoffmann, Die geograph. Gebundenheit der GroBindustrie an der Mainmündung. Eine standortanalytische Untersuchung der für das Mainmündungsgebiet typischen Industriezweige, maschr. naturwiss. Diss. Mainz 1954, S. 31ff.

${ }_{107}$ DGB 92 (1936), S. 49ff.; Hermann Pinnow, Gustav Dyckerhoff, in: NDB 4 (1959), S. 210f; Hermann Pinnow, Aus alten Schriften der Portland-CementFabrik Dyckerhoff und Söhne zur 75jährigen Wiederkehr des Gründungstages, München 1939, S. 15 (Der Chronik zweiter Teil, 1896-1924, Wiesbaden 1954); Gert von Klass, Weit spannt sich der Bogen 1865-1965. Die Geschichte der Bauunternehmung Dyckerhoff \& Widmann, Wiesbaden 1965, S. 13 ff. 
haupt- und Baunebengewerbe sozial eine ausgeprochene Aufstiegsbranche gewesen sein dürtten.

Eine regionale Besonderheit stellen die in Deutschland zu Beginn des 20. Jahrhunderts am dichtesten in Frankfurt und Offenbach angesiedelten Schriftgießereien dar ${ }^{108}$.

Gegenüber der älteren und länger andauemden handwerklichen Ausbildungs- und Berufsrichtung im Schriftgießereigewerbe sind die erfaßten Frankfurt-Offenbacher Schriftgießereiunternehmer mit breiter sozialer Herkunft und kaufmännischer Ausrichtung ihrer Ausbildung symptomatisch Ausdruck des in den Jahrzehnten vor 1914 erreichten Entwicklungsstadiums des deutschen Schriftgießereigewerbes. Es ist gekennzeichnet durch die Lösung der bis dahin häufigen Bindung an Druck- und Verlagsunternehmen, einen deutlichen betrieblichen Schrumpfungs- und Konzentrationsprozeß ab der Mitte des 19. Jahrhunderts und einen rasch anwachsenden Kapitalbedarf für Mechanisierung und Vertrieb. Dazu kamen die Trennung der Tätigkeit des Schriftentwerfers von der des Stempelschneiders auch unter dem Eindruck einer kunstgewerblich- typographischen Erneuerungsbewegung (William Morris), die Einführung der Gieß- und dann der Linotype-Setzmaschine bei gleichzeitiger Überführung der älteren handwerklichen Schriftgießereien in mehr oder weniger industriell organisierte und geleitete Unternehmen ${ }^{109}$. Unternehmerisch war dies aber offenkundig im Schriftgießereigewerbe die Stunde der Kaufleute, die zum Teil in glücklicher Weise unternehmerisches Wirken, typographisches Formgefühl und eigene künstlerische Veranlagung oder Interessen miteinander verbanden (z.B. Georg Hartmann (1870-1954) von der Bauer'schen Schriftgießerei in Frankfurt ${ }^{110}$, Gebrüder Kling-

${ }^{108}$ Georg Kurt Schauer, Deutsche Buchkunst 1890-1960, Bd. 1, Hamburg 1963, S. 147.

${ }^{109}$ Schauer, Buchkunst, S. 134f., 137-146; Fritz Funke, Buchkunde. Ein Überblick über die Geschichte des Buch- und Schriftwesens, München-Pullach 3. Aufl. 1969, S. 208ff; Dieter Gessner, Die Industrialisierung des graphischen Gewerbes an Mittelrhein und Untermain in der ersten Hälfte des 19. Jahrhunderts (1790-1865). Eine quantifizierende Regionaluntersuchung, in: Blätter für deutsche Landesgeschichte 117 (1981), S. 373-401, bes. auch S. 387f,, S. 399; Gustav Mori, Geschichte und Entwicklung des Schriftgießereigewerbes in Frankfurt am Main, in: Archiv für Buchgewerbe 44 (1907).

${ }^{110}$ Franz Lemer, Johann Georg Hartmann, in: NDB 7 (1966), S. 742f;; Werden und Wachsen einer deutschen Schriftgießerei. Zum hundertjährigen Bestehen der Bauer'schen Gießerei, Frankfiur/M. 1937, S. 35ff. 
spor in Offenbach ${ }^{111}$ oder David Stempel von der gleichnamigen Schriftgießerei in Frankfurt ${ }^{112}$ ).

Die zwölf unter "Verschiedene" zusammengefaßten Unternehmer haben branchenmäßig recht unterschiedliche Firmen der Metallproduktion und des Metallhandels, der Holzbearbeitung, der Papierfabrikation und der Textilindustrie gegründet. Ihre Zahlen sind allerdings für die einzelnen Wirtschaftszweige zu klein, um allgemeine branchendifferenzierende Aussagen oder Rückschlüsse über die Verbindungslinien von Herkunft und Zugang zur Unternehmertätigkeit machen zu können. Im Hinblick auf den Zusammenhang von Herkunftshintergrund, wirtschaftlicher Betätigung und hochkapitalistischem Unternehmensaufstieg ist allerdings bei den Gründern der Frankfurter Metallgesellschaft, Wilhelm Merton (1848-1916) und Leo Ellinger (1852-1916), die Abkunft von Teilhabern der Frankfurter Metallhandelsfrima Phil.Abr. Cohen und deren Verbindung zum Londoner Merton-Haus und Metallhandelsmarkt von größter Bedeutung ${ }^{113}$. Bei ihnen wie den vorher als Prokuristen bei der Firma Phil.Abr. Cohen tätig gewesenen Gründern der nach der Metallgesellschaft seinerzeit nächstbedeutendsten internationalen Metallhandelsfirma Beer \& Sondheimer in Frankfurt ${ }^{114}$, mag die Herkunft aus einem jüdischen

${ }^{111}$ Alfred Lück, Reinhard Klingspor. Chronik und Stammtafel der Familie Klingspor, Offenbach/M. 1956, S. 38; Wilhelm H. Lange, Gebr. Klingspor und die deutsche Schrift, in: Offenbacher Monatsrundschau 6 (Juni 1940), S. 59ff; Dem Erneuerer deutscher Schrift- und Buchkultur. Karl Klingspor zum 25. Juni 1938, Brünn, Leipzig, Wien 1938, S. 4ff; Hans A. Halbey, Karl Klingspor, in: NDB 12 (1980), S. $98 \mathrm{f}$.

112 Chronik der Schriftgießerei D. Stempel AG Frankfurt a.M. 60 Jahre im Dienste der Lettern 1895-1955, Frankfurt 1955, S. 6ff; David Stempel †, in: Frankfurter Nachrichten 3. Nov. 1927; Auskunft Standesamt Lambsheim/Rheinpfalz.

113 Walter Däbritz, Fünfzig Jahre Metallgesellschaft 1881-1931, Frankfurt/M. 1931, S. 15ff., 3lf., 102, 151, 206; Hans Achinger, Wilhelm Merton in seiner Zeit, Frankfurt/M. 1965, S. 15ff, S. 27f; Siegbert Wolf, Wilhelm Merton, in: Jüdische Stiftungen, S. 355-360. Leo Ellinger $\uparrow$, in: Jahresbericht des Physikal. Vereins zu Frankfurt 1916/17, S. 3f.; P. Prior, Leo Ellinger, in: 47. Bericht der Senckenbergischen Naturforschenden Gesellschaft in Frankfurt, Frankfurt/M. 1918, S. 104f;; Stadtarchiv Frankfurt, Einwohnermelderegister: Philipp und Leo Ellinger; Geschichte Handelskammer Frankfurt, S. 1200-1202.

${ }^{114}$ Däbritz, Metallgesellschaft, S. 65; Achinger, Merton, S. 31; Geschichte Handelskammer Frankfurt, S. 1200ff; Beer, Sondheimer \& Co. Frankfurt, in: Europas Volkswirtschaft in Wort und Bild. Hg. von der Frankfurter Zeitung 1925/26, S. 92; Paul Arnsberg, Die jüdischen Gemeinden in Hessen. Anfang, Untergang, Neubeginn 1. Bd. Frankfurt/M. 1971, S. 326. 
Elternhaus insofern von Bedeutung gewesen sein, da sich dieser Handelszweig fast ausschließlich in jüdischen Händen befand ${ }^{115}$.

Fragt man nach den allgemeinen Tendenzen und dem Wandel im Beziehungsverhältnis Herkunft der Firmengründer und Wirtschaftszweig während der rund 100 Jahre 1815-1914, so ist eine erstaunliche Kontinuität des unternehmerischen Aufstiegsverhaltens in den einzelnen Wirtschaftszweigen festzustellen. Zwar scheint - wie oben dargelegt - in der Gesamtsumme aller Branchen gegen Ende des Untersuchungszeitraums sich die soziale Herkunft ausgeweitet zu haben. Der durch die industrielle Revolution ausgelöste wirtschaftliche und gesellschaftliche Wandel hat aber bei keinem Wirtschaftszweig nach dem Übergang von der Frühindustrialisierung zur Hochindustrialisierung zu einer völligen Umpolung der Unternehmerrekrutierung geführt. Trotz gewisser Verschiebungen in den Herkunftsberufen mit dem Ausgang der Ära der Frühindustrialisierung blieben vielmehr diejenigen Branchen, die schon in der Frühindustrialisierung Aufstiegsbranchen waren (z.B. Teile des Maschinenbaus, Metallwarenindustrie, Lederwarenindustrie) dies auch in der Ära der Hochindustrialierung, zum Teil wurden sie sogar noch offener für sozial von unten Aufsteigende. Diejenigen Branchen aber, bei denen schon vor der Jahrhundertmitte die Herkunft aus der Oberschicht überwog (z.B. Chemisch-Pharmazeutische Industrie) waren in ihrem Kernbereich rund hundert Jahre später mit vereinzelten Ausnahmen ebenfalls nicht offen für sozial von unten Aufsteigende.

\section{Die regionale Herkunft der Firmengründer}

\subsection{Die einzelnen Herkunftslandschaften}

Zur Ermittlung der regionalen Mobilität der Firmengründer wurden diese entsprechend der Entfernung ihres Geburtsortes zum Ort der späteren Firmengründung in vier konzentrisch angeordnete Herkunftsgebiete eingeteilt: 1) Der Geburtsort ist gleich dem Ort der späteren

\footnotetext{
115 Robert Liefmann, Die internationale Organisation des Frankfurter Metallhandels, in: Weltwirtschaftliches Archiv 1 (1913), S. 108-122; S.M. Auerbach, Jews in the German Metal Trade, in: Leo Baeck Year Book 10 (1965), S. 188-203, insbes. S. 201.
} 
Firmengründung, 2) Herkunft aus dem übrigen Rhein-Main-Gebiet, 3) Herkunft aus den Nachbarlandschaften des Rhein-Main-Gebiets und 4) Herkunft aus dem restlichen In- und Ausland.

Von den 175 erfaßten Firmengründern des Rhein-Main-Gebiets 1815-1914 wurden 61,1\% (107 Personen) im Rhein-Main-Gebiet geboren $^{116}$. Mit der Zuwanderungsquote von 38,9\% der Industriegründer unterscheidet sich die Untemehmerherkunft im Rhein-Main-Gebiet vor allem von jenen Industrielandschaften, die - nicht selten anknüpfend an regionale Rohstoffvorkommen oder Verfügungsrechte an Produktionsmitteln (z.B. Wasser-, Hammerrechte) - eine ausgeprägt bodenständige gewerbliche Unternehmerschaft besaßen, „deren teilweise bis ins Mittelalter reichende Geschichte nie völlig abriß"1177.

Bis 1850 war der Trend der regionalen Mobilität überwiegend statisch. Bis zu diesem Zeitpunkt sind nämlich von 38 Firmengründern nur vier von außerhalb des Rhein-Main-Gebietes zugewandert, ein Indiz für eine geringe territoriale Mobilität der rhein-mainischen Unternehmerschaft in der Frühindustrialisierung. Ausgehend von einem wenig entwickelten industriellen Ausgangsniveau verschaffte der späte industrielle Start, die Konzentrationsmöglichkeit auf Wachstumsbranchen und der allgemeine industrielle Durchbruch in der langen Konjunkturwelle der 1850er bis Anfang der 1870er Jahre dem RheinMain-Gebiet ab der Jahrhundertmitte eine deutlich erkennbar verstärkte Zuwanderung von Firmengründern. Sie führte laufend zum Absinken des Anteils der rhein-main-gebürtigen Unternehmer und ab 1870 sogar zum Überwiegen der zugewanderten Firmengründer. Dabei hat es auch innerhalb der rhein-main-gebürtigen Gruppe der Firmengründer Ortsveränderungen gegeben. Nur $72(41,1 \%)$ haben am Geburtsort ihre Firma gegründet, $35(20,0 \%)$ sind aus anderen Orten des Rhein-Main-Gebietes zugewandert. Die räumliche Zirkulation setzt bei ihnen mit dem Doppeljahrzehnt 1831-1850 auch früher ein als bei den von außerhalb in das Rhein-Main-Gebiet Zugewanderten. Die Abwanderung aus dem Geburtsort ist damit ein wesentlicher und typischer Bestandteil der Lebensgeschichte und der Karriere der Mehrheit der erfaßten Firmengründer des Untersuchungsgebiets. Gegenüber der

${ }^{116}$ Für diese und die folgenden Zahlen siehe bitte Tabelle Anlage 4: Die regionale Herkunft der Firmengründer.

${ }^{117}$ Friedrich Zunkel, Der theinisch-westfälische Unternehmer 1834-1879. Ein Beitrag zur Geschichte des deutschen Bürgertums im 19. Jahrhundert (Dortmunder Schriften zur Sozialforschung Bd. 19), Köln, Opladen 1962, S. 13. 
sozialen Mobilität ist auch die regionale Mobilität erheblich größer gewesen.

Aus den unmittelbar an das Rhein-Main-Gebiet anschließenden Nachbarlandschaften von Hessen und Nassau, aus Franken, Nordbaden und der Pfalz stammten 27 (15,4\%) der 175 Firmengründer. Unter ihnen bildeten die Hessen und Nassauer - soweit sie nicht ohnehin zum Untersuchungsgebiet zu rechnen waren - mit 17 Herkunftsfällen das stärkste Kontingent, gefolgt von Nordbaden und Franken mit je vier Vertretern.

Als weiterer äußerer Ring von Herkunftslandschaften jenseits der Nachbarregionen des Rhein-Main-Gebiets schließt sich die als Fernzuwanderung $\mathrm{zu}$ begreifende Herkunft aus dem restlichen In- und Ausland mit $41(23,4 \%)$ von 175 Firmengründern an. Die Zuwanderer aus dem frühindustrialisierten Rheinland und Westfalen mit 15 Personen und die aus dem später industrialisierten Württemberg (ohne Baden) mit elf Firmengründern stellen unter ihnen die beiden größten Einzelherkunftsgruppen mit allerdings dem Gang der Industrialisierung entsprechender unterschiedlicher zeitlicher Schwerpunktbildung. Erreichen die Firmengründer aus dem Rheinland und Westfalen ihre größte Häufigkeit in den Jahrzehnten gleich nach 1850 mit sinkender Tendenz zum Ende des Untersuchungszeitraums hin, so verhält es sich bei den Württembergern gerade umgekehrt. Bei ihnen bilden den Schwerpunkt der Zuwanderung die Jahrzehnte unmittelbar vor 1914 .

Auch im Hinblick darauf, daß das Rhein-Main-Gebiet kein Hauptziel der mit der Industrialisierung einsetzenden und zudem fast ausschließlich die ländliche Arbeiterüberschußbevölkerung erfassenden Ost-West-Binnenwanderung war, ist bemerkenswert, daß einschließlich Berlin das gesamte ostelbische nördliche und östliche Deutschland, aber auch z.B. Altbayem als Herkunftsgebiet der 175 rhein-mainischen Firmengründer ausfallen, wenn sich auch bei einer Verbreiterung der Basiszahl einzelne Herkunftsfälle für diese Gebiete finden lassen ${ }^{118}$. Nicht so singulär scheint dagegen die Zuwanderung

${ }^{118}$ Aus Potsdam gebürtig war z.B. der Offenbacher Dampfkesselfabrikant Karl Friedrich Rochow (1844-1918), aus Stettin stammte der Offenbacher Maschinenfabrikant Karl Nube (1858-1925), in Neustadt (Krs. Ludwigslust) in Mecklenburg wurde der Offenbacher Maschinenfabrikant Wilhelm Fredenhagen (1843-1924) geboren, der Fabrikant für Filter-und Abfüllapparate in Worms Lorenz Adalbert Enzinger (1849-1897) stammte aus Wasserburg am Inn.

Zu Rochow: Einwohnermeldeamt Offenbach/M., Einwohnermeldekartei Rochow; Müller, Entwicklung, S. 100. 
aus dem nordwest- und mitteldeutschen Raum gewesen zu sein. Bei den vier im Ausland geborenen Unternehmern (Frankreich, USA) handelt es sich um Söhne deutscher Geschäftsleute im Ausland beziehungsweise eines USA-Auswanderers und damit eigentlich um „unechte " Fälle einer ausländischen Herkunft.

Insgesamt hat aber das in bezug auf die Rohstoffgrundlage der rhein-mainischen Industrie zutreffende Merkmal ihrer geringen Bodenständigkeit im Hinblick auf die regionale Herkunft der Firmengründer in abgeschwächter Form und in anderem Sinne auch für viele der Gründer seiner Industriebetriebe Gültigkeit.

3.2. Die regionale Mobilität der Firmengründer nach Wirtschaftszweigen

Ähnlich den Unterschieden der sozialen Herkunft nach einzelnen Wirtschaftszweigen läßt auch die örtliche Mobilität der Firmengründer in den einzelnen Wirtschaftszweigen ein unterschiedliches Ausmaß der regionalen Zirkulation erkennen ${ }^{119}$. Dabei standen die räumliche und die soziale Mobilität in einem gewissen Gegensatzverhältnis zueinander. Entgegen manchen Erwartungen stammten nämlich nach dem vorliegenden Material die Gründer in sozialen Aufstiegsbranchen häufiger aus dem Rhein-Main-Gebiet, sie waren also regional immobiler. Dies gilt schon für die Gründer von Maschinenbaufirmen. Insbesondere stellen aber die in und um Offenbach konzentrierten Lederwarenfabrikanten ein eindrucksvolles Beispiel dar, in welchem Ausmaß spezifisch regional begrenzte Wirtschaftszweige die regionale Immobilität ihrer Firmengründer wie die ihrer Arbeiterschaft gefördert ha-

$\mathrm{Zu}$ Nube: Einwohnermeldeamt Offenbach/M., Einwohnermeldekartei Nube; Von der Werkstätte zum Industriewerk. Fünfzigjähriges Bestehen der Maschinenfabrik Kurt Nube, in: Offenbacher Nachrichten 7. Mai 1938.

Zu Fredenhagen: DGB 143 (1967), S. 409f. und 461ff; Evgl. Kirchenbuch Offenbach, Heiraten 9.3.1873.

Zu Enzinger: Stadtarchiv Worms, Personenstandsregister Heiraten 1874: Enzinger -Rudinger; Auskunft kathol. Stadtpfarramt Wasserburg/Inn; Otto Eberhardt, Die industrielle Entwicklung der Stadt Worms, maschr. phil. Diss. Heidelberg 1922, S. $74 \mathrm{f}$.

${ }^{119}$ Auf die Wiedergabe der Tabelle regionale Herkunft und Wirtschaftszweig wurde aus Platzgründen verzichtet. 
ben ${ }^{120}$. Die Angehörigen dieser sozial aufstiegsfreundlichen Gruppe und Branche haben fast durchwegs am Ort ihrer Geburt oder in dessen unmittelbarer Nachbarschaft ihr Unternehmen gegründet.

Demgegenüber haben die geringere Bindung der "Studierten“" an ihren Geburtsort, ihre größere Anpassungsfähigkeit und ihre zum Teil auch größere finanzielle Unabhängigkeit sowie rationalere Überlegungen bei der Standortwahl und wohl auch die geringere Abhängigkeit ihrer Produkte von lokalen oder regionalen Absatzmärkten bei Nachkommen von Oberschichtsangehörigen und theoretisch besser geschulten Mittelschichtsnachkommen deren räumliche Mobilität gefördert. Dies gilt schwächer ausgeprägt für die Herkunft der Chemieindustriellen, besonders aber für die Gründer der elektrotechnischen und feinmechanischen Industrie, bei denen von 13 erfaßten Firmengründern zehn Fernzuwanderer waren, von denen wiederum die Hälfte aus Württemberg stammte.

\subsection{Die Herkunftsverteilung auf Stadt und Land}

In bezug auf die Herkunftsverteilung der Firmengründer auf Stadt und Land ergibt sich, wie schon die soziale Herkunft mit ihrem geringen Anteil von bäuerlich-landwirtschaftlichen Abkunftsberufen nahelegt, ein deutliches Übergewicht mit $136(77,5 \%)$ stadtgebürtiger gegen nur $39(22,5 \%)$ aus Markt- oder Landgemeinden gebürtiger Unternehmer. In allen Zeitabschnitten überwiegen dabei, zum Teil beträchtlich, die stadtgebürtigen Unternehmer; nur das letzte Untersuchungsdoppeljahrzehnt 1891-1914 läßt eine Annäherung der stadt- und der landgebürtigen Untemehmer erkennen ${ }^{121}$.

Der auch in Paralleluntersuchungen erkennbare Chancenvorsprung der Stadtbevölkerung für die unternehmerische Betätigung ${ }^{122}$ infolge der besseren Bildungsmöglichkeiten und dem Kontakt mit einer höherentwickelten gewerblich-technischen Umwelt sowie teilweise auch einem höheren sozioökonomischen Herkunftshintergrund gewinnt

${ }^{120}$ Max Morgenstem, Auslese und Anpassung der industriellen Arbeiterschaft betrachtet bei der Offenbacher Lederwarenindustrie (Schriften des Vereins für Socialpolitik 135. Bd., 3. Teil), Leipzig 1912, S. 39.

${ }^{121}$ Auf die Wiedergabe der Tabelle der Herkunftsverteilung der Firmengründer auf Stadt und Land wurde aus Platzgründen verzichtet.

${ }^{122}$ Stahl, Elitekreislauf, S. 195ff; Hartmut Kaelble, Berliner Unternehmer während der frühen Industrialisierung. Herkunft, sozialer Status und politischer Einfluß, Berlin, New York 1972, S. 21. 
noch an Gewicht vor dem Hintergrund der im Laufe des 19. Jahrhunderts rasch fortschreitenden Landflucht, der Verstädterung und der Industrialisierung, der den hohen abwandernden ländlichen Bevölkerungsanteil offenkundig in derart untergeordnete gewerblichindustrielle Berufe brachte, daß ihm ein unternehmerischer Aufstieg nicht ohne weiteres möglich war. Zudem umfaßt die Quote der landgebürtigen Unternehmer die Söhne von Pfarrern, Förstern und weiterer wohl am Lande lebender, nicht aber eigentlich ländlicher Berufe.

3.4. Die regionale Herkunft der Firmengründer rhein-mainischer Städte

65 der 175 Firmengründer haben ihre Unternehmung in Frankfurt am Main gegründet ${ }^{123}$. Diese Zahl unterstreicht den industriellen Bedeutungsaufstieg Frankfurts nach dem Ende der freistädtischen Zeit neben ihrer traditionellen und gegenüber Berlin absteigenden Börsen- und Bankenplatzfunktion.

Mit 38,5\% (25 Personen) ortsgebürtiger Firmengründer und 61,5\% (40 Personen) Zuwanderer, darunter dem höchsten Anteil von Fernzuwanderem $(33,9 \%$ oder 22 Personen) unter den Firmengründern aller rhein-mainischen Städte überhaupt, weist Frankfurt eine unter dem Durchschnitt liegende Selbstergänzungsquote aus der Stadt stammender Unternehmensgründer auf. Angesichts der Wirtschaftsbedeutung und der Wirtschaftskraft der ökonomisch führenden Schichten Frankfurts drücken sich in diesen Zahlen die restriktive reichs- und freistädtische Frankfurter Industrieansiedlungs- und Gewerbepolitik genauso aus wie die bis ins letzte Drittel des 19. Jahrhunderts andauernden Mentalitätsvorbehalte der Frankfurter Privatbankiers und der Börse gegen das Industrieanlagengeschäft.

Die unterdurchschnittliche Selbstergänzungsquote der Frankfurter Firmengründer aus ihrer Stadt ist aber auch insofern bemerkenswert als sie in Widerspruch steht zu einer Reihe häufig geäußerter Meinungen über die Gründer und die Ursachen der Entstehung der Frankfurter Industrie im 19. Jahrhundert. Danach hätten „immer wieder“ oder „nur“ die Frankfurter Kaufleute und Bankiers die Industrie in Frankfurt und im Frankfurter Raum gegründet, finanziert und entwickelt 
und der Frankfurter Handel hätte "sich das industrielle Potential" geschaffen, für dessen Erzeugnisse er den Zugang zu den Märkten besaß oder erschließen konnte ${ }^{124}$.

Diese überörtliche Funktionsaufteilung zwischen der Handelsfunktion Frankfurts und der Produktionsfunktion der Umgebung hatte aber nur solange Gültigkeit, solange die entsprechenden wirtschaftspolitischen Voraussetzungen und Rahmenbedigungen bestanden, die Verkehrsverhältnisse ein kleinräumiges Absatzdenken der Produzenten erzwangen, die Warenmessen als Hauptumschlagplätze und Warenstapel Geltung hatten, die Produzenten keine eigenen Bezugs- und Absatzorganisationen aufbauten und die nach 1815 großräumiger werdenden Einzelstaaten im Rhein-Main-Gebiet eine derartige überstaatliche Verflechtung zuließen, soweit sie sie nicht zur Entwicklung des eigenen Gewerbes förderten ${ }^{125}$. Davon unabhängig haben sich insbesondere in der zweiten Hälfte des 19. Jahrhunderts, speziell in einigen konsumnahen Gewerbezweigen (z.B. Lederwarenindustrie, Konfektionskleider- und Wäscheherstellung, Möbelschreinerei) gänzlich, überwiegend oder teilweise organisiert in den unterschiedlichsten Formen von Verlagssystem und Heimarbeit -, verschiedentlich neue Abhängigkeiten zwischen Frankfurter und sonstigen städtischen Grossisten und Umlandgewerben ausgebildet ${ }^{126}$.

Geht man aber von der pauschalen Annahme der innigen Verflechtung von Handel und Industrie als industrieinitiierendem Impuls ab und geht man von den Industriegründern der modernen Produktionsund Investitionsgüterindustrien in Frankfurt und seinen später eingemeindeten Vororten ab der Mitte des 19. Jahrhunderts aus, sind diese Betriebe entsprechend der regionalen Herkunft der Gründer in einem hohen Maße von Nicht-Frankfurtern gegründet und auch initiiert worden. Von dieser Erkenntnis bleibt unberührt, daß eine ganze Reihe von

${ }^{124}$ Almanach der Frankfurter Wirtschaft, Ausgabe 1975/76, bearb. von Franz Lerner, Frankfurt/M. 1975, S. 21; Almanach der Frankfurter Wirtschaft, Ausgabe 1964/65, bearb. von Franz Lerner, Frankfurt/M. 1964, S. 19; Franz Lerner, Wirtschafts- und Sozialgeschichte des Nassauer Raumes 1816-1964, Wiesbaden 1965, S. 173; Franz Lerner, Das tätige Frankfurt, Frankfurt 1955, S. 309.

${ }^{125}$ Dieter Gessner, Großhandel und Industrialisierung an Mittelrhein und Untermain (1780-1856), in: Scripta Mercaturae 12, 1/2 (1978), S. 21-28.

${ }^{126}$ Darüber siehe die umfassende Enquete im Zusammenhang mit der Frankfurter Heimarbeitsausstellung von 1908: Paul Arndt, Die Heimarbeit im rheinmainischen Wirtschaftsgebiet, 3 Bde, Jena 1909, 1911, 1913, insbes. 3. Bd., 1. Teil über die Konfektionsherstellung; J. Schloßmacher, Die Lederwarenindustrie im rhein-mainischen Wirtschaftsgebiet, im 1. Bd., S. 300-326. 
Frankfurter Industriebetrieben auf Handelsbetriebe zurückgehen (z.B. Cassella-Farbwerke) oder sie vor oder nach der Produktionsaufnahme noch Handelsgeschäfte betrieben haben (z.B. bei zahlreichen Frankfurter Maschinenbaubetrieben) ${ }^{127}$. Sie konnten auf diese Weise den Markt und seine Bedürfnisse sowie die Schwächen der Produkte besser kennenlernen und im Handel erworbenes Kapital für investive Zwecke einsetzen und gleichzeitig ihr Maschinenangebot erweitern. Unbestritten ist auch, daß die Konzentration von Handel und Finanzgewerbe in Frankfurt für die Rohstoff- und Kreditbeschaffung sowie für die Einwerbung kurzfristiger Umlaufkapitalien und die Abwicklung des Zahlungsverkehrs der Industrie beste Voraussetzungen geboten haben. Dies gilt auch für die Fremdfinanzierung langfristiger industrieller Investitionen wie auch mancher Industriezweig, wie z.B. die Elektrotechnik, sich von Anfang an der besonderen Förderung von Frankfurter Bankfirmen, Privaten und der Handelskammer erfreute ${ }^{28}$,

Wie in vielem stellt das in unmittelbarer Nachbarschaft zu Frankfurt gelegene Offenbach am Main wegen der unterschiedlichen histori-

${ }^{127}$ Handelsgeschäfte haben ursprünglich oder zeitweise betrieben u.a. z.B. die Maschinen- und Armaturenfabrik vorm. H. Breuer \& Co. in Hoechst, Samuel Moser in der Fabrik landwirtschaftlicher und gewerblicher Maschinen $\mathrm{Ph}$. Mayfarth \& Co., der Nähmaschinenfabrikant Joseph Wertheim, die Schuhmaschinenfabrik Moenus AG, insbesondere in ihren früheren Stadien, Heinrich Kleyer in den späteren Adlerwerken, die Maschinen- und Armaturenfabrik Alfred Teves (ATE) oder die in den Tabellen nicht erfaßten Inhaber der Mühlenbaufirma Simon, Bühler \& Baumann und die Dampfkesselfirma von Simonis \& Lanz.

Generell zur Verbindung von Maschinenhandel und Maschinenproduktion Voigt, Maschinenindustrie, S. 5.

$\mathrm{Zu}$ Breuer: Histor.-biograph. Blätter, Reg.-Bez. Wiesbaden, Maschinen- und Armaturenfabrik vorm. $\mathrm{H}$. Breuer \& Co., Denkschrift der Maschinen- und Armaturenfabrik vorm. H. Breuer \& Co., Höchst/M. o.J. [1921].

$\mathrm{Zu}$ Mayfarth, Wertheim und Kleyer: Siehe unten Anm. 170 und oben Anm. 16 und 54.

Zu Moenus: Voigt, Maschinenindustrie, S. 5 und 16; Günther Gall, Eugen A. Haberstroh, 100 Jahre Maschinenfabrik Moenus AG 1863-1963, Frankfurt/M. 1963, S. 53 ff.

$\mathrm{Zu}$ Alfred Teves: Dreißig Jahre Werksgeschichte der Firma Alfred Teves GmbH, Frankfurt/M. 1906-1936, S. 17ff.

$\mathrm{Zu}$ Simon, Bühler \& Baumann: Bau automatisierter Walzenmühlen, in: Histor.biograph. Blätter, Reg.-Bez.: Wiesbaden.

Zu Simonis \& Lanz: Voigt, Maschinenindustrie, S. 5.

${ }_{128}$ Wolf-Arno Kropat, Frankfurt. Zwischen Provinzialismus und Nationalismus. Die Eingliederung der Freien Stadt in den preußischen Staat (1866-1871) (Studien zur Frankfurter Geschichte, H. 4), Frankfurt/M. 1971, S. 100, 102f., 105, 111 und 191. 
schen Entwicklungsbedingungen und der Struktur seiner Industrie auch in der regionalen Herkunft seiner Firmengründer das Kontrastbeispiel zu seiner Nachbarstadt dar. Von immerhin 40 erfaßten Firmengründern dieser hessen-darmstädtischen Landes-Fabrikstadt mit seiner auf die Isenburger Grafen bzw. Fürsten zurückgehenden freiheitlichen Gewerbeverfassung waren überdurchschnittlich viele aus Offenbach (45,0\% oder 18 Personen) und dem übrigen Rhein-MainGebiet $(25,0 \%$ oder zehn Personen) gebürtig. Dagegen sind die $\mathrm{Zu}-$ wanderer aus den Nachbarregionen des Rhein-Main-Gebietes (10,0\% oder vier Personen) und die Fernzuwanderer (20,0\% oder acht Personen) untervertreten. Die Zahl der Fernzuwanderer unter den erfaßten Offenbacher Unternehmern erklärt sich überdies zum Teil daraus, daß diese an sich ihre Fabrikbetriebe in Frankfurt gründen wollten, sie aber wegen der restriktiven Gewerbeverfassung und Antipathie gegen Fabrikanlagen in Frankfurt, zum Teil auch wegen der hohen Löhne und der schwierigen Ausdehnungsmöglichkeiten oder auch wegen des Fehlens von geeignetem Betriebsgelände im an sich angestrebten Frankfurt veranlaßt wurden, sich mit ihrer Firma in Offenbach anzusiedeln (z.B. Seifen- und Parfümeriefabrik Carl Naumann, Ernst Sell, Anton Collet und Otto Engelhard, Ludwig Eduard Faber und Adolf Schleicher, Gerhard und Felix Becker) ${ }^{129}$.

Hauptursache der geringeren territorialen Mobilität der Offenbacher Firmengründer ist aber die Struktur und Arbeitsorientierung der Hauptbranchen der Offenbacher Industrie gewesen. Sie hat, wie z.B. in der Lederwaren- und Gürtlerwarenindustrie, die Ausbildung qualifizierter, aber lokal konzentrierter Arbeitskräfte zur Folge gehabt, von denen sich immer wieder welche in richtiger Einschätzung der fortschreitenden Produktionsstufenteilung (z.B. als Zulieferer) selbständig machten. In ihrer größeren sozialen Mobilität, der dazu sich konträr verhaltenden geringeren horizontalen Mobilität, in der Größenstruktur ihrer häufiger Klein- und Mittelbetriebe bleibenden Unternehmen,

129 Jean Naumann, Die technische Entwicklung der Seifen-Industrie in Offenbach/M., Frankfurt/M. 1879, S. 15; Geschichte Handelskammer Frankfurt, S. 1278; Müller, Entwicklung, S. 77 f; Hermann Schmidt, Die Entstehung der chemischen Industrie im Maintal und seiner Umgebung. Maschr. wirtschafts- und sozialwiss. Diss., Frankfurt/M. 1919, S. 46; Mahr, Collet \& Engelhard, S. 8; Ludwig Kern, Faber \& Schleicher, in: Offenbacher Monatsrundschau H. 9 (Sept. 1940), S. 30; Wilhelm H. Lange, 75 Jahre Faber \& Schleicher AG 1871-1946, Frankfurt/M. 1946, S. 7; Karl Kanka, Von einer Offenbacher Lederfabrik, in: Offenbacher Monatsrundschau H. 9 (Sept. 1940), S. 19; Den Freunden gewidmet von Lederwerke Becker \& Co., Offenbach-Bürgel, o.O. o.J. [1923], S. 5. 
aber auch in ihrer sozialen Gesamterscheinung bilden damit die Offenbacher Unternehmer eine höchst eigenständige Facette und dokumentieren, daß Offenbach eben mehr war als nur eine „Industrievorstadt" von Frankfurt ${ }^{130}$.

Die Entwicklung der ehemaligen kurfürstlichen Bischofs- und Residenzstadt Mainz ist im 19. Jahrhundert, in einer Zeit als andere Städte im Zuge der Verstädterung und Industrialisierung rapid wuchsen, entscheidend durch ihre, die städtische Ausdehnung empfindlich hemmende Bundesfestungs- und Reichsfestungsfunktion beeinträchtigt worden. Dazu kam die politische Unterstellung nach 1815 unter die geschichtsärmere Residenzstadt Darmstadt, die tatsächliche oder vermeintliche Vernachlässigung der Mainzer wirtschaftlichen Belange durch die hessische Staatsverwaltung und der Verlust des alten Einzugsgebiets des Rheingaus - auch dank der subtilen preußischen Eisenbahnpolitik, die Wiesbaden zum Umsteigebahnhof der Bahnlinie vom Rheingau nach Mainz machte. Mainz blieb dadurch stärker als vergleichbare Städte eine von einem leistungsfähigen Handel (u.a. Wein-, Landes- und Kolonialproduktenhandel), Gewerbe (z.B. Schifffahrt und Speditionsgewerbe) und einem zum Teil industrialisierten Handwerk (z.B. Möbelherstellung. Ledererzeugung, Schuhfabrikation) bestimmte Stadt ${ }^{132}$.

Wenn nun von den zwanzig erfaßten Mainzer Firmengründern je die Hälfte aus Mainz und dem übrigen Rhein-Main-Gebiet stammte und die andere Hälfte Zuwanderer aus den an das Rhein-Main-Gebiet angrenzenden Landschaften und dem restlichen In- und Ausland waren, so ist zur besseren Erkenntnis zwischen Mainz und den späteren eingemeindeten Rheinufer-Vororten zu unterscheiden.

\footnotetext{
${ }^{130}$ Krenzlin, Werden, S. 336.

${ }^{131}$ Utber Mainz und Frankfurt im Vergleich: Hermann Aubin, Mainz und Frankfurt. Vergleich zweier Städteschicksale, in: Histor. Vierteljahrsschrift 25 (1931), S. 529ff;; Rosemarie Pott, Die wirtschaftliche Entwicklung der Stadt Mainz unter dem Großherzogtum Hessen 1815-1914, phil. Diss. Mainz 1966, Mainz 1968, S. 29ff., 94; Paul Meesmann, Die Handelskammer zu Mainz 1798-1898, Mainz 1898, S. 25ff;; Kurt Glück, Rheinhessens Wirtschaftsraum in seinem Werden nach 150 Jahren. Zum 150jährigen Bestehen der Industrie- und Handelskammer Mainz 1948, Mainz 1948, S. 7ff.; Paul Georg Custodis, Mainz im Wandel 1850-1900, Saarbrücken 1982, S. 9ff.; Dieter Gessner, Industrialisiertes Handwerk in der Frühindustrialisierung. Ein Beitrag zu den Anfängen der Industrie am Mittelrhein und Untermain 1790 bis 1865 , in: Blätter für deutsche Landesgeschichte 117 (1981), S. 255ff; ; Richard Hirsch, Die Möbelschreinerei in Mainz, in: Schriften des Vereins für Socialpolitik 64 (1893) (Untersuchungen über die Lage des Handwerks in Deutschland T. 1), S. $293 \mathrm{ff}$.
} 
Die einmalige Verkehrsgunst am Zusammenfluß von Rhein und Main und die Standortvorteile dieser Rheinufervororte, verbunden mit dem Vorkommen von für die Zementherstellung geeigneten Kalkmergeln, haben auf von auswärts stammende Unternehmer schon gleich nach der Jahrhundertmitte eine erhebliche Anziehungskraft ausgeübt (z.B. Chem. Werke vorm. H. \& E. Albert, Portland-Zementfabrik Dyckerhoff \& Söhne, Verein für Chemische Industrie - Gebr. Dietze, Eisengießerei, Eisenbau- und Maschinenfabrik Julius Römheld, Reederei und Zellstoffabrik Hubert Anton Disch) ${ }^{132}$.

Die mangelnden Ausdehnungsmöglichkeiten in der Stadt Mainz veranlaßten zudem in der Folge eine Reihe Stadt-Mainzer Firmen mit der Ausweitung des Geschäfts in die Vororte abzuwandern (z.B. die Waggonfabrik Gebr. Gastell, die Maschinenfabrik und Kesselschmiede Joh. Schmahl, die Rheinische Maschinen- und ApparatebauAnstalt Peter Dinckels Söhne oder die Lackfabrik Ludwig Marx) ${ }^{133}$. Die Sektkellerei Henkell wich 1909 überhaupt nach WiesbadenBiebrich aus ${ }^{134}$. Die einzelnen Fabrikationszweige der Stadt Mainz selbst sind nun „vorwiegend aus alten Handwerksbetrieben hervorgegangen ${ }^{\text {"133; }}$; der Anteil der ortsgebürtigen Untemehmer dürfte daher bei ihnen höher liegen. Da sich allerdings auch für eine Reihe, nicht in die Tabellen einbegriffener Stadt-Mainzer Metallwaren-, Apparatebau-

${ }^{132}$ Hoffmann, Gebundenheit, S. $29 f f$.

$\mathrm{Zu}$ Albert: Siehe oben Anm. 10.

Zu Dyckerhoff: Siehe oben Anm. 107.

$\mathrm{Zu}$ Dietze: Siehe oben Anm. 20 und Verein für Chem. Industrie AG, in: Histor.biographische Blätter, Reg.Bez. Wiesbaden.

Zu Römheld: Siehe oben Anm. 23 und Jürgen Schwab, Eine eiseme Tradition 1859-1959, hg. anläßlich des hundertjährigen Bestehens der Firma Julius Römheld Eisengießerei, Maschinen- und Stahlbau Mainz, Darmstadt 1959, S. 5ff; Julius Römheld, Eisengießerei, Eisenbau und Maschinenfabrik, in: Histor.-biograph. Blätter, Großherzogtum Hessen.

Zu Disch: Franz Lerner, Hubert Anton Disch, in: NDB 3 (1957), S. 743; Johann Jung, Hubert Anton Disch, in: Hessische Biographien 2 (1927), $207 \mathrm{f}$.

${ }^{133}$ Zu Gastell: Siehe oben Anm. 5.

Zu Schmahl: 75 Jahre Joh. Schmahl, Maschinenfabrik und Kesselschmiede MainzMombach 1876-1951, Mainz 1951.

Zu Dinckels: Rheinische Maschinen- und Apparatebau-Anstalt Peter Dinckels \& Sohn GmbH, in: Histor.-biogr. Blätter, Großherzogtum Hessen.

Zu Marx: Ludwig Marx Lackfabriken, in: Histor.-biogr. Blätter, Großherzogtum Hessen.

${ }^{134}$ Henkell \& Co., Sektkellerei, Biebrich, in: Histor.-biogr. Blätter, Reg.Bez. Wiesbaden.; 150 Jahre Henkel \& Co. 1832-1982, Wiesbaden 1982.

${ }^{135}$ Pott, Entwicklung, S. 50. 
und Maschinenbaufabrikanten eine Nicht-Mainzer Herkunft nachweisen läßt ${ }^{136}$, ist es fraglich, ob eine Verbreiterung der Basiszahlen das ungünstige Verhältnis der aus Mainz gebürtigen Unternehmer gegenüber den Zuwanderern erheblich verändern würde. Möglicherweise haben die eingesessenen Mainzer Familien statt in der industriellen Betätigung ihr Auskommen auch bevorzugt in den hergebrachten Handels- und Gewerbezweigen gefunden, wie auch aus der Mainzer Bevölkerung verhältnismäßig wenig Arbeiter kamen, da die Erwerbstätigen es vorzogen, nicht in einer Fabrik, sondern in einem Handwerksbetrieb, Geschäft, Kontor oder dergleichen zu arbeiten ${ }^{137}$.

Nach der Herkunftsverteilung der in den Tabellen einbegriffenen Darmstädter Firmengründer dominieren unter ihnen die ortsgebürtigen oder aus Nachbarorten des unmittelbaren Einzugsbereichs wie Pfungstadt oder Ober-Ramstadt stammenden Unternehmer mit neun von 12 Firmengründern bei weitem ${ }^{138}$.

${ }^{136}$ Aus Pegau stammte z.B. der Metallwarenfabrikant Louis Busch (1811-1888), siehe oben Anm. 86; aus Venlo gebürtig war Peter Dinckels (1838-1923), 1869 Gründer der Rheinischen Maschinen- und Apparatebau-Anstalt, in: Histor.-biogr. Blätter, Großherzogtum Hessen; Standesamt Mainz, Familienregister \& Nr. 14919 und 28808.

Der Galanteriestoffwarenfabrikant Balthasar Karl Hanss (1807-1880) stammte aus Frankenthal. Standesamt Mainz, Familienregister 5974 und 17331; Metallwarenfabrik Wilhelm Hanss Mainz/Rhein 1847-1922, Mainz 1922.

Der Fabrikant von Kellerei-Maschinen, Pumpen und Gießerei Peter Hilge (1832-1891) stammte aus Welterode. Standesamt Mainz, Familienregister Nr. 14216 und 29197; Philipp Hilge, Mainz. Gießerei, Pumpen, Kellerei-MaschinenFabrik 1862-1937, Erinnerungsblätter anläßlich des 75jährigen Bestehens der Firma, Mainz 1937; Philipp Hilge, Mainz. Gießerei-Pumpen-Armaturen-Fabrik 1862-1912, Mainz 1912.

Aus Mannheim gebürtig war Martin Oberdhan (1860-1942), 1889 Mitgründer der Fabrik von Beleuchtungsgegenständen Oberdhan \& Beck. Standesamt Mainz, Familienregister Nr. 13149; Oberdhan \& Beck, Fabrik von Beleuchtungsgegenständen, in: Histor.-biogr. Blätter, Großherzogtum Hessen.

${ }^{137}$ Pott, Entwicklung, S. 60.

${ }^{138}$ Zum Beispiel Theodor Beck (1839-1917): Carl Graf von Klinkowstroem, Theodor Beck, in: NDB 1 (1953), S. 699f;; Voigt, Maschinenindustrie, S. 9; Arthur Uecker, Die Industrialisierung Darmstadts im 19. Jahuhundert, Darmstadt 1928, S. 90f. und oben Anm. 18;

Georg Donges (1843-1924), siehe oben Anm. 50;

Johamn Peter Gandenberger (1804-1869) und Johann Georg Goebel (1830-1900), siehe oben Anm. 41 und 42;

Johann August Jacobi (1811-1891), siehe oben Anm. 60;

Wilhelm Kleyer (1822-1879): Stadtarchiv Darmstadt, Einwohnermelderegister Wilhelm Kleyer, und oben Anm. 54; Heinrich Emanuel Merck (1794-1855), siehe oben Anm. 29; 
Die begrenzte Anziehungskraft Darmstadts auf von auswärts stammende Gründer, besonders Fernzuwanderer, ist verständlich. Die Stadt war in erster Linie Residenz- und Beamtenstadt und ihr Gewerbe und Handel blieben im 19. Jahrhundert noch lange unentwickelt, beziehungsweise von der Befriedigung der Bedürnisse der Einwohner, des Hofes und der Garnison in der Stadt bestimmt. Ihre Wirtschaftsmöglichkeiten werden im Unterschied zu den übrigen rheinmainischen Großstädten, mit denen sie die Rohstofferne gemeinsam hat, durch ihre Flußferne bestimmt ${ }^{139}$. Bei einer Heranziehung weiterer Darmstädter Unternehmer scheint sich einerseits die erhebliche Selbstergänzung der Firmengründer dieser Stadt aus der eigenen Bevölkerung zu bestätigen ${ }^{140}$. Andererseits hat aber Darmstadt in den letzten Dezennien vor 1914 offensichtlich an Anziehungskraft für zuwandernde Gründer, besonders auch für Fernzuwanderer gewonnen.

War schon der Gründer der Dampfkesselfabrik Arthur Rodberg (1868 gegr.) aus Belgien gebürtig ${ }^{141}$, so lassen z.B. die Greburtsorte der Gründer und Teilhaber der 1902 errichteten Motorenfabrik Darmstadt (MODAG) ${ }^{142}$, des Inhabers der Hessenwerke Elektrotech-

Georg Philipp Roeder (1842-1912) und Ludwig Roeder (1846-1914): Stadtarchiv Darmstadt, Einwohnermelderegister Roeder; Denkschrift zum 50jährigen Geschäftsjubiläum der Firma Erste Darmstädter Herdfabrik und Eisengießerei Gebr. Roeder, Darmstadt 1916, S. 3ff; Herdfabrik und Eisengießerei Gebr. Roeder, in: Histor.-biogr. Blätter, Großherzogtum Hessen.

${ }^{139}$ Uecker, Industrialisierung, S. 23ff,, 38ff,, 78ff;; Wemer Zimmer, Darmstadt. Grenzen und Möglichkeiten einer Stadt (Rhein-mainische Forschungen H. 41), Frankfurt/M. 1954, S. 18f; Eckhart G. Franz, Vom Biedermeier in die Katastrophe des Feuersturms, in: Darmstadts Geschichte. Fürstenresidenz und Bürgerstadt im Wandel der Jahrhunderte. Von Friedrich Battenberg u.a., Darmstadt 1980, S. 361, 376.

${ }^{140}$ So waren ebenfalls gebürtige Darmstädter z.B. der Maschinenfabrikant Heinrich Blumenthal (1824-1901) und die Möbelfabrikanten Ludwig Alter (18471908), Jakob Glückert (1815-1881) und Joseph Trier (1816-1865). Der Maschinenbauer Gustav Goeckel (1849-1928) stammte aus Darmstadt-Bessungen. Alle Nachweise im Stadtarchiv Darmstadt, Einwohnermelderegister unter diesen Namen. Zu Trier siehe: Juden als Darmstädter Bürger. Hg. von Eckhart G. Franz, Darmstadt 1984, S. $368 \mathrm{ff}$.

${ }^{141}$ Stadtarchiv Darmstadt, Einwohnermelderegister Theodor und Arthur Rodberg.; Dampfkesselfabrik vorm. Arthur Rodberg AG Darmstadt, in: Histor.-biogr. Blätter, Großherzogtum Hessen.

${ }^{142}$ In der 1902 errichteten MODAG kamen Johann Gräb (1867-1929) aus Birstein/Oberhessen, August Koch (geb. 1867) aus Eppendorf/Krs. Gelsenkirchen, Oskar Findeisen (geb. 1876) aus Bremen und Friedrich May (1875-1939) aus Groß-Zimmern: Stadtarchiv Darmstadt, Einwohnermelderegister unter diesen 
nische und Maschinenfabrik ${ }^{143}$, sowie des Chemiefabrikanten Otto Röhm (1876-1936) ${ }^{144}$ auf eine weiträumigere regionale Herkunft der Darmstädter Firmengründer unmittelbar vor 1914 schließen.

Die Entwicklung zur Kur- und bevorzugten Rentnerwohnstadt macht Wiesbaden zum bemerkenswerten Sonderfall einer Stadt, die in der zweiten Hälfte des 19. Jahrhunderts ohne Industrialisierung zur Großstadt wurde ${ }^{115}$. Insofern verwundert es nicht, daß von den ohnehin nur sieben erfaßten Wiesbadener Firmengründern sechs von außerhalb stammten $^{146}$ und diese bevorzugt ihre Unternehmungen in den erst später eingemeindeten Rheinufervororten gründeten. Von ihrer geringen Ortsgebürtigkeit her, ihrer meist vorhandenen Oberschichtsabkunft, ihrem Ausbildungsniveau und ihrer häufigen Hinwendung zu kapital- und bildungsintensiven Industriezweigen wie der rationalen Standortwahl und Größenstruktur ihrer Betriebe bilden diese Unternehmer der Industriezone der Rheinufervororte von Mainz und Wiesbaden am Zusammenfluß von Rhein und Main eine Einheit, die man am besten unter dem Begriff "Mainmündungsunternehmer" zusammenfassen könnte. Wie schon bei Mainz ausgeführt, heben sie sich in ihrem Erscheinungsbild und der Sozialstruktur erkennbar von den Unternehmern derjenigen Städte $a b$, in welche diese Rheinufervororte später eingemeindet wurden.

Eine zahlenmäßig kleine, wirtschaftlich, gesellschaftlich und politisch aber höchst erfolgreiche und eigenständige Gruppe stellen die erfaßten Wormser Unternehmerfamilien dar. Diese Familien ( $\mathrm{Heyl}$, Martenstein, Schoen, Valckenberg, Doerr und Reinhart) haben - be-

Namen; MODAG Motorenfabrik Darmstadt GmbH. 50 Jahre MODAG 1902-1952, Düsseldorf 1952, S. 4ff.

${ }^{143}$ Kurt Hesse (1868-1931) war aus Fronhausen bei Marburg gebürtig: Stadtarchiv Darmstadt, Einwohnermelderegister Kurt Hesse.

${ }_{144}$ Auskunft der Firma Röhm \& Haas, Darmstadt; Chronik der Firma Röhm \& Haas Darmstadt, maschr. Manuskript in Firma Röhm \& Haas, o.J., bes. S. 20lff; Kasimir Edschmid, In memoriam Dr. Otto Röhm. Zum 50jährigen Bestehen der chemischen Fabrik Röhm \& Haas, Darmstadt 1957, S. 5ff.

${ }^{145}$ Krenzlin, Werden, S. 342f: Herbert Müller-Werth, Geschichte und Kommunalpolitik der Stadt Wiesbaden unter besonderer Berücksichtigung der letzten 150 Jahre, Wiesbaden 1963, S. 82ff.

${ }^{146}$ Zum Beispiel Ludwig Beck (1841-1918), siehe oben Anm. 18;

Jakob Friedrich Kalle (1837-1935) und Paul Wilhelm Kalle (1838-1919), siehe oben Anm. 14;

Eugen Dyckerhoff (1844-1924), siehe oben Anm. 107;

Carl v. Linde (1842-1934), siehe oben Anm. 34;

Johann Jakob Söhnlein (1817-1912), siehe oben Anm. 105. 
sonders auf der Basis weniger der Textilindustrie als vielmehr der Lederindustrie, die vor dem Ersten Weltkrieg die bedeutendste der Welt war ${ }^{147}$ - in hohem Maße die wirtschaftliche Erneuerung der Stadt aus beinahe dörflicher Rückentwicklung seit Beginn des 19. Jahrhunderts initiiert und vorangetrieben. Angesichts des überragenden wirtschaftlichen Gewichts der von diesen Unternehmern gegründeten Firmen, dem mäzenatischen Kunstsammel- und Stiftungseifer einzelner, dem öffentlichen und politischen Einsatz wie dem grandseigneuralen, zum Teil durch Erwerb umfangreichen Grundbesitzes abgesicherten Lebensstil, der bei den Heyl zu Hermsheim und den ihnen verwandten Schoen durch Nobilitierung überglänzt war ${ }^{148}$, läßt sich bei Worms sagen, daß hier wie vielleicht bei keiner anderen Stadt die Industrialisierung das Werk eingesessener oder durch Einheirat mit Worms engstens verbundener Unternehmer war. Diese „Bodenständigkeit“ gilt, „wenn man von den Neugründungen der letzten Jahre vor dem Kriege absieht", für weitere Wormser Unternehmer ${ }^{149}$.

Das Wirtschaftsleben des dank einer wirtschaftsliberalen und toleranten Politik der Hanauer Grafen früh gewerbereichen Hanau weist im 19. Jahrhundert insofern eine interessante Variante unter den untersuchten Städten auf, als es trotz erheblicher Traditionsbrüche und Neuanfänge - besonders am Beginn des vorigen Jahrhunderts - am stärksten in der Kontinuität einer vorindustriellen handwerklich-

${ }^{147}$ Otto Eberhardt, Die industrielle Entwicklung der Stadt Worms. Maschr. phil. Diss. Heidelberg 1922, S. 15ff,, über die Lederindustrie, S. 54ff.

${ }^{148}$ Günther Kriegbaum, Die parlamentarische Tätigkeit des Freiherrn C.W. Heyl zu Herrnsheim (Mainzer Abhandlungen zur mittleren und neueren Geschichte Bd. 9), Miesenheim/Glan 1962; siehe oben Anm. 70; Gothaisches Genealogisches Taschenbuch der briefadeligen Häuser 4 (1910), S. 703f; über einzelne dieser Wormser Persönlichkeiten Carl J.H. Villinger, Wormser Profile, Worms 1966, S. 17ff., 32ff., 56ff:; Hans Kühn, Politischer, wirtschaftlicher und sozialer Wandel in Worms 1798-1866 unter besonderer Berücksichtigung der Veränderungen in der Bestellung, den Funktionen und der Zusammensetzung der Gemeindevertretung (Der Wormsgau Beih. 26), Worms, 1975, S. 59ff.

${ }_{149}$ Eberhardt, Entwicklung, S. 159; aus Worms stammte auch noch Ludwig Melas (geb. 1810), 1859 Gründer einer Lederfabrik: Stadtarchiv Worms, Personenstandsverzeichnis, Heiraten 16. Juli 1840. Dagegen war der Filter- und Abfüllapparatefabrikant Lorenz Adalbert Enzinger (1849-1897) aus Wasserburg am Inn gebürtig, siehe oben Anm. 118; gebürtiger Wormser war auch Markus Edinger (1819-1879), auf dessen Firma Edinger Söhne die Einführung der Herrenkonfektionsindustrie 1847 in Worms und Süddeutschland zurückgehen soll, Kühn, Wandel, S. 256 und S. 194f;; Geschichte Handelskammer Frankfurt S. 1308; NDB 4 (1959), S. 313; Eberhardt, Entwicklung, S. 29f; Arnsberg, Gemeinden 2. Bd., S. 430. 
manufakturellen Fertigung und einer klein- und mittelbetrieblichen Betriebsgrößenstruktur verblieb.

Der Hanauer Unternehmerschaft fehlen zwar auch im 19. Jahrhundert nicht die Zuwanderer, so in der an sich älteren, aber um 1825 durch Bremer, Hamburger und Amsterdamer Zuwanderer gleichsam neubegründeten Tabakindustrie ${ }^{i 50}$. Ebenso lassen sich in der Hanauer Schmuck- und Edelmetallwarenindustrie Zuwanderer, besonders aus Städten mit ähnlichen Gewerbeschwerpunkten (z.B. Augsburg - Silberwaren, Idar-Oberstein - Diamantschleifereien) feststellen ${ }^{151}$. Das deutliche Übergewicht der Ortsgebürtigkeit und die geringe territoriale Mobilität der Firmengründer, wie diese bei allerdings nur sechs erfaßten Hanauer Unternehmern erkennbar wird, dürfte aber doch üblich gewesen sein für die Mehrheit der Unternehmerschaft einer Stadt mit ausgeprägt lokal begrenzten Spezialindustrien und einem entsprechenden Facharbeiterstamm (Tabak-, Schmuck-, Edelmetallverarbeitung, auslaufende Textilindustrien wie Seiden-, Wollwaren- und Teppichfabriken), wobei sich um die Stammindustrien eine Reihe aufeinander bezogener Zulieferer-, Neben- und Hilfsindustrien entwickelte (z.B. Zigarrenkisten- und Wickelformenfabriken, lithographische Anstalten) ${ }^{132}$. Die zunächst ebenfalls im Zusammenhang mit der Edelmetall-

${ }^{150}$ Harm-Hinrich Brandt, Wirtschaft und Wirtschaftspolitik im Raum Hanau 15971962. Die Geschichte der Industrie- und Handelskammer Hanau-GelnhausenSchlüchtern und ihrer Vorläufer, Hanau 1963, S. 59-72, insbes. S. 65 und S. 123132.

${ }^{131}$ Die Silberwarenfabrik J.D. Schleißner in Hanau wurde z.B. von Johann Daniel Schleißner aus Augsburg gegründet, siehe: Karl Siebert, Hanauer Biographien aus drei Jahrhunderten, August Schleißner, in: Hanauer Geschichtsblätter, Neue Folge 3/4 (1919), S. 176-178; Dieter Gessner, Wachstumszyklen und staatliche Gewerbepolitik im Zeitalter der Frühindustrialisierung. Konjunkturelle und strukturelle Probleme des Bijouteriegewerbes an Untermain und Mittelrhein 1790-1865. Eine Fallstudie, in: Scripta Mercaturae 15/H. 1 (1981), S. 39, 43; Friedrich Houy, der Begründer der Hanauer Diamantschleiferei stammte aus Idar-Oberstein, siehe: Siebert, Hanauer Biographien, S. 86f.; Die Bijouteriefabrikanten Küstner in Hanau stammten ursprünglich aus Kassel: DGB 121 (1956), S. 385f.

${ }^{152}$ Lorenz Caspari, Die Entwicklung des Hanauer Edelmetallgewerbes von seiner Entstehung im Jahre 1597 bis zum Jahre 1873, jur. und staatswiss. Diss. Freiburg/Brsg., Elberfeld 1916, S. 130ff.; Emst Thieme, Der wirtschaftliche Aufbau der Hanauer Edelmetallindustrie (Zeitschrift für die gesamte Staatswissenschaft Erg.H. 53), Tübingen 1920, S.12ff., 65, 117f., weist darauf hin, daß 1901 80,5\% der Arbeiter in der Hanauer Edelmetallindustrie in Hanau und 19,5\% in den umliegenden Dörfem wohnten; Dieter Gessner, Lokalisation, Struktur und Entwicklung der Textilindustrie an Mittelrhein und Untermain von 1780 bis $1861 / 65$. Eine quantifizierend-qualifizierende Regionaluntersuchung, in: Nassauische Annalen 93 (1982), S. 35-60; über die Zigarrenkisten- und Zigarrenwickelformenfabrik sowie 
warenindustrie entstandenen und von ortsgebürtigen Unternehmem gegründeten Platinschmelzen Heraeus ${ }^{153}$ und Siebert (heute DEGUSSA) $)^{154}$ trugen aber dann nach dem Geschmackswandel und Wegfall der vermögenden Käuferschichten nach dem Ersten Weltkrieg im Verein mit anderen, teilweise älteren Industriezweigen (z.B. Eisengießereien, Maschinen- und Apparatebau, Reifenherstellung Dunlop 1892) zur Umorientierung und Umstrukturierung der Hanauer Wirtschaft bei ${ }^{135}$.

Für die einzelnen kleineren Städte und Gemeinden des Rhein-MainGebiets werden die Zahlen der erfaßten Unternehmer zu klein, um für diese allgemeine Aussagen zur Unternehmerherkunft machen zu können. Im einzelnen haben aber auch hier die unterschiedlichen Traditionen und Entwicklungsbedingungen, die jeweiligen Wirtschaftsfunktionen und -strukturen, aber auch das verschiedene Ausmaß der Beteiligung der vorhandenen wirtschaftsaktiven Bevölkerung an Industriegründungen zu einem unterschiedlichen Erscheinungsbild des Unternehmertums und der Unternehmerherkunft geführt.

So wurde für die Fabrikanten der Stadt Bensheim a.d. Bergstraße für das 19. Jahrhundert einschließlich des ersten Viertels des 20. Jahrhunderts festgestellt, daß „von den besprochenen Unternehmern mit 33 Gründern oder Nachkommen... 26, gleich 80 Prozent, Fremde ${ }^{\text {" }}$ waren ${ }^{136}$. Es ist dies eine bemerkenswert hohe Quote der Zuwanderung für eine Stadt mit einer doch nur begrenzten wirtschaftlichen Ausstrahlungskraft.

In Oberursel waren ebenfalls bis gegen Ende des 19. Jahrhunderts die Fabrikbesitzer "in der Hauptsache Zugezogene, z.T. Frankfurter". Erst mit der steigenden industriellen Erfahrung haben sich dann in einer zweiten Phase der Oberurseler Industriegründungen häufiger gebürtige Oberurseler an Industriegründungen beteiligt ${ }^{157}$.

die lithographische Anstalt Brüning, siehe: Siebert, Hanauer Biographien, S. 1921.

153 Siehe oben Anm. 30.

154 Siehe oben Anm. 12.

${ }^{155}$ Brandt, Wirtschaft, S. 131 und $159 f f$.

${ }^{196}$ Aloys Winter, Die wirtschaftliche Entwicklung der Stadt Bensheim a.d. Bergstraße, wirtschafts- und sozialwiss. Diss. Frankfurt/M., Bensheim 1927, S. 71ff., 80.

${ }^{157}$ Josef Kaltenhäuser, Taunusrandstädte im Frankfurter Raum. Funktion, Struktur und Bild der Städte Bad Homburg, Oberursel, Kronberg und Königstein (Rheinmainische Forschungen 43), Frankfurt/M. 1955, S. 63, 71. 


\section{Die Konfessionszugehörigkeit der Firmengründer}

\subsection{Die Zugehörigkeit der Firmengründer zu den einzelnen Konfes-} sionen

Die relativ leichte Feststellbarkeit der Konfessionsangehörigkeit ermöglicht die Ausweitung der Basiszahl der in die Konfessionsstatistik einbezogenen Unternehmer von 175 auf 250 Personen. Von diesen 250 Industriegründern waren 165 Personen (66,0\%) evangelisch, 55 Unternehmer $(22,0 \%)$ römisch-katholisch, $29(11,6 \%)$ Juden und einer von ihnen war gottgläubig ${ }^{158}$.

In ihrem zeitlichen Auftreten weisen die einzelnen Konfessionen eine charakteristische Reihenfolge ihres ersten verstärkten Auftretens auf. Am frühesten sind die Protestanten unter den Firmengründern vertreten, Sie stellen von elf Gründem im Zeitraum 1815-1830 zehn. Im zweiten Untersuchungsabschnitt 1831-1850 kamen zu den protestantischen Firmengründern verstärkt die Katholiken, wobei ein Teil ihrer Gründungen in diesem Abschnitt bis 1850 vielleicht noch am wenigsten industriellen Charakter besaß. Dies gilt allerdings bis zu einem gewissen Grad auch für andere Gründungen dieser frühindustriellen Ära. Immerhin: Sechs der zwölf katholischen Gründer der Zeitspanne 1831-1850 gründeten Sektkellereien. Nach 1851 beteiligten sich dann die Juden als Folge der allseitigen Beseitigung der rechtlichen Diskriminierung und ihrer Integrierung in die Gesamtwirtschaft verstärkt auch an der Gründung von Industriebetrieben.

Wenn auch wegen der Nichtübereinstimmung der Abgrenzung des Untersuchungsgebiets mit den an politischen Grenzen orientierten amtlichen Statistiken nur eine Annäherung der Zahlenwerte möglich ist, scheint der Anteil der Protestanten unter den Firmengründern ihrem konfessionellen Anteil an der Gesamtbevölkerung des RheinMain-Gebiets zu entsprechen, er dürfte vielleicht sogar etwas darunter liegen. Eindeutig unterrepräsentiert sind die Katholiken. Dagegen

${ }^{158}$ Für diese und die folgenden Zahlen siehe bitte Tabelle Anlage 6: Die Konfessionszugehörigkeit von 250 Firmengründem des Rhein-Main-Gebiets 1815-1914 nach Zeitstufen. Für die Zuordnung eines Firmengründers zu einer Konfession war maßgebend dessen ursprüngliches Glaubensbekenntnis, nicht die spätere Religionszugehörigkeit im Falle eines Religionswechsels, sofem der ursprüngliche Glaube ermittelt werden konnte. 
überflügeln die israelitischen Industriegründer bei weitem ihren geringen Bevölkerungsanteil.

4.2. Die Konfessionszugehörigkeit der Firmengründer nach Wirtschaftszweigen

In der Verteilung der Konfessionen auf die einzelnen Wirtschaftszweige sind die Protestanten in allen Branchen vertreten. Höchst bemerkenswert ist aber, daß sie in allen Produktions- und Investitionsgüterindustrien durchwegs einen Anteil erreichen, der über dem Gesamtdurchschnitt der evangelischen Firmengründer liegt und diesen zum Teil sogar erheblich übertriff ${ }^{159}$. Es sind dies diejenigen Industriezweige, wie die chemische Industrie, der Maschinen-, Stahl- und Fahrzeugbau, die Metallverarbeitung sowie die elektrotechnische und feinmechanische Industrie, deren frühe und starke Besetzung sowie wirtschaftliche und technische Dynamik dem Aufstieg des rheinmainischen Industriegebiets im deutschen Wirtschaftskörper zugutegekommen ist ${ }^{160}$. Thre innovatorischen Fortschritte basierten in erster Linie auf methodisch-experimentell erprobten oder auf theoretischem Wege gewonnenen naturwissenschaftlichen und technischen Erkenntnissen einerseits; andererseits beruhte ihre wirtschaftliche Dynamik auf der konsequenten Anwendung des ökonomischen Rationalismus, der rechenhaften Organisation ihrer Unternehmen, der Verwendung akkumulierten Fremdkapitals zu ihrer Finanzierung und der Produktion in großen Mengen, wenn auch besonders in manchen Zweigen der produktdifferenzierten Maschinen- und Metallwarenindustrie der unternehmerische Erfolg auch aufgrund des fachlichen Geschicks, der Erfahrung und einer gewissen praktischen Experimentier- und Probierfreudigkeit beruhen konnte. Man wird daher für die überdurchschnittliche Hinwendung der Protestanten zu diesen Industriezweigen am ehesten das protestantische Interesse an Erziehung, Bildung, individuellem Erkenntnisdrang und Leistung, an Nützlichkeitsdenken, nüchtern-rationaler Weltbetrachtung und Wissenschaft sowie an methodischer Herrschaftsgewinnung über die Natur verantwortlich ma-

\footnotetext{
${ }^{139}$ Für diese und die folgenden Zahlen siehe bitte Tabelle Anlage 7: Die Konfessionszugehörigkeit von 250 Firmengründern des Rhein-Main-Gebiets 1815-1914 nach Wirtschaftszweigen.

${ }^{160}$ Hessen im Wandel der letzten hundert Jahre 1860-1960. Hg. vom Hess. Statistischen Landesamt (Hessenkunde Bd. 3), Wiesbaden 1960, S. 185 f.
} 
chen können, ohne daß hier den religionsethischen und kultursoziologischen Gründen dieser Erscheinung eigens nachgegangen werden soll ${ }^{161}$.

Die Katholiken sind mit Ausnahmen, wie in der elektrotechnischen und feinmechanischen Industrie, in der sie überhaupt keine Firmengründer stellen, ebenfalls in den erwähnten Produktions- und Investitionsgüterindustrien mit Anteilen vertreten, welche beim Maschinenbau über, bei der chemischen Industrie unterhalb ihres Anteils an der Gesamtunternehmerschaft liegen. Nur in der Branche der bevorzugt im Umkreis von Weinbaugebieten angesiedelten und mehr kaufmännische als produktionsschöpferische Fähigkeiten verlangenden Branche der Sektkellereien und Weinbranderzeugung überflügeln die Katholiken mit 73,7\% ihren Gesamtdurchschnitt erheblich. Nachdenklich stimmt auch, daß die Katholiken neben der wegen ihrer geringen Unternehmerzahl nur wenig aussagefähigen Industrie der Steine und Erden am höchsten noch in der Maschinen- und Metallwarenindustrie vertreten sind. Es sind dies ja diejenigen Industriezweige, in deren Einzelsparten oft weniger das Wissen als das Können die Wurzel unternehmerischen Aufstiegs war. Für sie ist auch unabhängig von der Konfession der Firmengründer ihr sozialer Aufstiegscharakter festgestellt worden.

Ähnlich den katholischen Firmengründern sind auch die jüdischen nicht in allen Industriezweigen vertreten. Bemerkenswert ist, daß in allen denjenigen Branchen, in denen die Protestanten überdurchschnittlich repräsentiert sind, bei ihnen genau das Gegenteil der Fall ist. Dagegen erreichen die Juden in der Sparte der Leder-, Lederwaren- und Schuhfabrikation einen weit überdurchschnittlichen Anteil von $35,3 \%$ gegenüber $11,6 \%$ in der Gesamtunternehmerschaft. Neben drei Lederindustriellen und einem Portefeuillefabrikanten haben nun acht der zwölf jüdischen Unternehmer dieser Branche Schuhfabriken gegründet. Es ist dies ein Produktionszweig, der im Rhein-MainGebiet offensichtlich in stärkstem Ausmaße von jüdischen Unternehmern betrieben wurde und der ausgehend von Mainz in dieser Stadt, in Frankfurt sowie in Offenbach zu einem bedeutenden Industriezweig

161. Alfred Müller-Armack, Religion und Wirtschaft, Stuttgart 1959, S. 100ff; David McClelland, Die Leistungsgesellschaft, Stuttgart, Berlin, Köln, Mainz 1966, S. 305; Hugo Ott, Die katholische Wirtschaftsethik und ihr Einfluß auf die wirtschaftliche Aktivität der Katholiken am Beginn des industriellen Zeitalters, in: VSWG 56 (1969), S. 289; vgl. auch die Werte und die Begründungen bei Stahl, Elitekreislauf, S. $210 \mathrm{ff}$, er weist auf den steigenden Anteil der Protestanten bei steigender Unternehmensgröße hin. 
heranwuchs ${ }^{162}$. Er gehört damit zu jenen Gewerbezweigen wie die Bekleidungskonfektionsindustrie, das Geldgeschäft und Bankwesen sowie bestimmte Formen des Detail- und Großhandels, die im kaiserlichen Deutschland durch einen relativ hohen Anteil jüdischer Unternehmer gekennzeichnet waren ${ }^{163}$.

Ein wesentlicher Faktor des Unternehmererfolgs in der Schuhfabrikation lag nun neben ausreichenden Betriebsmitteln und der maschinellen Einrichtung in der „Fähigkeit Konjunkturen auszunützen" ${ }^{\text {"164 }}$. Bei der Entstehung zum Beispiel der Offenbacher Schuhindustrie

${ }^{162}$ C. Schreiber, Handbuch der mechanischen Schuhfabrikation, Leipzig 2. Aufl, 1904, S. 9ff;; Pott, Entwicklung, S. 53 behandelt die Mainzer Schuhindustrie nur kursorisch; Müller, Entwicklung, S. 76f.; Link, Lederindustrie, S. 56ff., bes. S. 61; Beispiele für Schuhfabrikanten: 1880 gründete Isaak, gen. Julius, Speier (18541923) aufgrund seiner amerikanischen Erfahrungen die Hako-Schuhwerke in Frankfurt. Stadtarchiv Frankfurt, Einwohnermeldekartei: Julius Speier; Staatsarchiv Wiesbaden Judenregister 339; Die Westdeutsche Wirtschaft und ihre führenden Männer. Land Hessen Teil 1 und 2, FrankfiurtM. 1952 und 1956, hier Teil 2, S. 134; Amsberg, Gemeinden 1, S. 344.

Eine Spezialfabrik fuir Damen- und Babyschuhe errichteten 1900 in Frankfurt die Brüder Alfred (geb. 1869), Richard (geb. 1873) und Wilhelm (geb. 1875) Nathan, die nachmals als Ada-Ada Schuh AG firmierte. Stadtarchiv Frankfurt, Einwohnermeldekartei Hermann Nathan; Stadtarchiv Frankfurt S. 3/R 1049 Bericht von Frau Willy Nathan über die Ada-Ada Schuh AG; Wirtschaft, Hessen 1, S. $205 \mathrm{ff}$.

Eine Gründung von Emil Liebmann ist die 1901 aufgerichtete Schuhfabrik Hassia in Offenbach; Wirtschaft, Hessen 1, S. 209ff.; Arnsberg, Gemeinden 2, S. 169.

Die Frankfurter Schuhfabrik J. \& C. A. Schneider (ICAS) ging drei Jahre nach ihrer Gründung 1908, 1911, in den Besitz der beiden Brüder Lothar (geb. 1887) und Fritz (geb. 1888) Adler über. Stadtarchiv Frankfurt, Einwohnermeldekartei Lothar und Fritz Adler; Wirtschaft, Hessen 1, S. 213f.

Offenbacher Schuhfabriken waren neben den bereits 1860 von einem Faktor von Simon Wolf in Mainz, dem Lüneburger Heinrich Behrens (1830-1915) gegründeten Leanderwerken zum Beispiel noch Dreschfeld \& Wallerstein, Gebrüder Schönhof und Gebrüder Heilbrunn. Müller, Offenbach, S. 76; Die FrankfurtOffenbacher Lederindustrie, in: Frankfurter Generalanzeiger Nr. 204, 1. Sept. 1927, S. 11; über Heinrich Behrens siehe auch: Heinrich Behrens $\dagger$ in: Offenbacher Zeitung 23.2.1915 und Einwohnermeldeamt Offenbach, Heinrich Behrens.

${ }^{163}$ Werner E. Mosse, Jews in the German Economy. The German-Jewish Economic Elite 1820-1935, Oxford 1987, S. 380-405, bes. S. 389-391 und S. 393f; Werner Sombart, Die Juden und das Wirtschaftsleben, München, Leipzig 1928, S. 132ff.; siehe auch Eckhart G. Franz, Fabrikanten, Kaufleute, Bankiers. Die wirtschaftliche Bedeutung der Darmstädter Juden im beginnenden Industriezeitalter, in: Juden als Darmstädter Bürger. Hg. von Eckhart G. Franz, Darmstadt 1984, S. $100 \mathrm{ff}$.

${ }^{164}$ Schreiber, Handbuch, S. 3. 
„können die Lederhändler als die treibenden Faktoren angesehen werden", sie haben auch selbst häufig die Produktion aufgenommen ${ }^{103}$. Die Ursache der Häufung jüdischer Unternehmer in der Schuhfabrikation dürfte daher vordergründig weniger im religiösen Bereich als vielmehr im historischen Gruppenschicksal der Juden begründet liegen mit der ihnen auferlegten traditionellen Verengung ihrer Wirtschaftstätigkeit auf den kommerziell-händlerischen Sektor und der Entwicklung besonderer wirtschaftsorganisatorischer Fähigkeiten. Das amerikanische Vorbild bei der Aufnahme der mechanischen Schuhfabrikation durch den Schuhmacher Simon Wolf und den Lederhändler Otto Herz 1854 in Mainz ${ }^{166}$ oder die Übernahme zuerst vorwiegend französischer, dann wiederum amerikanischer maschineller und gerbereitechnischer Innovationen in der Ledererzeugung (z.B. Übergang von der vegetabilischen zur mineralischen Chromgerbung ${ }^{167}$ ) zeigt auch, daß dies - teilweise unabhängig von der Konfession der Firmeninhaber - Branchen waren, die durch den Technologietransfer, neue Produktionsformen und Distributionstechniken zur weltwirtschaftlichen Integration und zur Ausbreitung hochkapitalistischer Wirtschaftsformen beigetragen haben ${ }^{168}$.

Über die Schuhindustrie hinausgehend scheint auch in anderen Industriezweigen für Firmengründer jüdischen Glaubens der Zugang zur Industriegründung häufig vom Handel, verschiedentlich auch die vornehmliche Betätigung im kommerziellen Sektor der Betriebsführung häufiger gewesen zu sein als für Nicht-Juden. Es dürfte sich darin eine sicher nicht ausschließliche, jedoch mehrheitlich anzutreffende Eigenart der Firmengründer jüdischer Konfession abzeichnen ${ }^{169}$. So betrieben Maschinenhandlungen oder hatten betrieben neben oder vor der Produktionsaufnahme zum Beispiel die Maschinenfabriken Philipp

\footnotetext{
${ }^{165}$ Müller, Offenbach, S. 76f.

${ }^{166}$ Über die Firma S. Wolf gibt es eine Denkschrift, die allerdings nicht zu beschaffen war: Denkschrift zum 60jährigen Bestehen der Schuhwarenfabrik S. Wolf, Mainz 1901; Müller, Offenbach, S. 76.

${ }^{167}$ Siehe z.B. die Firmenentwicklungen der Lederwerke Cornelius Heyl in Worms, der Lederwerke J. Mayer in Offenbach und der Lederwerke Becker \& Co. in Offenbach-Bürgel.
}

Zu Heyl: Illert, Umriß, S. 6, 17, $20 \mathrm{ff}$.

$\mathrm{Zu}$ Mayer \& Sohn: Erinnerungsblätter zur Feier des 50jährigen Bestehens der Lederwerke J. Mayer \& Sohn, Offenbach $/ \mathrm{M}$. 1857-1907, o.O. o.J. [wohl Offenbach 1907]; J. Mayer \& Sohn, in: Histor.-biogr. Blätter, Großherzogtum Hessen.

$\mathrm{Zu}$ Lederwerken Becker: Siehe oben Anm. 129.

${ }^{168}$ Diesen integrativen Aspekt betont besonders Mosse, Jews, S. 399.

${ }^{169}$ Vergleiche oben Anm. 163. 
Mayfarth in Frankfurt, die der Regsamkeit des Kaufmanns Samuel Moser (1849-1917) ihren Aufschwung verdankt, Heinrich Blumenthal (1824-1901) in Darmstadt oder der Frankfurter Maschinenfabrikant Joseph Wertheim (1834-1899). Die Frankfurter Asbestwerke vorm. Louis Wertheim (1838-1905) gingen aus einem Handelsbetrieb für Asbestprodukte hervor, während Julius Pfungst (1834-1899) nach dem Betrieb einer Haarschneidefabrik und dem Handel in Leder, Fellen und Häuten en gros sowie der Sicherung des Absatzmonopols des griechischen Naxos-Schmirgels die Produktion von Schleifmitteln und Schleifmaschinen in der Firma Naxos-Union aufnahm. Für den ungewöhnlichen Aufstieg des Fuld-Konzerns, der nachmaligen Telefonbau und Normalzeit Lehner \& Co. (Telenorma) in Frankfurt wiederum war in erster Linie die kaufmännisch-organisatorische Begabung Harry Fulds (1879-1932) verantwortlich ${ }^{170}$. Darauf, daß die Ursprünge der verschiedenartigsten Produktionsbetriebe wie der Chemischen Fabrik Cassella in Frankfurt, der renommierten Portefeuillefabrik E. Posen in Offenbach am Main oder der Feist-Belmont'schen Sektkellerei in Frankfurt in einschlägigen Handlungen gelegen hatten, sei in diesem Zusammenhang nochmals hingewiesen ${ }^{171}$. Wie sehr aber die Zugehörigkeit zu einer kommerziell-elitären Minorität, wie hier zum

${ }^{170} \mathrm{Zu}$ Ph. Mayfarth und S. Moser: 50 Jahre Philipp Mayfarth \& Co., Fabrik landwirtschaftlicher Maschinen Frankfurt 4. April 1872-1922, Frankfurt 1922, S. 5ff;; Geschichte Handelskammer Frankfurt, S. 1259; Stadtarchiv Frankfurt, Einwohnermeldekartei Samuel Moser.

Zu Heinrich Blumenthal: Stadtarchiv Darmstadt, Einwohnermelderegister, Vermerk auf dem Halbblatt der Karte Heinrich Blumenthal; Eckhart G. Franz, Heinrich Blumenthal (1824-1901), in: Juden, S. 235-239.

$\mathrm{Zu}$ Joseph und Louis Wertheim: Siehe oben Anm. 16.

Zu Julius Pfungst: Stadtarchiv Frankfurt, Geburtsregister 1834, fol. 624; Stadtarchiv Darmstadt, Einwohnermelderegister Moses Pfungst; Frankfurter Adreßbuch 1870, Eintrag Julius Pfungst; Gesellschaft des ächten Naxos-Schmirgels NaxosUnion, in: Histor.-biogr. Blätter, Reg. Bez. Wiesbaden; Geschichte Handelskammer Frankfurt, S. 1258; Wirtschaft Hessen 1, S. 171ff;; Julius Pfungst $\dagger$, in: Frankfurter Kleine Presse 2, und 7. 11. 1899.

Zu H. Fuld: Franz Lemer, Harry Herz Salomon Fuld, in: NDB 5 (1961), S. 725f; Leo Parth, Harry Fuld. Eine Lebensskizze, Oldenburg 1933, S. 20ff;; Kurt Möllgaard, 50 Jahre Frankfurter Telefonbau, in: TN-Nachrichten. Hausmitteilungen der Telefonbau und Normalzeit 39 (1949), S. 1680-1709.

${ }^{171} \mathrm{Zu}$ Cassella: Siehe oben Anm. 13.

Zu E. Posen: K. Brockmann, Werdegang der Lederwaren- und Reiseartikelfabrik Eduard Posen \& Co. Offenbach a. M. 1811-1923, in: Deutsche Lederwarenindustrie Nr. 22 (1923), S. 3-14; Eduard Posen. Aus Anlaß der 75. Wiederkehr seines Todestages, in: Offenbacher Zeitung 7.12.1928.

Zu Feist-Belmont: Siehe oben Anm. 100. 
Judentum, in manchen stark von dieser Minorität besetzten Wirtschaftssparten ein Mittel der Geschäftspolitik und gleichsam "Kapital" sein konnte, ergibt sich aus den Worten von Liefmann über die internationale Organisation des Frankfurter Metallhandels, nach denen „sich der große Metallhandel ausschließlich, wie vielleicht kein anderer Erwerbszweig, in jüdischen Händen befindet, dergestalt, daß z.B. die beiden größten deutschen Metallhandlungen außer dem Merton-Konzern, die Firma Beer, Sondheimer \& Co. in Frankfurt/Main und Aaron Hirsch \& Co. in Halberstadt überhaupt keinen nichtjüdischen Teilhaber aufnehmen würden" ${ }^{\text {"172 }}$.

Gleichzeitig hat aber offensichtlich gerade die Lebensführung zumindest eines Teils der jüdischen Unternehmer unter dem Eindruck ethischer Forderungen und eines zum Teil noch ausdrücklich religiös begründeten individuellen Bewährungsglaubens gestanden, die zum Teil anscheinend die wirtschaftliche Aktivität anspornten und denen ein ausgeprägtes Bewußtsein der sittlichen Verantwortlichkeit des Besitzenden gegenüber der Allgemeinheit entsprachen. Dies gilt durch offenkundig zum Verhaltensmuster gewordene herkunfts- und umweltbedingte Einflüsse auch für aus dem Judentum konvertierte Unternehmer ${ }^{173}$. In dem Zusammenhang ist auch auf die im Verhältnis zum Bevölkerungsanteil ungewöhnlich große Zahl jüdischer Stiftungen insbesondere in Frankfurt, wie auch auf die mit der jüdischen Stiftungstätigkeit wiederholt verbundene Eigentümlichkeit ihrer Zielsetzungen im menschen- und sozialreformerischen Bereich sowie ihrer umfassenderen pädagogisch-philanthropischen und emanzipatorischen Absichten $\mathrm{zu}$ verweisen. Sie gehen über die zeitübliche Beschäftigung mit sozialpolitischen Fragen und Unternehmer-Stiftungen für Betriebsangehörige sowie für sonstige soziale, kirchliche, caritative oder kulturelle Zwecke hinaus. Hier wäre unter anderem hinzuweisen auf

${ }^{172}$ Liefmann, Organisation, S. 121.

${ }^{173}$ Einzelbelege dafür bieten verschiedene Nachrufe und Biographien, z.B. Louis Feist, Was war er uns und was bleibt er uns?, Frankfurt/M. 1914, S. 12f; über einen weiteren Teilhaber der Metallhandelsfirma Beer, Sondheimer \& Co.: Isaak Leopold Beer $\uparrow$, in: Frankfurter Kleine Presse 9. Dez. 1908; Stadtarchiv Frankfurt Firmengschichten S 3/R 2779: Beer, Sondheimer \& Co.

Zu Ludo Mayer, „Offenbachs gröBtem Wohltäter“: Reinhold Ruhr, Offenbacher Lebensbilder 26. Ludo Mayer, in: Offenbacher Volkszeitung 23.7.1923 und oben Anm. 167.

Zu Leo Ellinger: Siehe oben Anm. 113; über die Stiftungen in Frankfurt insgesamt: Bruno Müller, Stiftungen in Frankfurt am Main, Frankfurt am Main 1958; auf die große Zahl und die religiösen und sozialethischen Wurzeln jüdischer Wohltätigkeit weist hin Arno Lustiger, Einfuihrung, in: Lustiger (Hg.), Stiftungen, S. 8f. 
die „pädagogische Leidenschaft" eines Wilhelm Merton und seinen Einsatz für die Gründung der in Deutschland singulären Erscheinung einer Stiftungsuniversität in Frankfurt, die Umwandlung und Einbringung der Schleifmittel- und Schleifmaschinenfabrik Naxos-Union in die "Dr-Arthur-Pfungst-Stiftung“ zur Förderung der Volksbildung oder die für Deutschland ebenfalls ungewöhnliche Stiftung einer öffentlichen Bibliothek durch eine Angehörige der Bankiersfamilie Rothschild in Frankfurt ${ }^{174}$.

\subsection{Die Konfessionszugehörigkeit der Firmengründer nach Städten}

Mit knapp 62\% entspricht der Anteil der evangelischen Firmengründer in Frankfurt im wesentlichen dem der Evangelischen an der $\mathrm{Ge}$ samtbevölkerung dieser Stadt. Die Katholiken sind mit 16,3\% bei den Firmengründern beinahe um die Hälfte unterrepräsentiert, während die Israeliten mit $21,7 \%$ bei weitem ihre Quote sowohl an der Gesamtbevölkerung Frankfurts als auch an der der Firmengründer übertreffen $^{175}$. Soweit jüdische Firmengründer unter den 250 Unternehmern einbegriffen sind, konzentrieren sie sich daher zu gut zwei Drittel auf Frankfurt, dessen jüdische Gemeinde wiederum erheblich über dem Durchschnitt der umliegenden Städte und des umliegenden Landes lag.

Bei Frankfurt wird aber auch bereits eine Erscheinung sichtbar, der in allen Städten mit einer ursprünglich evangelischen Bevölkerungsmehrheit nahezu alle katholischen Firmengründer unterworfen waren: Die Katholiken sind fast durchwegs erst mit dem Firmengründer in

${ }^{174} \mathrm{Zu}$ den jüdischen Stiftungen in Frankfurt allgemein siehe: Lustiger (Hg.), Stiftungen.

Zu Wilhelm Merton: Achinger, Merton, S. 108f., 244f., 286f., 291; Paul Kluke, Die Stiftungsuniversität Frankfurt am Main 1914-1932, Frankfurt am Main 1972, S. 32-35; Siegbert Wölf, Wilhelm Merton, in: Lustiger (Hg.), Stiftungen, S. 555560.

Zu Atthur Pfungst: Müller, Stiftungen, S. 152; Lustiger (Hg.), Stiftungen, S. 63ff.

Zu Rothschild: Die Rothschild'sche Bibliothek in Frankfurt am Main. Hg. von der Gesellschaft der Freunde der Stadt- und Universitätsbibliothek in Frankfurt am Main, Frankfurt am Main 1988.

${ }^{175}$ Für diese und die folgenden Zahlen siehe bitte Tabelle Anlage 8: Die Konfessionszugehörigkeit von 250 Firmengründern einiger Städte des Rhein-Main-Gebiets 1815-1914; nach Dietrich Andernacht, Eleonore Sperling, Dokumente zur Geschichte der Frankfurter Juden 1953-1945, Frankfurt am Main 1963, S. 179 betrug 1954 der Anteil der Juden in den bedeutendsten Wirtschaftszweigen Frankfurts (also nicht nur in der Industrie) im Durchschnitt 35 Prozent. 
diese Städte zugewandert. Zum Teil gilt dies auch für die Juden, ohne da $ß$ es allerdings deren Prozentanteil an der Gesamtunternehmerschaft negativ beeinflußt hat.

Einen bedeutenden Überschuß der protestantischen Firmengründer mit 75,9\% gegenüber der Quote der Protestanten an der Gesamtbevölkerung weist Offenbach auf. Die katholischen Firmengründer bleiben mit 14,8\% unter der Hälfte ihres Anteils an der Gesamteinwohnerschaft, doch könnte deren Anteil als Folge der Teilverlagerung der Lederwarenindustrie in das gebietsweise mehrheitlich katholische Umland in der Zwischenkriegszeit ansteigen ${ }^{176}$. Ein Anstieg des Anteils von 7,4\% ist auch bei den Juden zu erwarten, für die speziell auf dem Schuh- und Ledersektor noch Beispiele beigebracht werden könnten.

Eine Besonderheit unter den erfaßten Städten des Rhein-MainGebiets stellt in seiner konfessionellen Zusammensetzung Mainz dar. Die alte Bischofsstadt ist die einzige mit einer katholischen Bevölkerungsmehrheit. Dieser katholischen Bevölkerungsmehrheit in Mainz entspricht nach dem vorliegenden Material allerdings keine Mehrheit katholischer Firmengründer. Katholische und evangelische Firmengründer halten sich vielmehr neben den Juden mit je 15 Personen genau die Waage. Der hohe Anteil evangelischer Firmengründer in Mainz geht dabei - wiederum in genauer Umkehrung zu den sonstigen Städten des Rhein-Main-Gebiets - mit einer einzigen Ausnahme auf das Konto zugewanderter Firmengründer. Diese hohe Zuwanderungsquote evangelischer Firmengründer bewirkte, daß selbst in der Stadt, in der nach der Konfessionsstruktur am ehesten ein numerisches Übergewicht katholischer Industrieller zu erwarten gewesen wäre, dies nicht der Fall war. Das gewerbliche, handwerkliche und handeltreibende Wirtschaftsbürgertum der Stadt Mainz selbst ohne die Rheinufervororte dürfte jedoch überwiegend katholisch gewesen sein.

Ein klares Übergewicht evangelischer Firmengründer im Verhältnis zu ihrer an sich schon hohen protestantischen Einwohnerzahl ist bei Darmstadt zu konstatieren.

Ähnlich hohe Prozentsätze evangelischer Industriegründer weisen Hanau und Wiesbaden auf, wobei diese bei Wiesbaden sogar hundert Prozent erreichen, Es sind dies Städte mit einer evangelischen Bevöl-

${ }^{176} \mathrm{KlöB}$, Heimarbeit, S. 14ff; Ellen Schneider, Die Stadt Offenbach am Main im Frankfurter Raum. Ein Beitrag zum Problem benachbarter Städte (Rheinmainische Forschungen 52), Frankfurt am Main 1962, S. 86ff. 
kerungsmehrheit, doch ist bei ihnen wegen der geringen Basiszahl eine Verallgemeinenung kaum statthaft.

Diese Vorsicht vor einer Verallgemeinerung gilt in gewissem Sinne auch für Worms. Die Konfessionstruktur dieser von der Stadtverfassung und Bevölkerungsmehrheit her ehemaligen lutherischen Reichsstadt war bereits am Ende des alten Reiches insofern kompliziert, als sich schon damals ein Drittel der Gesamtbevölkerung zur reformierten, zum katholischen und zum mosaischen Glauben bekannt hat. Dieser Ausgangslage und dem Wandel von Bevölkerungs-, Konfessions- und Sozialstruktur in der französischen und der hessischen Zeit scheint die konfessionelle Spaltung der führenden Wormser IndustrieUntemehmerfamilien im 19. Jahrhundert zu entsprechen. Die (von) Heyl und die (von) Schoen waren wie die Martenstein protestantisch, teilweise ursprünglich reformiert, die Valckenberg, Doerr und Reinhart waren genauso wie der Filter- und Abfüllapparatefabrikant Lorenz Adalbert Enzinger (1849-1897) katholisch. Dazu kamen entsprechend der relativ großen. Wormser jüdischen Gemeinde noch israelitische Unternehmer wie z.B. der Konfektionskleiderfabrikant Marcus Edinger (1819-1879) und der Lederfabrikant Ludwig Melas (geb. 1810). Herkunft, Erziehung und wohl auch die durch die örtliche Konfessionsstruktur verfestigten Glaubensüberzeugungen haben offensichtlich dazu beigetragen, daß bei beiden christlichen Konfessionen durchaus von ihrem Glauben durchdrungene Persönlichkeiten wirkten, so zum Beispiel auf katholischer Seite Wilhelm Joseph Dieudonnée Valckenberg (1844-1914) und auf protestantischer Seite Cornelius Wilhelm Freiherr Heyl zu Herrnsheim (1843-1923). Sein Lebensweg und sein sozialpolitisches und politisches Wirken als langjähriges nationalliberales Mitglied des Reichstags sind ohne seine an der Herrnhuter Knabenanstalt in Neuwied empfangene Prägung kaum verständlich ${ }^{17}$.

${ }^{177}$ Zum Stand und Wandel von Bevölkerungs-, Konfessions- und Sozialstruktur seit Ende des alten Reiches in Worms siehe: Kühn, Wandel, S. 11-18, insbes. S. 14, S. 69-102.

Zu Valckenberg: DGB 64 (1929), S. 259; Beerdigung des Geh. Kommerzienrats Valckenberg, in: Wormser Zeitung 1. Okt. 1914.

Zu Heyl: Kriegbaum, Tätigkeit, S. 16ff.

$\mathrm{Zu}$ Edinger, Enzinger und Melas: Siehe oben Anm. 149. 


\subsection{Der Konfessionswechsel}

Ein Hauptproblem der Erfassung des Glaubensbekenntnisses der Firmengründer stellen die Konversionen und Kirchenaustritte dar. Sie lassen bereits im konfessionsstatistischen Ansatz, der ja an sich nichts aussagt über die Beweggründe dieser Glaubensübertritte, nicht nur das Ausmaß des Konfessionswechsels erkennen, sondern zeigen auch an, welche Religionsgemeinschaften bei diesen Konversionen bevorzugt wurden und von welchen man sich in erster Linie abwandte.

Der Entschluß zu diesen Konversionen war bei den erfaßten Personen, soweit er erkennbar ist, beinahe generell ein Akt der Anpassung. Typisch für den Versuch der Assimilierung durch konfessionelle Anpassung an die Religion der Mehrheit der Angehörigen der politischwirtschaftlichen Führungsschicht in Deutschland sind vor allem die Übertritte mancher jüdischer Großindustrieller zum Protestantismus. Dies trifft zu zum Beispiel für die Gebrüder Friedrich von Gans (1833-1920) und Leo Gans (1843-1935) und von Weinberg von der Firma Cassella in Frankfurt oder für Wilhelm Merton von der Metallgesellschaft. Thre Namen repräsentieren Familien, die nobilitiert oder nichtnobilitiert auch in ihrem zum Teil hochadeligen Konnubium in einem bewußten Assimilierungsvorgang um die gesellschaftliche Amalgamierung bemüht waren ${ }^{178}$. Milieuanpassungen im engeren Sinne als Folge des unmittelbaren Zusammenlebens mit einer weit überwiegend mehrheitlich evangelischen Bevölkerung in fast allen rhein-mainischen Städten waren besonders auch die katholischen Firmengründer und ihre Nachkommen unterworfen. Gerade bei ihnen kann man nicht selten von einem Hinübergleiten von einer Konfession in die andere, zum Teil im Gefolge von konfessionellen Mischehen sprechen $^{179}$. Eine ansonst nicht selten festzustellende stärkere Kirchen-

${ }^{178} \mathrm{Zu}$ Gans: Vgl. auch oben Anm. 13 und Gothaisches Genealogisches Taschenbuch, Alter und Briefadel 25 (1931), S. 197-199.

Zu Weinberg: Reichshandbuch der Gesellschaft, 2. Bd., Berlin 1931, S. 2006; Gotha, Teil B 24 (1932), S. 659f. und Gotha, Briefadel 4 (1910), S. 882f.

Zu Merton: Achinger, Merton, S. 248 und 323f.; Auerbach, Jews, S. 196, Anm. 6. Über allgemeine Gründe der Assimilation: Felix A. Theilhaber, Der Untergang der deutschen Juden, München 1911, S. 88ff.

${ }^{179}$ So sind z.B. die ursprünglich katholischen Untemehmerfamilien Neubecker in Offenbach oder Albert in Wiesbaden-Biebrich evangelisch geworden. Der in konfessioneller Mischehe verheiratete und katholisch getaufte Offenbacher Taschenbügel- und Metallwarenfabrikant Adam Philipp Bender (1827-1901) starb als Mitglied des evangelischen Kirchengemeinderates, während der mit einer Pasto- 
treue der Katholiken läßt sich unter den erfaßten Unternehmern jedenfalls nicht fassen. Ihr Katholizismus mag zudem durch das konfessionell vorwiegend im Protestantismus und wirtschaftsethisch im Individualismus und Fortschrittsglauben verwurzelte Selbstverständnis des liberalen, politisch eher preußenorientierten Bürgertums paralysiert worden sein.

Bürgerliches Emanzipationsstreben, Kampf gegen Ultramontanismus, liberales und freigeistiges Gedankengut und nationalkirchliche Reminiszenzen sowie eine allgemeine Oppositionsstimmung mehr politischer Natur waren die Ursachen der 1845 einsetzenden deutschkatholischen Bewegung. Sie fand ihren süddeutschen Schwerpunkt im frühindustrialisierten und wohl auch bereits stärker säkularisierten Offenbach und wurde besonders vom dortigen Wirtschafts- und Bildungsbürgertum getragen. Die Offenbacher katholische Unternehmerfamilie Pirazzi spielte bei der Gründung dieser Gemeinde eine führende Rolle. Zu ihr gingen aber auch evangelische Unternehmer über, wie zum Beispiel der Offenbacher Seifen- und Parfumeriefabrikant Johann Martin Kappus (1820-1905) ${ }^{180}$.

Ähnlich wechselten zu den zeitlich später aufkommenden Freireligiösen, die einen Teil ihrer Anhänger wiederum unter den Deutschkatholiken fanden, einzelne, auch evangelische Firmengründer über, wie zum Beispiel die Gründer der Frankfurter Torpedowerke Heinrich Weil (1863-1929) und Peter Weil (1866-1911) ${ }^{181}$. Diese Konversionen weg von den alten christlichen Konfessionen sind allerdings nicht allein typisch für die Unternehmer, sie sind ein Hinweis auf die durch eine emeuerte Pastoraltheologie und Volksseelsorge nur verzögerte, ingesamt aber langfristige Erosion der hergebrachten religiösen Bindungen ${ }^{182}$.

rentochter verheiratete Offenbacher Lederfabrikant und ehemalige Jesuitenzögling Felix Becker (1866-1921) zu den Freireligiösen überwechselte.

${ }^{180}$ Emil Pirazzi, Die Gründung der deutschkatholischen Gemeinde in Offenbach am Main. Eine Festschrift zur ersten Halbjahthundertfeier ihres Bestehens, Offenbach am Main 1895, S. Iff;; G. Maron, Artikel Deutschkatholizismus, in: Religion in Geschichte und Gegenwart, 2. Bd., Tübingen 3. Aufl. 1958, Sp. 112f; Erich Winckelmann, Beiträge zur evangelischen Kirchengeschichte der Stadt Offenbach am Main 1. Bd. 1734-1848 (Offenbacher Geschichtsblätter 8), Offenbach am Main 1958 , S. $33 \mathrm{ff}$.

${ }^{181}$ Stadtarchiv Frankfurt, Einwohnermeldekartei Peter und Heinrich Weil; evangel. Pfarramt Frankfurt-Rödelheim Trauungen 1860: Weil-Engel.

${ }_{182}$ Hermann Dechent, Kirchengeschichte von Frankfurt am Main seit der Reformation 2. Bd., Leipzig, Frankfurt 1929, S. 268 und 426, beschreibt diesen Erosionsprozeß, 
Es hat allerdings den Anschein, daß sich gegen Ende des Jahrhunderts im Zuge der allgemeinen Retardierung der bürgerlichen Emanzipation in Deutschland, besonders in großbürgerlichen Kreisen ein neuer kirchlicher Geist in dem Sinne entwickelt hat, daß den Kirchen eine wesentliche Funktion als Ordnungsmacht und Faktor der sittlichen Erziehung zukomme.

Eine Sonderstellung nehmen die Reformierten ein. Soweit reformierte Kirchengemeinden im Rhein-Main-Gebiet die Unionsbestrebungen im deutschen Protestantismus in der ersten Hälfte des 19. Jahrhunderts überdauerten, hat nämlich die kleine elitäre Gruppe der Französisch-Reformierten mit ihrem hohen Anteil wirtschaftlich und gesellschaftlich arrivierter Mitglieder eine nicht zu übersehende Anziehungskraft auf wirtschaftlich erfolgreiche Personen, besonders Lutheraner ausgeübt. So traten zum Beispiel der offenbar französischreformierten Gemeinde bei: der Metallwarenfabrikant Ludwig Nicolaus Hector Becker (geb. 1841), der durch Einheirat Teilhaber der Seifenfabrik C. Naumann gewordene Heinrich Theodor Mohr (18221901) und Lorenz Lauer (1879-1937), der Schwiegersohn des Maschinenfabrikanten Friedrich Schmaltz (1854-1932) ${ }^{183}$. In der Regel bestätigen aber diese meist im Zusammenhang mit Heiraten erfolgten Übertritte eher das Nachlassen religiös motivierter Konversionen und der prägenden Kraft der Dogmen auf die Lebensgestaltung im 19. Jahrhundert.

Gleichzeitig liegt aber die Bedeutung des Ergebnisses dieses Abschnitts darin, daß die Konfessionsstatistik eine eindeutige Gewichtung der Verteilung der protestantischen, katholischen und jüdischen Firmengründer auf die einzelnen Industriezweige ergeben hat. Es läßt auch für die Unternehmer des 19. Jahrhunderts und hier wiederum vornehmlich dessen zweiter "säkularisierteren" Hälfte, die formende Kraft des Elternhauses und religiöser Unterweisung auf die praktische Lebensgestaltung erkennen.

${ }^{183}$ Französ.-reform. Kirchengemeinde Offenbach Familienbuch 1698-1872, Nr. 88, 634 und $1872 \mathrm{ff}$., Nr. 1310. 
Liste der in der Konfessionsstatistik zasătzlich ausgewerteten 75 Firmengründer des Rhein-Main-Gebiets 1815-1914

Name (mit Lebensdaten)

Adler, Friedrich (geb. 1888)

Adlaer, Lothar (geb.1887)

Alter, Johann Justus Ludwig (1847-1908)

Bader, Johann Christian (1802-1867)

Becdker, Ludwig Niccolaus Hector (geb. 1841)

Behrens, Heinrich (1830-1915)

Blumenthal, Heinrich (1824-1901)

Braun, Matthäus (geb. 1882)

Busch, Adolf Ludwig (1811-1888)

Collet, Anton Joseph (1830-1885)

Colshom, Gustav (1847-1892)

Cunz, Peter Wilhelm (1869-1951)

Dalquen, Jacob Martin (81859-1931)

Dinckels, Peter Franz Hubert (1838-1923)

Disch, Hubert Anton (1821-1891)

Eickemeyer, Carl (1813-1880)

Elster, Siegmar (1823-1891)

Enzinger, Lorenz Adalbert (1849-1897)

Faulstroh, Jakob (1860-1920)

Feist, Leopold und Brüder

Feistmann, Joseph (geb. 1825)

Findeisen, Oskar (geb. 1876)

Fredenhagen, Wilhelm (1843-1924)

Glïckert, Jakob (1815-1881)

Gräb, Johamn (1867-1929)
Ont

Erankfurt a.M.

Frankfurt a.M.

Darmstadt

Frankfiut a.M

Offenbach a.M

Offenbach a.M

Darmastadt

Frankfurt a.M

Mainz

Offenbach a.M

Frankfurt a.M.

Frankfurt a.M

Frankfunt a.M.

Mainz

Mainz

Mainz

Mainz

Worms

Groß-Gerau

Frankfurt a.M

Offenbach a.M.

Darmstadt

Offenbach a.M.

Darmstadt.

Darmstadt
Firmenname (Kurzname)

J. \& C. A. Sctmeider Schrohfabriken

J. \& C.A. Schneider Schubfabriken

Möbelfabrik Ludwig Alter

Bauer'sche SchriftgieBere

Metallwaren-umd Armaturenfabrik

Schuhfabr. Leanderwerke (vorm. K. Ochsenhirt

\& Betrrens)

Maschinenfabrik Blumenthal, Terrain. \& Bauges. Mitteldeutsche Kühlerfabr. Teves \& Braun

Metallwarenfabrik Louis Busch

Werkzeugmaschinenfabr. Cellet \& Cengethard

Schraubenfabrik Gustav Colshom

Schritgießerei D. Stempel

I.M. Dalquen, Eisenkomstruktionen f. Schaltanlagen

Rhein. Maschinen u. Apparatebau-Anst.

P.Dinckels

Holzzellstoffabrik, Reeder, GroBkaufmann

Sektkellerei C. Eickemeyer

Gasmesseffabrik Mainz Elster \& Co.

Fabrik fir Filter u. Abfullapparate

Preß- u. Stanzwerk Jak. Faulstroh

Feist-Belmont'sche Sektkellerei

Handschuhfabr. v. Lederwerke J. Mayer \& Solm MODAG Motorenfabrik Darmstadt GmbB

Maschinenfabr. u. Eisengießerei Fredenhagen

Mōbelfabrik J. Glückert

MODAG Motorenfabrik Darmstadt GmbH 
Haege, Ludwig (Louis) (geb. 1847)

Hanss, Balthasar Karl (1807-1880)

Heim, Wilhelm Ferdinand (1822-1887)

Helfmann, Joham Philipp (1843-1899)

Helfmann, Balthasar Johamn (1847-1896)

Herz, Otto

Hesse, Konrad (1868-1931)

Hilge, Peter Jakob (1832-1891)

Hochschild, Zachary (1854-1912)

Hoehl, Bemhard (1834-19219

Hoenh, Philipp Carl (1835-1897)

Holmann, Johann Philipp (1805-1870)

Huppe, Johamn Georg (1814-1871)

Kalkbrenner, Christian (1857-1924)

Klimsch, Ferdinand Karl (1812-1890)

Kach, August (geb. 1867)

Lauteren, Clemens Friedr. Aug (1786-1877)

Lehmann, hermann (1818-1877)

Liebmann, Emil

Mappes, Johann Conrad (1786-1869)

May, Friedrich (1875-1939)

Mayer, Isaak Juliua (1817-1887)

Melas, Ludwig (geb. 1810)

Mertz, Georg Christian Heinr. (geb. 1854)

Merz, Fritz Karl Julius (1879-1954)

Merz, Georg (1881-1946)

Metzger, Christian (1826-1909)

Millex, Friedrich (1832-1892)
Offenbach a.M

Mainz

Offenbach a.M

Frankfurt, 1924 Essen

Frankfurt, 1924 Essen

Mainz, 1871 Frankf.

Darmstadt

Mainz

Frankfurt a.M

Geisenheim/Rheing

Geisenheim/Rheing

Frankfurt a.M

Offenbach a.M

Wiesbaden

Frankfurt a.M

Darmstadt

Mainz

Offenbach a.M

Offenbach a.M.

Mainz

Darmstadt

Offenbach a.M

Worms

Mainz

Frankf.-Rödetheim

Frankf-Rödelheim

Homburg v.d.H

Frankfurt a.M
Metallwareafabrik Ludwig Haege

Metallwarenfabrik Witheim Harms

Maschinenfabrik Withelm Ferdinand Heim

Bauunternimn. Hochtief, vorm Gebr. Helfmann

Bauuntemebm. Hochtief, vorm Gebr. Helfmann

Schuhwarenfabrik S. Wolf

Hessenwerke Elektrotechn. u. Maschinenfabrik

GieBerei, Purmpen, Kellerei-Masch.fbr. Ph. Hilge Metallgesellschaft.

Sektkellerei Gebr. Hoen]

Sektkellerei Gebr. Hoehl

Bauunternehmung Philipp Holzmann

Taschenbügel- u. Metallwarenfbr. Huppe \&

Bender

Maschinenfbr. C. Kalbrenner (Masch.fbr.Wiesb.Dotheim)

Lithograph. Anstalt F.C. Klimsch

MODAG Motorenfabrik Darmstadt $\mathrm{GmbH}$

Sektkellerei Lauteren, Mappes \& Dael (C. Laute ren \& S.)

Portefeuille- und Gürtelwarenfbr. H. Lehmamn

Schuhfabrik Hassia

Sektkellerei Lauteren, Mappes \& Dael

Motorenfabrik Darmstadt Gmb

Lederwerke J. Mayer \& Sohn

Lederwarenfabrik Melas \& Gemsheim

Wemer \& Mertz Erdalwerke (Wactsw.-

Schuhcreme)

Metallwarenfabrik Gebr. Merz

Metallwarenfabrik Gebr. Mer

Masch.fbr. u. Eisengießerei Chr. Metzger

Weber \& Miller EisengieB. (Msch.fbr. Moenus) 
Moser, Samuel (1849-1917)

Nathan, Richard (geb. 1873)

Nathan, Wilhelm (geb. 1875)

Nube, Kurt Karl Albert (1858-1925)

Posen, Eduard Firsch (1792-1853)

Racke, Adam Josef

Remmler, Georg August Wilh. (1865-1921)

Rochow, Karl Friedr. Gustav (1844-1916)

Rodberg, Theodor (1815-1884)

RöBlex, karl (1788-1863)

Rousselet, Daniel

Schanz, Adam (1843-1914)

Schanffe, August (1826-1884)

Scherer, Georg Martin (1805-1874)

Schweickardt, Josef Ignaz (1811-1858)

Speier, Isaak, gen. Julius (1854-1923)

Trier, Joseph (1816-1865)

Weinberg, Bemhard Otto (1815-1877)

Weismüller, Emmerich Gustav Adolf (1837-1909)

Weismüller, Peter Franz (1842-1926)

Wiesche, Jakob Ludwig (1833-1899)

Wolf, Simon
Frankfurt a.M

Frankfurt a.M

Frankfurt a.M

Offenbach a.M.

Offenbach a..M

Bingen

Frankfurt a.M

Offenbach a.M

Darmstadt

Hanau

Friedrichsdorf/Ts

Erankfurt a.M

Frankfurt a.M.

Langen

Hochheim am Main

Frankfurt a.M

Darmstadt

Frankf.-Fechenheim

Frankf.-Bockenheim

Frankf.-Bockenheim

Frankfurt a.M.

Mainz
Fbr. Landwirtschaftl. u. gewerbl. Maschinen Ada-Ada-Schuhfabrik

Ada-Ada-Schubfabrik

Maschinenfabrik Kurt Nube

Portfeuillefabrik Echuard Posen

Essigfabrik, Weinbremerei A Racke

Lamperfabrik Bünte \& Remmier

Dampfkesselfbr. u. Apparatebauanst. G. Rochow

Damptkesselfabrik vorm Arthur Rodberg

RöBler'sche Hutfabrik

Hutfabrik L.F. Rousselet

Stahlbau-Schanz, Schanz-Metallbau

Masch.fbr., Eisengieß., Hebez. Wiesche \&

Scharffe

Weinbrennerei, Likörfabr. Kelterei Scherer

Sektkellerei Burgeff \& Schweickardt

Hako-Schuh-Ag, ehemals J. Sooeier AG

Möbelfabrik Joseph Trier, Hofmöbelhandlung

Cassella Farbwerke Mainkur

Maschimenfabrik Gebr. Weismüller

Maschinenfabrik Gebr. Weismüller

Masch fbr., EisengieB., Hebez Wiesche \&

Scharffe

Schuhwarenfabrik $S$. Wolf 
Name (mit Lebersiaten)

Albert, Eugen Josef (1830-1879)

Albert, Heinrich (1835-1908)

Albert, Kurt Theodor (1881-1945)

Andreae, Alhard (1861-1916)

Asbach, Hugo Johann (1868-1935)

Avenarius, Emst A. Richard (1840-1917)

Baist, Ludwig Withelm K. (1825-1899)

de Barry, Christian Julius (1809-1877)

Bauer, Wilhelm Friedrich (1881-1961)

Beck, Ludwig (1841-1918)

Beck, Theodor (1839-1917)

Becker, Gerhard Felix (1866-1921)

Becker, Eronst Hermann Maria (1872-1949)

Beer, Isaak Leopold (1836-1908)

Bender, Adam Philipp (1827-1901)

Bettethäuser, Friedr. Carl (1801-1880)

Boehm, Gustav (1827-1900)

Boehringer, Albert (1861-1939)

Botm, Johann Vizenz (1824- )

Braun, Wunibald (1839-1912)

Breuer, Hermann Josef Maria (1848-1905)

Brönner, Franz Julius (1823-1888)

Brüning Johannes (1823-1897)

Brüning, Johann Adoif (von) 1837-1884)

Bünte, Karl Victor (1853-1913)

Burgeff, Carl (1813-1871)
Ont

Mainz-Amöneburg/Biebrich

Mainz-Amöneburg/Biehrich

Mainz-Amõneburg/Biebrich

Frankfurt ama Main

Rüdesheim.

Gau-Algesheim.

Frankfurt-Griesheim

Offenbach am Main

Offenbach-Bieber

Wiesbaden-Biebrich

Darmstadt

Offenbach-Bürgel

Offenbach-Bürgel

Frankfiurt am Main

Frankfurt a.M

Mainz

Offenbach/M

Ingelheim/Rhein

Geisenbeim/Rhein

Frankfurt 2.M

Frankfurt-Hoechst

Frankfurt a.M.

Langendiebach/Hanan

Frankfurt-Hoechst

Frankfurt a.M

Hocbheim/Rhein
Firma (Kurzname)

Chemische Werke vorm. H \&E. Albert Chermische Werke vorm H. \&E. Albert Cherrische Fabriken Dr. Kurt Albert.

Maschinenfabrik Moenus

Weinbremerei Asbach.

Chemische Fabrik Avenarius

Chemische Fabrik Griesheim-Elektron

Maschinenfabrik de Barry (voht. J. Houben)

Lederwaren- und Reiseartikelfabrik

Eisengießerei und Maschinenfabrik

Maschinenfabrik Kleyer \& Beck

Lederwerke Becker \& Co.

Lederwerke Becker \& Co

Beer, Scondheimer \& Co. (Metallihandel und -produktion)

Taschenbügel- u. Metallwarenfabr. Ruppe \& Bender

Lederfabrik C. Bettelhäuser (dann R. Inm)

Toilettenseifen - u. Parfumeriefabr. Boehm

Chemische Fabrik C.H. Boehringer Sohn

Druckmaschinenfabrik Johamnisberg

Hartmann \& Braun, MeB-u. Regeltechnik

Werkzeugmaschinen-.u. Armaturenfabrik

Chemische Fabrik Franz Julius Brönner

Zigarrenkisten- u. Zigarrenwickelformenfbt.

Farbwerke Hoechst

Lampenfabrik Bünte \& Remmier

Sektkellerei Burgeff \& Co. 
Deines, Peter (1793-1866)

Deines, Karl Konrad Chr. (1808-1880)

Dietze, Christian Heinrich (1835-1874)

Dietze, Emst Hermann (1837-1917)

Doerr Johamn Baptist (1811-1892)

Donges, Georg Theodor (1843-1924)

Dyckerhoff, Wilhelm Gustav (1805-1894)

Dyckethoff, Gustav Wilhelm W. (1838-1923)

Dyckeshoff, Rudolf Philipp W. (1842-1917)

Dyckechoff, Eugen Julius R. (1844-1924)

Ellenberger, Gustav Emil (1834-1885)

Ellinger, Leo (1852-1916)

Engelhard, Otto (1838-1926)

Engelhard, Karl Philipp (1836-1924)

Eulex, Wilhelm Julius (1847-1934)

Faber, Christian Ludwig E. (1841-1896)

Feist, Lonis (1857-1913)

Fellher, Joham Christian (1851-1920)

Flinach, Heimich Friedr. G. (1802-1865)

Fresenius, Johann Eduard (1874-1946)

Fries, Johamn Simon (1777-1835)

Fuld, Harry Herz S. (1879-1932)

Gandenberger, Johann Peter (1804-1869)

Gans, Friedrich I ludwig (von) (1833-1920)

Gans, Leo Ludwig (1843-1935)

Gasteil, Joseph (1785-1852)

Goebel, Joham Georg (1830-1900)

Haas, Joham Emil (1834-1904)

Haeffiner, Adolf Jacob (1862-1947)

Hartmann, Wilhelm Eugen (1853-1915)

Hartmann, Friedrich August A. (1855-1925)
Hanau

Hanau

Mainz-Mombach

Mainz-Mombach

Worms

Darmstadt

Mz-Amöneburg

Mz-Amöneburg

Mz Amöneburg

Wiesbaden-Biebrich

Darmstadt

Frankfurt a.M

Offenbach/M

Frankfurt a.M.

Bensheim

Offenbach $/ M$

Frankfirt a.M.

Frankfurt-Bockenh.

Frankfurt a $M$

Frkf, damn B.Homburg

Frankfurt a.M

Frankfurt a.M

Darmstadt

Frankf.-Fechenheim

Frankf.-Fechenheim

Mainz(-Mombach)

Darmstadt

Mainz

Frankfurt a.M

Frankfurt a.M

Offenbach $/ \mathrm{M}$
Bijouteriefabrik Peter Deines

Zigarrenkisten- u.Wickelformenfabrik

Verein für chemische Industrie

Verein für chemische Industrie

Lederwerke Doerr \& Reimhant

Danges Stahlbau

Portland-Zement-Fabr. Dyckerhoff \& Sähne

Portland-Zement-Fabr. Dyckemoff \& Söhne

Portland-Zement-Fabr. Dyckenoff \& Söhne

Dyckenoff \& Widmann Zementwarenfabr.

u. Bauuntem.

Maschinenfabrik Venuleth \& Ellenberger

Metallgesellschaf

Werkzeugmaschinenfabrik Collet \& Engelhard

Fabrik pharmazeutischer Fabrikate K. Engelhard

Papierfabrik W. Euler

Druckmasctinenfabrik Faberr \& Schleicher

Beer, Sondheimer \& Co. (Metallhandel u, prod.)

Maschin. fbr. u. Apparatebau Fellner \& Ziegler

Schriftgießerei Flinsch

Chem. Pharm. Industrie Dr. E. Fresenius.

Stahlhoch-, Maschinenbau usw. J.S. Fries

Telefonbau u. Nomalzeit Letmer \& Co.

Gandenberger'sche Maschinenfbr. G. Goebel

Cassella Farbwerke Mainkur

Cassella Farbwerke Mainkur

Waggonfabrik Gebr. Gastell

Gandenberger'sche Maschinenfbr. G. Goebel

Gasmesserfabrik Mainz Elster \& Co.

Elektrotectm. Fabrik Voigt \& Haeffner

Hartmann \& Braun, MeB- u. Regeltechnik

Maschinenfabrik Hartmann 
Hartmann, Withelm Johann G. (1858-1925)

Hartmann, Joham Georg (1870-1954)

Hauser, Alberg (1884- )

Heim, Johamnes (1786-1844)

Henkell, Adam (1801-1866)

Heraeus, Wilhelm Carl (1827-1904)

Hesse, Peter Hubert (1826-1908)

Hesse, Theodor (1828-1901)

Heyl, Jdhamn Comelius (1792-1858)

Heyne, Christoph Friedr. Emst (1841-1915)

Heyne, Georg Johann (1844-1908)

Hill, Ludwig August (1816-1893)

Hinkel, Emst Philipp (1829-1894)

Hofruann, Johann Heinrich (1830-1880)

Ihm, Christ. Friedr. Rudolf (1833-1911)

Jacobi, Johamn August (1811-1891)

Kalkhof, Johames Jul Ernst (1884-1949)

Kalle, Jakob Friedrich (1837-1915)

Kalle, Paul Withelm (1838-1921)

Kappus, Johamn Martin (1820-1905)

Klein, Johames (1819-1896)

Kleyer, Withelm (1822-1879)

Kleyer, Heinich Ludwig (1853-1932)

Kling, Franz (1841-1908)

KlingsporChrist. Karl Julis (1868-1950)

Knapp, Wilhelm Karl (1870-1948)

Koch, Johannes Friedr. Ludwig (1786-1865)

Kaepp, Rudolph (1830-1897)

Krug, Carl Oskar (1881- )

Krumm, Ludwig Friedrich (1827-1886)

Kupferberg, Christ. Adalberg (1824-1876)

Kupferberg, Florian (1858-1921)
Offenbach $/ \mathrm{M}$

Frankfurt a.M

Frkf., dann Oberursel

Offenbach/M

Mainz (Ws.-Biebrich)

Hanau

Frkf.-Hedeemheim

FIkf-Eleddembeim

Worms

Offenbach/M

Offenbacts $/ M$

Offenb aca $M$

Offenbach $/ \mathrm{m}$.

Offenbach/M

Mainz

Darmstadt

Mainz

Wiesb.-Biebrich

Wiesb.-Biebrich

Offenbach/M.

Geiserheim/Rhein

Darmstadt

Frankfurt a.M.

Hanau

Offenbact $/ \mathrm{M}$

Frankfurt a.M

Oppenheim/Rhein

Oestrich/Rheingau

Frankfurt a.M

Offenbach $/ M$

Mainz

Budenheim b. Mainz
Maschinenfabrik Hartmann

Bauer'sche Schriftgießerei (gegr. 1838), EMDA

Fabrik für Meß- u. Kontrollinstrumente

Maschinenfabrik Johames Heim

Sektkellerei Herkell

Platinschmelze W.C. Heraeus

Heddembeimer Kuperwerke vorm. F.A. Hesse S.

Heddemheimer Kuperwerke vorm. F.A. Hesse S.

Lederwerke Comelius Heyl

Spezialfabr. f. Drehteile, Schrauben usw.

Spezialfabr. F. Drehteile, Schrauben usw.

Buntpapierfabrik J.B.Weber (gegr. 1825-30)

Gürtlerwarenfabrik Ernst Philipp Hinkel

Lederwarenfabrik Joh. Heinrich Hofmann

Fabr-gefärbter Leder (vorm. C. Bettelhäuser)

Seidenfabrik August Jacobi

Schellackbleiche, Chem. Fabrik

Chemische Fabrik Kalle

Chemische Fabrik Kalle

Seifen-u. Parafämeriefabrik M. Kappus

Druckmaschinenfabrik Johannisberg

Maschinenfabr. W. Kleyer, dann Kleyer \& Beck

Adler Fahrrad- (Auto-, Sctreibmasch-) werke

Kling-Fumier-Werk

Druckgireßerei Gebr. Klingspor (vorm. Rudhard)

G. Schanzenbach, Elektro-u. lichttechn. Fbr.

Chinin-Fabrik Koch

Chemische Fabrik Rudolph Koepp

Diskus-Werke Flachschleifmaschinenfabrik

Ludwig Krumm Gold-Pfeil-Lederwaren

Sektkellerei Christ. Adalb. Kupferberg

Glashütte Budenheim (Flaschenfbg. Kupferbg.) 
Lahmeyer, Wilhelm (1859-1907)

Landauer, Georg Friedrich (1794-1866)

Lavis, Michael (1842-1906)

Lehner, Carl Georg Friedr. (1871-1969)

Linde, Carl (von) (1842-1934)

Iothary, Christian (1814-1868)

Lucius, Nikolaus Eugen (1834-1903)

Ludwig, Jean Noé Carl J. (1843-1926)

Martenstein, Johamn Carl (1798-1874)

May, Johamn Martin (1825-1919)

Mayfarth, Philipp (1833-1913)

Meister, Carl Friedr. Wilhelm (1827-1895)

Merck, Heinrich Emanuel (1794-1855)

Merton, Wilhelm (William) (1848-1916)

Merz, Friedrich (1884- )

Messer, Adolf Joseph (1878-1954)

Meyn, Claus (1871-1953)

Mönch, Johann Jakob (1786-1874)

Mōnch, Johamn Jakob (1842-1926)

Müller, Matheus (1773-1847)

Naumann, Carl Christ. Otto (1794-1865)

Neubecker, Carl Adam (1840-1900)

Oehler, Karl Gottlieb R. (1797-1874)

Opel, Adam (1837-1895)

Passavant, Samuel Adolf (1841-1926)

Peter, Friedrich Ludwig (Louis) (1841-1921)

Peter, Christian Friedrich (1870-1941)

Petri, Johamn Philipp (1791-1853)

Pfaff, Jean Baptist Oskar (1850-1903)

Pfingst, Julius (1834-1899)

Philippi, Jacob Wilhelm (1829-1877)

Pokomy, Ludwig Jacob (1843-1904)
Frankfurt a.M

Frkf. (Idstein/Ts.)

Offenbach/M

Frankfurt a.M

Wiesbaden

Mainz-Weisenau

Frankfurt-Hoechst

Frankfurt a.M.

Worms

Frankfurt a.M

Erankfurt a.M

Frankfurt-Hoechst

Darmstadt

Frankfurt a.M

Frankfurt a.M

Frankfurt a.M

Frankfirt a.M

Offenbach $/ \mathrm{M}$

Offenbach/M

Eltville

Offenbach $M$

Offenbach $/ \mathrm{M}$

Offenbach $/ \mathrm{M}$

Rüsselsheim

Michelbach

Frankfurt a.M

Klein-Auheim/Main

Offenbach/M

Frankfirt a.M

Frankfunt a.M

Wiesbaden

Frankfurt-Bockenh.
Elektrizitäts-AG. vorm. W. Lahmeyer

Lederfabrik G.F. Landauer-Donner

Stahlbau Michael Lavis

Telefonbau u. Normalzeit Lehner \& Co.

Gesellschaft f. Linde's Eismaschinen

Portlandzementfbr. Christ.Lothary

Farbwerke Hoechst

Schriftgießerei Ludwig \& Mayer

Lederwerke C. Heyl (vorm. Heyl \& Martenstein)

Lederwerke Martin May

Fbr. landwirtschafll. u. gewerbl Maschinen

Farbwerke Hoechst

Chemische Fabrik E. Merck

Metallgesellschaft

Chem. Fabrik (Pharma, Kosmetika) Merz \& Co.

Messer Griesheim

Glasdachfabrik Claus Meyn

Lederwarenfabrik Jakob Mänch

Gürtlerwaren- u. Tascheabügelfbr. J. Mönch

Sektkellerei Matheus Mĩller

Seifen-u. Parfümeriefabrik C. Naumamn

Maschinenfabrik C.a. Neubecker

RuB- u. Kreosotfabrik K. Oehler, Chem Fabrik

Adam Opel (Nähmaschinen, Fahrräder, Autos)

Passavant-Werke, Michelbacher Hütte

Mitteldeutsche Gummiwarenfbr. Louis Peter

Hessische Gummiwarenfabrik Fritz Peter

Lederwarenfabrik Jakob Mōnch

Schleifmittelwerk Fontaine \& Co.

Schleifmittel-u. Schleifm.fbr. Naxos-Umion

Maschinenfabrik Wiesbaden

Maschinenfabrik Pokorny \& Wittekind 
Ratazzi, Johamm Heinrich (1837-1896)

Reifert, Clemens (1807-1878)

Reinhart, Nikolaus Andreas (1809-1871)

Reuleaux, Ludwig (Louis) (1828-1900)

Roeder, Georg Philipp (1842-1912)

Roeder, Ludwig (Louis) (1846-1914)

Rooetm, Otto Karl J (1876-1939)

Römheld, Julius Wilhelm (1823-1904)

Roessler, Friedrich Emst (1813-1883)

Rossbach, Friedrich (1822-1894)

Rügner, Oswald Philipp (1879-1958)

Ruthoff, Christof (1837-1920)

Sandvoss, Heinrich Konrad (1871- )

Schanzenbach, Gotthold (1857-1920)

Schenck, Carl Heinrich Joh. (1835-1910)

Schiele, Bemhard Jacob Chr. F. (1823-1869)

Schiele, Johann Georg Remigius (1837-1896)

Schleicher, Martin Adolf (1846-1910)

Schlesinger, Peter (1859-1934)

Schleussner, Johann Carl (1830-1899)

Schmaltz, Johamn Philipp (1819-1881)

Schmaltz, August Felix (1821-1874)

Schmaltz, Georg Friedxrich (1854-1932)

Schoeller, Alfred (1869-1950)

Schoen, Comelius Julius (1848-1894)

Schramm, Joham Jakob (1814-1868)

Scriba, Ludwig Philipp Karl (1847-1933)

Seck, Withelm (1832- )

Seebass, Alfred Richard (1805-1884)

Seeger, Karl Wilhelm (1860-1923)

Seitz, Johamn Jakob Heinrich
Offenbach $/ M$

Frankf.-Bockenheim

Worms

Mainz

Darmstadt

Darmstadt

Darmstadt

Mainz

Frankfurt a.M.

Friedberg/Hessen

Offenbach $/ M$

Mainz-Kastel

Frankfurt a.M

Frankfurt a.M

Darmstadt

Frkf., spāter Eschboon

Frkf., spät. Eschibom

Offenbach/M

Offenbach/M

Frankfurt a.M

Offenbactim

Offenbach/M

Offenbacts/M

Frankfurt a.M

Worms

Offenbach $/ \mathrm{M}$

Frankfurt-Hoechst

Oberursel

Offenbacis/M

Offerbach $M$

Frankfurt a.M
Metalltuch- u. Drathgewebefbr. Ratazzi \& May

Reifert'sche Waggonfabrik

Lederwerke Doerr \& Reinhart

Farben-u. Fimisfabrik Louis Reuleaux

Erste Darmstāởer Herdfbr. u. Eisengießerei

Erste Darmstädter Herdfbr. u. EisengieBerei

Röhm \& Haas Chemische Fabrik

Eisengießerei, Eisenbau u. Masch.fbr. Röhmheld

Dt Gold-u. Silberscheideanst. (DEGUSSA)

Spiritus- u. Oellackfabrik F. Roßbach

Oswald Rügner Fabrik feinster farb. Leder

Schiffswert u. Masch fbr. Chr. Ruthof

Samson Apparatebau

G. Schanzenbach, Elektro- u. lichttedon. Fbr.

EisenbieBerei, Waagen-, Masch.fbr. C. Schenck

Maschinenfbr. u. EisenbieBerei G. Schiele

Maschinenffbr. u. FisenbieBerei G. Schiele

Druckmaschinenfbr. Faber \& Schleicher

Metallwarenfabrik Peter Schlesinger

Trockemlattenfabrik, ADOX-Fotow.

C. Schleussne

Maschinenfbr. u. EisengieBeBrei Gebr. Schmaltz

Maschinenfbr. u. Eisengießeri Gebr. Schmaltz

Schleifmasctionen u. Schleifräderfbr. F. Schmaltz

Elektrotedn. Fabrik Schoeller \& Co.

Kammgamspinnerei u. Weberei Valckenberg

Sctramm'sche Lack-u. Farbenfabriken

Höchster Gießerei L. Scriba

Mootorenfabrik Oberursel, vorh.W. Seck \& co.

Eisenkunstgießerei Alfred Rich. SeebaB

Reiseartikelfabrik Karl Seeger

Anilinfarben-Fabrik-Geschäft Gebr. Seitz 
Sell, Emst Karl Ludwig (1808-1854)

Siebert, Johann Georg Heinr. Wilh. (1862-1927)

Siebert, Joharm (Jean) Martin D. (1867-1925)

Sievers, August Eduard (1843-1906)

Söhnlein, Jchann Jakob (1827-1912)

Sondheimer, Moses Tobias (1837-1891)

Stempel, David (1869-1927)

Teves, Alfred (1868-1953)

Trapp, August Ferdinand (1836-1907)

Valckenberg, Withelm Jos. Diendanné (1844-1914)

Voigt, Heinrich Ferd. Julius (1857-.1937)

Wecker, Karl Theodor (1828-1893)

Weil, Heinrich (1863-1929)

Weil, Peter (1866-1911)

Weintralld, Joham Christian F. (1809-1878)

Weintraud, Robert Ferd. Aug. (1860-1927)

Wemer, Friedrich Christoph (1842-1918)

Wertheim, Joseph (1834-1899)

Wittekind, Franz Anton Karl (1855-1912)

Wurmbach, Julius (1831-1901)

Ziegler, Joseph Carl (1854-1926)

Zimmex, Carl Christian C.
Offenbach/M

Hanau

Hanau

Offenbach $/ \mathrm{M}$

Wiesb.-Schierstein

Frankfurt a.M

Frankfurt a.M

Frankfurt a.M

Friedberg/Hessen

Worms

Frankfurt a.M

Offenbach/M

Frankf--Rödetheim

Frankf.-Rödelheim

Offenbach/M

Offenbach/M

Mainz

Frankf.unt a.M

Frankf.-Bockenheim

Frankf.-Bockenheim

Frankf.-Bockenheim

Frankfurt a.M
Teerdestillations- n. Asphaltfbr. Dr.E. Sell

Platinschmelze G. Siebert

Platinschmelze G. Siebert

Celhuloid-Fabrik Schreiner \& Sievers

Söhnlein Rheingold Sektkellereien

Beer, Sondheimer \& Co. (Metallhandel u. -produktion)

SchriftgieBerei D. Stempel

Maschinen- u. Armaturenfbr. (ATE) A. Teves

Fabrik photograph. Papiere Trapp \& Mönch

Kammgarnspimncrei u. Weberei Valckenberg

Elektrotechn. Fabrik Voigt \& Haefffiner

Wagen-, dam Achsen- u. Fedemfbr. Dick \&

Kirschten

Fahrrädext-u. Schreibmasch fbr. Torpedo-Werke

Fahrnäder- u. Schreibmasch.fbr. Torpedo-Werke

Etuis-Portefeuillefbr. Chr. Weintraud jun.

Metallwarenfbr. Rob.Weintraud (ROWENTA)

Werner \& Mertz Erdalwerke (Wachsw.-

Schuhcreme)

Frkf. Asbestwerke vorm. Loouis Wertheim

Maschinenfabrik Pokomy \& Wittekind

Eisengießerei, Ofen-u. Herdfbr. Jul. Wurmbach

Masch.fbr. u. Apparatebau Fellner \& Ziegler

Vereinigte Chininfabriken Zimmer \& Co. 
Anlage 2: Die beruflich-soziale Herkunft der Firmengründer

\begin{tabular}{|c|c|c|c|c|c|c|}
\hline Die Berufe der Vāter der Firmengründer & $1815-30$ & $1831-50$ & $1851-70$ & $1871-90$ & 1891-1914 & Gesamt \\
\hline Großgundbesitzer & - & - & - & - & - & - \\
\hline Fabrikanten, Industrielle, Direktoren, Bauuntemehmer & 1 & 2 & $\overline{12}$ & 5 & 7 & $27(16,6 \%)$ \\
\hline Großkaufleute (einschl. Bankiers, Hoteliers, Verleger) & - & 4 & 8 & 10 & 2 & $24(14,7 \%)$ \\
\hline Höhere Beamte (einschl. Offiziere, Professoren) & - & 2 & 7 & 7 & 2 & $18(11,0 \%)$ \\
\hline Pfarrex & 1 & 1 & 1 & 3 & - & $6(3,7 \%)$ \\
\hline Freie (akademische) Berufe und Apotheker & 1 & - & 3 & 3 & 1 & $8(4,9 \%)$ \\
\hline Ingenieure, Chemiker, Techniker & - & - & - & - & - & - \\
\hline Leitende Angestellte (soweit nicht in 2 o. 7 ) & - & - & - & 2 & - & $2(1,2 \%)$ \\
\hline Mittlere Beamte und Volksschullehrer & - & 3 & - & 3 & 3 & $9(5,5 \%)$ \\
\hline Kaufleute und Wirte & 1 & 4 & 4 & 5 & 2 & $16(9,8 \%)$ \\
\hline Handwerksmeister, selbständige Handwerker & 4 & $\overline{9}$ & $\overline{9}$ & 4 & 6 & $32(19,6 \%)$ \\
\hline Bauem, Winzer und landwirtschaftliche Pächter & - & 2 & - & 1 & $\overline{3}$ & $6(3,7 \%)$ \\
\hline Nichtleitende Angestelite (soweit nicht in 8) & - & - & 1 & - & - & $1(0,6 \%)$ \\
\hline Werkmeister und Betriebspersonal & - & $\overline{-}$ & - & 3 & 1 & $4(2,5 \%)$ \\
\hline Untere Beamte & 1 & $\overline{-}$ & - & 1 & 1 & $3(1,8 \%)$ \\
\hline Gesellen, Arbeiter in Industrie und Landwirtschaft & - & 1 & - & 1 & 3 & $5(3,1 \%)$ \\
\hline Soldaten und Invalide & - & - & - & - & - & - \\
\hline Taglömer & - & & - & - & $\overline{-}$ & - \\
\hline Sonstige, Nichtermittelte & - & - & 2 & - & - & $2(2,1 \%)$ \\
\hline Gesamt & 9 & 28 & 47 & 48 & 31 & $163(100 \%)$ \\
\hline
\end{tabular}


Anlage 3: Die beruflich-soziale Herkunft und der Wirtschaftszweig

\begin{tabular}{|c|c|c|c|c|c|c|c|c|c|}
\hline Die Berufe der Väter der Firmengründer & $\begin{array}{c}\text { Masch.-, } \\
\text { Stahl- u. } \\
\text { Fahrzeug } \\
\text { bau }\end{array}$ & $\begin{array}{c}\text { Chem. } \\
\text { Industrie }\end{array}$ & $\begin{array}{c}\text { Leder- u. } \\
\text { Leder- } \\
\text { waren- } \\
\text { industrie }\end{array}$ & $\begin{array}{l}\text { Eisen- u. } \\
\text { Metall- } \\
\text { waren- } \\
\text { industrie }\end{array}$ & $\begin{array}{l}\text { Elektro- } \\
\text { techn. u. } \\
\text { fein- } \\
\text { mechan. } \\
\text { Industrie }\end{array}$ & $\begin{array}{c}\text { Sekt- } \\
\text { fabrika- } \\
\text { tion u. } \\
\text { Wein- } \\
\text { brenner- } \\
\text { eien }\end{array}$ & $\begin{array}{c}\text { Industrie } \\
\text { der } \\
\text { Steine u. } \\
\text { Erden }\end{array}$ & $\begin{array}{c}\text { Schrift- } \\
\text { gießer- } \\
\text { eien }\end{array}$ & Versch. \\
\hline Großgrumdhesitzer & - & - & - & - & - & - & - & - & - \\
\hline Fabrikanten, Industrielle, Direktoren, Bauunternehmer & 4 & 9 & 3 & 3 & 1 & - & 4 & 2 & 1 \\
\hline Großkaufleute (einschl. Bankiès, Hoteliers, Verleger) & 6 & 5 & 4 & 2 & 1 & - & 1 & - & 5 \\
\hline Höhere Beamte (einschl. Offiziere, Professoren) & 4 & 7 & - & 4 & 2 & - & - & - & 1 \\
\hline Pfarter & 3 & 2 & - & - & - & - & - & - & - \\
\hline Freie (akaderaische) Berufe und Apotheker & 2 & 6 & - & - & - & - & - & - & - \\
\hline Ingenieure, Chemiker, Tedmiker & - & - & - & $\overline{-}$ & - & - & - & - & - \\
\hline Leitende Angestellte (soweit nicht in 20.7 ) & - & - & - & 1 & - & - & - & 1 & - \\
\hline Mittlere Beamote und Volksschullehrer & $\overline{3}$ & 1 & - & - & 3 & 1 & - & - & 1 \\
\hline Kaufleute und Wirte & 4 & 3 & 2 & 2 & 2 & 1 & I & - & 1 \\
\hline Handwerksmeister, selbständige Handwerker & 17 & 3 & 5 & 2 & - & 2 & - & 1 & 2 \\
\hline Bauem, Winzer und landwirtschaftliche Pächter & - & 1 & 2 & - & - & 1 & - & 1 & 1 \\
\hline Nichtleitende Angestellte (soweit nidht in 8) & 1 & - & - & - & - & - & - & - & - \\
\hline Werkmeister und Betriebsaufsichtspersonal & 2 & - & - & 1 & - & 1 & - & - & - \\
\hline Untere Beante & - & - & 2 & - & 1 & - & - & - & - \\
\hline Gesellen, Arbeiter in Industrie und Landwitschaft & 1 & 1 & 1 & $\overline{-}$ & 2 & - & - & - & - \\
\hline Soldaten und Invalide & - & - & - & $=$ & - & - & - & - & - \\
\hline Taglähner & - & - & - & - & - & - & - & - & - \\
\hline Sonstige, Nichtermittelte & 1 & - & 1 & - & - & - & - & - & - \\
\hline Gesamt & 48 & 38 & 20 & 15 & 13 & 6 & 6 & 5 & 12 \\
\hline
\end{tabular}


Anlage 4: Die Regionale Herkunft der Firmengründer

\begin{tabular}{|c|c|c|c|c|c|c|c|}
\hline & Hekunftslandschaften & $1815-30$ & $1831-50$ & $1851-70$ & $1871-90$ & 1891-1914 & Gesamt \\
\hline \multirow{2}{*}{$\begin{array}{c}\text { Rhein-Main- } \\
\text { Gebiet }\end{array}$} & Geburtsort ist Ort d. Firmengrindung & 8 & 14 & 21 & 19 & 10 & $72(41.14 \%)$ \\
\hline & Utrribes Rhein-Main-Gebiat & 1 & 11 & 12 & 8 & 3 & $35(20 \%)$ \\
\hline \multirow{4}{*}{$\begin{array}{l}\text { Nachbar- } \\
\text { regionen des } \\
\text { Rhein-Main- } \\
\text { Gebiets }\end{array}$} & Hessen und Nassau (auBeth d. RMG) & - & 1 & 5 & 7 & 4 & $17(9,71 \%)$ \\
\hline & Rhemland-Pfalz (auBecth d. RMG) & - & - & - & 1 & 1 & $2(1.14 \%)$ \\
\hline & Franken & 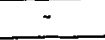 & - & 2 & 2 & - & $4(2,28 \%)$ \\
\hline & Baden & - & 1 & 3 & - & - & $4(2,28 \%)$ \\
\hline \multirow{10}{*}{$\begin{array}{l}\text { Restliches } \\
\text { In- und } \\
\text { Ausland }\end{array}$} & Wüttenberg & - & - & 1 & 4 & 6 & $11(6.28 \%)$ \\
\hline & Nordmein-Westalen & - & - & 6 & 5 & 4 & $15(8.57 \%)$ \\
\hline & Niedersachsen & - & - & - & 2 & 2 & $4(2,28 \%)$ \\
\hline & Bremen und Hamburg & - & 1 & 1 & - & - & $2(1,14 \%)$ \\
\hline & Scbleswig-Holstein & - & - & - & - & 1 & $1(0,57 \%)$ \\
\hline & Thüringen & - & - & 1 & - & - & $1(0,57 \%)$ \\
\hline & Sactisen-Anhalt & - & - & 1 & 1 & - & $2(1.14 \%)$ \\
\hline & Sactisen & - & 1 & - & - & - & $1(0.57 \%)$ \\
\hline & Frankreich & - & - & 2 & 1 & - & $3(1.71 \%)$ \\
\hline & USA & - & - & - & - & 1 & $1(0.57 \%)$ \\
\hline & Nichtermittelte & - & - & - & - & $=$ & - \\
\hline & Gesamt & 9 & 29 & 55 & 50 & 32 & $175(100 \%)$ \\
\hline
\end{tabular}

Anlage 5: Die regimale Herkunft der Firmengründer einiger Stäute des Rhein-Main-Gebiets $\underline{1815-1914}$

\begin{tabular}{|c|c|c|c|c|c|c|c|c|c|}
\hline Ferkanftsregionen & Frankfurt & Offenbach & Mainz & Darmstadt & Wiesbaden & Worms & Ganau & $\begin{array}{c}\text { versch. } \\
\text { Orte }\end{array}$ & Gesamt \\
\hline Geburtsont ist Ort d Grïndung & $25(38,5 \%)$ & $18(45,0 \%)$ & $6(30,0 \%)$ & $7(58,3 \%)$ & $1(14,2 \%)$ & $4(66,7 \%)$ & $5(83,6 \%)$ & $6(31,6 \%)$ & $72(41,14 \%)$ \\
\hline Ubriges Rhein-Main-Gebiat & $9(13,8 \%)$ & $10(25,0 \%)$ & $4(20,0 \%)$ & $2(16,7 \%)$ & $2(28,6 \%)$ & $2(33,3 \%)$ & - & $6(31,6 \%)$ & $35(20,00 \%)$ \\
\hline Nachbarregionen des RMG & $9(13,8 \%)$ & $4(10,0 \%)$ & $6(30,0 \%)$ & $2(16,7 \%)$ & $2(28,6 \%)$ & - & $1(16,3 \%)$ & $3(15,8 \%)$ & $27(15,42 \%)$ \\
\hline Restliches In-und Ausland & $22(339 \%)$ & $8(20,0 \%)$ & $4(20,0 \%)$ & $1(8,3 \%)$ & $2(28,6 \%)$ & - & - & $4(21,0 \%)$ & $41(23,42 \%)$ \\
\hline Gesamat & $65(100 \%)$ & $40(100 \%)$ & $20(100 \%)$ & $12(100 \%)$ & $7(100 \%)$ & $6(100 \%)$ & $6(100 \%)$ & $19(100 \%)$ & $175(99,98 \%)$ \\
\hline
\end{tabular}




\begin{tabular}{|c|c|c|c|c|c|c|}
\hline Konfessionszugehörigkeit & $1815-30$ & $1831-50$ & $1851-70$ & $1871-90$ & $1891-1914$ & Gesamt \\
\hline $\begin{array}{c}\text { Protestantisch } \\
\text { (davon Reformierte) }\end{array}$ & $\begin{array}{c}10(90,90 \%) \\
(2)\end{array}$ & $\begin{array}{c}28(66,67 \%) \\
(7)\end{array}$ & $\begin{array}{c}47(60,26 \%) \\
(6)\end{array}$ & $\begin{array}{c}50(69,44 \%) \\
(2)\end{array}$ & $\begin{array}{c}30(63,83 \%) \\
(2)\end{array}$ & $\begin{array}{c}165(66,00 \%) \\
(19)(7,60 \%)\end{array}$ \\
\hline Römisch-Katholisç & $1(9,10 \%)$ & $12(28,57 \%)$ & $19(24,36 \%)$ & $13(18,06 \%)$ & $10(21,28 \%)$ & $55(22,00 \%)$ \\
\hline Israelítisch & - & $2(4,76 \%)$ & $12(15,38 \%)$ & $9(12,50 \%)$ & $6(12,76 \%)$ & $29(11,60 \%)$ \\
\hline Sonstige & - & - & - & - & $1(2,12 \%)$ & $1(0,40 \%)$ \\
\hline Gesamt & $11(100 \%)$ & $42(100 \%)$ & $78(100 \%)$ & $72(100 \%)$ & $47(100 \%)$ & $250(100 \%)$ \\
\hline
\end{tabular}

Anlage 7: Die Konfessionszughuörigkeit von 250 Firmengründem des Rhein-Main-Gebiets 1815 1914 nach Wirtschaftszweigen

\begin{tabular}{|c|c|c|c|c|c|c|c|c|c|}
\hline $\begin{array}{l}\text { Konfessions- } \\
\text { xugehōrigkeit }\end{array}$ & $\begin{array}{c}\text { Maschin--, } \\
\text { Stahl- u. } \\
\text { Fahrzeug- } \\
\text { bau }\end{array}$ & $\begin{array}{c}\text { Chem. } \\
\text { Industrie }\end{array}$ & $\begin{array}{c}\text { Leder-u. } \\
\text { Leder- } \\
\text { waren- } \\
\text { industrie }\end{array}$ & $\begin{array}{c}\text { Eisen- u. } \\
\text { Metall- } \\
\text { waren- } \\
\text { industrie }\end{array}$ & $\begin{array}{l}\text { Elektro- } \\
\text { techn u. } \\
\text { fein- } \\
\text { mechan. } \\
\text { Industrie }\end{array}$ & $\begin{array}{c}\text { Sekt- } \\
\text { fabrikation } \\
\text { u. Wein- } \\
\text { brenner- } \\
\text { eien }\end{array}$ & $\begin{array}{c}\text { Industrie } \\
\text { der Steine } \mathrm{L} . \\
\text { Erden }\end{array}$ & $\begin{array}{l}\text { Schrift- } \\
\text { giefereien }\end{array}$ & Versch. \\
\hline $\begin{array}{c}\text { Protestantisch } \\
\text { (davon Reformierte) }\end{array}$ & $\begin{array}{c}52(68,42 \%) \\
(5)\end{array}$ & $\begin{array}{c}35(77,78 \%) \\
(6) \\
\end{array}$ & $\begin{array}{c}16(47,06 \%) \\
(5)\end{array}$ & $\begin{array}{c}22(78,57 \%) \\
(1)\end{array}$ & $\begin{array}{c}14(93,33 \%) \\
(1) \\
\end{array}$ & $\begin{array}{c}3(20,00 \%) \\
(-)\end{array}$ & $\begin{array}{c}4(5794 \%) \\
(-) \\
\end{array}$ & $\begin{array}{c}7(100 \%) \\
(-)\end{array}$ & $\begin{array}{c}12(52.17 \%) \\
(1) \\
\end{array}$ \\
\hline Römisch-Katholisch & $20(26,32 \%)$ & $7(15,56 \%)$ & $5(14.71 \%)$ & $6(21,43 \%)$ & - & $11(73,33 \%)$ & $2(28,57 \%)$ & - & $4(17.39 \%)$ \\
\hline Istaelitisch & $4(5,26 \%)$ & $3(6,66 \%)$ & $12(35,29 \%)$ & - & $1(6,67 \%)$ & $1(6,67 \%)$ & $1(14,29 \%)$ & - & $7(30.44 \%)$ \\
\hline Sonstige & - & - & $1(2,94 \%)$ & - & - & - & - & - & - \\
\hline Gesamt & $76(30,40 \%)$ & $48(18,00 \%)$ & $34(13,60 \%)$ & $28(11,20 \%)$ & $15(6,00 \%)$ & $15(6,00 \%)$ & $7(2,80 \%)$ & $7(2,80 \%)$ & $23(9,20 \%)$ \\
\hline
\end{tabular}

Anlage 8: Die Kanfessionszugehōrigkeit von 250 Firmengründem einiger Stäùte des Rhein-MainGebiets 1815-1914

\begin{tabular}{|c|c|c|c|c|c|c|c|c|c|}
\hline $\begin{array}{l}\text { Konfessions- } \\
\text { zugehörigkeit }\end{array}$ & Franldurt & Offenbach & Mainz & Darmstadt & Wiesbaden & Worms & Hanau & $\begin{array}{l}\text { versch. } \\
\text { Orte }\end{array}$ & Gesamt \\
\hline $\begin{array}{c}\text { Protestantisch } \\
\text { (davon Reformierte) }\end{array}$ & $\begin{array}{c}57(61,96 \%) \\
(5)\end{array}$ & $\begin{array}{c}41(75,93 \%) \\
(8)\end{array}$ & $\begin{array}{c}15(46,88 \%) \\
(1)\end{array}$ & $\begin{array}{c}19(86,35 \%) \\
(-)\end{array}$ & $\begin{array}{c}8(100 \%) \\
(-)\end{array}$ & $\begin{array}{c}3(37,50 \%) \\
(2)\end{array}$ & $\begin{array}{c}6(85,71 \%) \\
(1)\end{array}$ & $\begin{array}{c}16(59,26 \%) \\
(2)\end{array}$ & $\begin{array}{l}165(66.00 \%) \\
(19)(7,60 \%)\end{array}$ \\
\hline Römisch-Katholisch & $15(16,30 \%)$ & $8(14,81 \%)$ & $15(46,88 \%)$ & $1(4,55 \%)$ & - & $4(50,00 \%)$ & $1(14,29 \%)$ & $11(40,74 \%)$ & $55(22,00 \%)$ \\
\hline Israelitisch & $20(21,74 \%)$ & $4(7,41 \%)$ & $2(6,24 \%)$ & $2(9,10 \%)$ & - & $1(12,50 \%)$ & - & - & $29(11,60 \%)$ \\
\hline Sonstige & - & $1(1,85 \%)$ & - & - & - & - & - & - & $1(0,40 \%)$ \\
\hline Gesamt & $92(36,80 \%)$ & $54(21,60 \%)$ & $32(12,80 \%)$ & $22(8,80 \%)$ & $8(3,20 \%)$ & $8(3,20 \%)$ & $7(2,80 \%)$ & $27(10,80 \%)$ & $250(100 \%)$ \\
\hline
\end{tabular}

